\title{
The Social Bond and Place: \\ A Study of How the Bureau of Land Management Contributes to Civil Society
}

\author{
Eric K. Austin
}

Dissertation submitted to the Faculty of the

Center for Public Administration and Policy

at

Virginia Polytechnic Institute and State University

Falls Church, Virginia

In partial fulfillment of the requirements for the degree of

Doctor of Philosophy

Committee Members:

Orion F. White, Chair

Joseph V. Rees

James F. Wolf

Alnoor Ebrahim

R. McGreggor Cawley

December 2, 2002

Key Words: Civil Society, Citizen Participation, Public Lands

Copyright 2002, Eric K. Austin 


\title{
The Social Bond and Place: A study of How the Bureau of Land Management Contributes to Civil Society
}

\author{
Eric K. Austin
}

(ABSTRACT)

Civil society is a widely discussed concept, often proposed as a means to address problems associated with a weakening of the social fabric. Nearly all civil society literature works from the notion that creating more or richer discourse around any given issue will help build agreement about the key values and in so doing, civil society will emerge. What this literature has not yet turned its attention to is, what is necessary for a strong social bond, which is a prerequisite for the possibility of social discourse in the first place, to exist. Historically, the social bond has been built on common religious, cultural and/or political perspectives. However, the constitutive power of the institutions that comprise each of these areas has diminished substantially. This research draws on concepts developed in the field of environmental psychology to understand how place can serve as the basis for the development of a social bond and subsequent emergence of civil society. Two concepts drawn from environmental psychology -- place attachment and place identity -- are used to demonstrate how individuals and groups become connected to place, and how such a connection shapes and contributes to social relations. Specifically, this study contributes to the body of civil society literature by illuminating how a public agency can foster the development of the social bond by drawing explicitly and symbolically on place and in doing so, contributes to the emergence of civil society -or on the other hand, fails to foster it as effectively as it could by being attentive to the role that place can play in creating the social bond. 
To my father, who taught me what it is to be a life long learner and showed me the importance of sharing what we love with others.

And

To Christine and Max, for their unwavering support and extraordinary patience. 


\section{Acknowledgements}

My heartfelt thanks go out to many people who have contributed in different ways to this project. Thanks first to my committee, who have provided wonderful support, guidance and direction. I am particularly grateful my Chair, Orion White, who had the uncanny ability to listen to my often muddled thoughts and ideas, and then reflect back in a way that the important elements became clear. I am indebted to Gregg Cawley, who first revealed to me that the study of public administration suited both my interest in political philosophy and my desire to find real solutions to real problems. Thanks also to the entire faculty of the Center for Public Administration and Policy, each of whom have done so much to guide my personal journey into the field. Last, but certainly not least, thanks to the staff of the Bureau of Land Management and the current and former members of the Northwest California Resource Advisory Council for their generous offerings of time and information. This research would have been both different and much more difficult without their willing and thoughtful contributions. 


\section{Table of Contents}

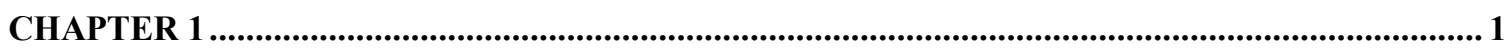

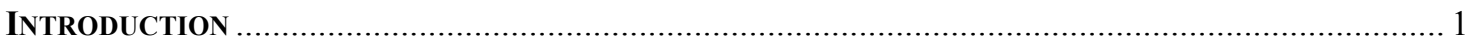

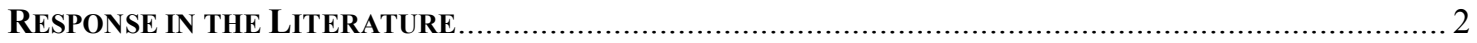

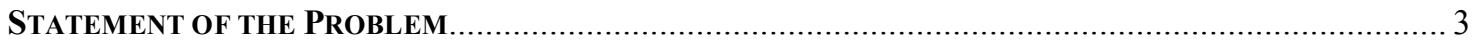

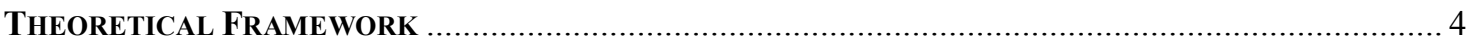

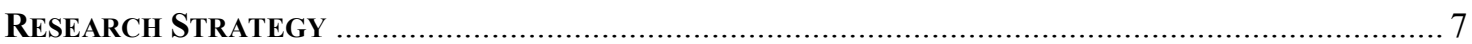

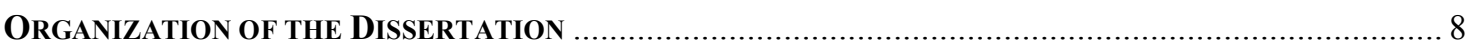

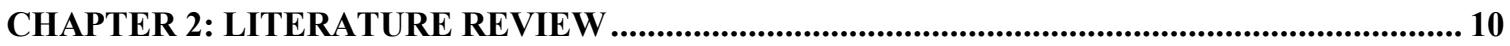

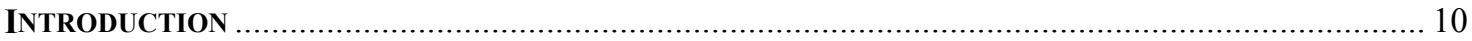

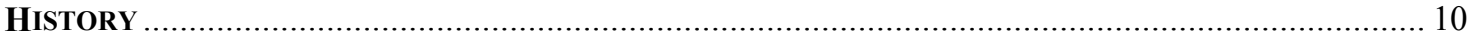

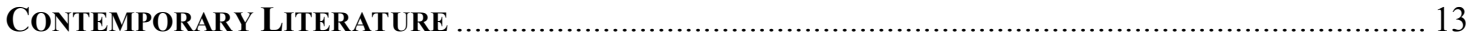

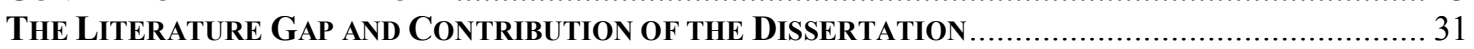

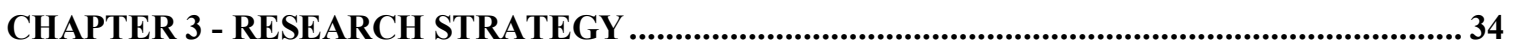

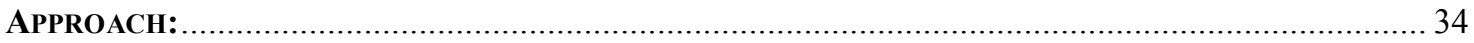

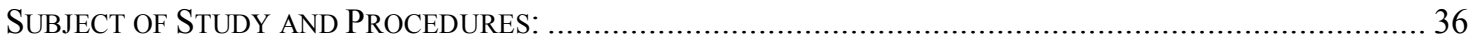

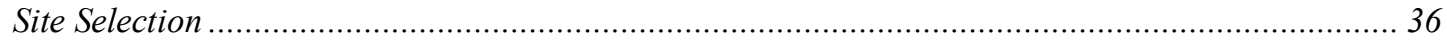

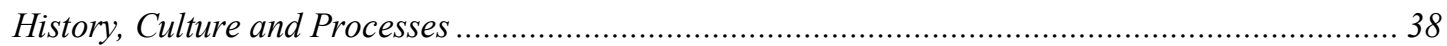

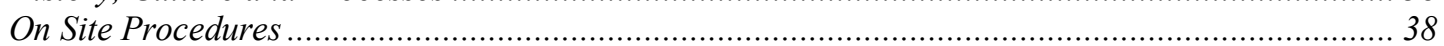

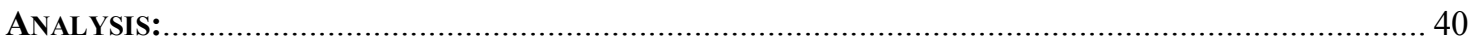

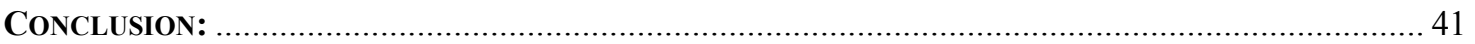

CHAPTER 4: THEORETICAL FRAMEWORK - A THEORY OF PLACE...................................... 42

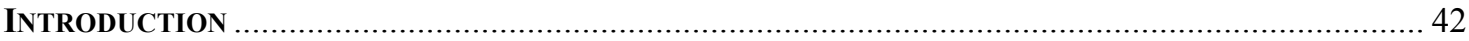

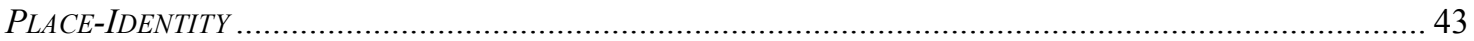

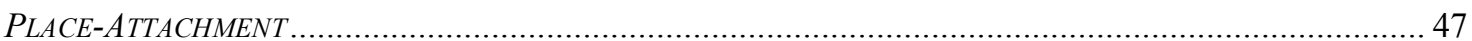

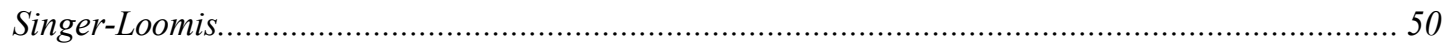

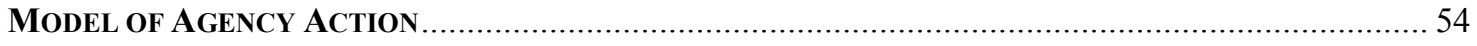

CHAPTER 5 - HISTORICAL, INSTITUTIONAL AND PHYSICAL CONTEXT ............................ 56

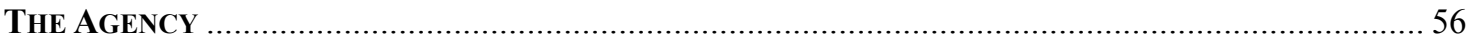

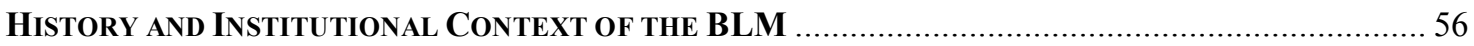

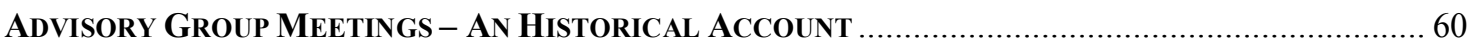

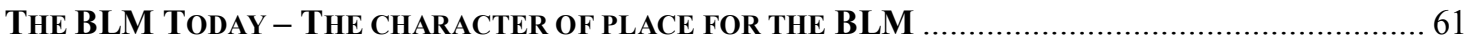

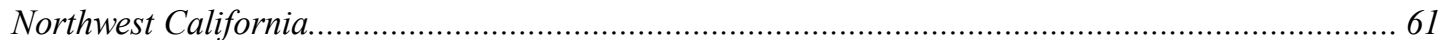

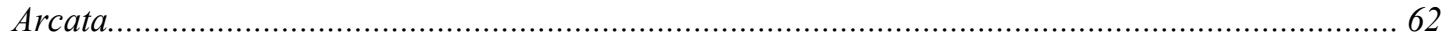

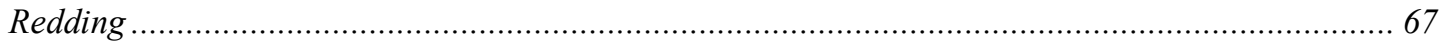

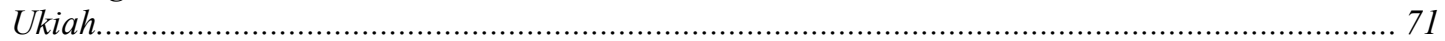

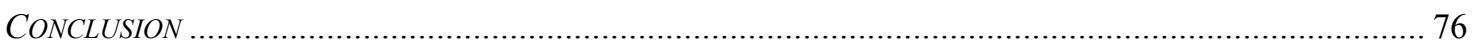

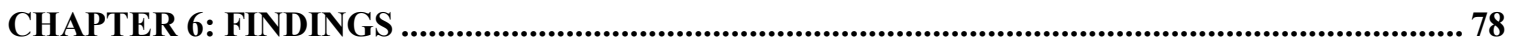

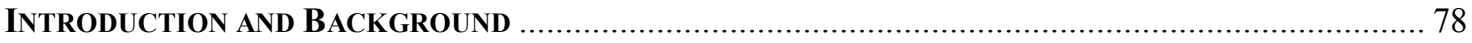

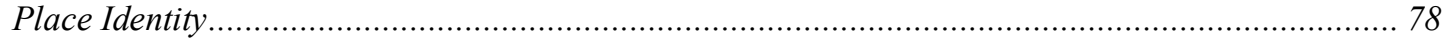

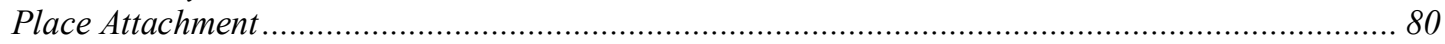

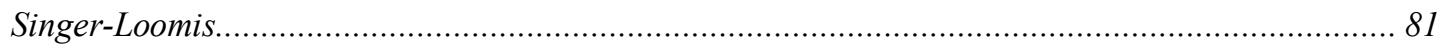

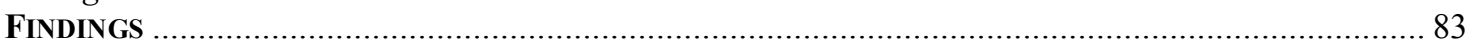

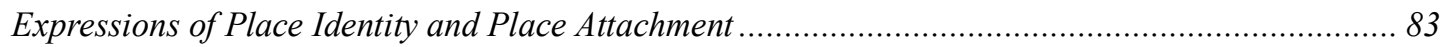

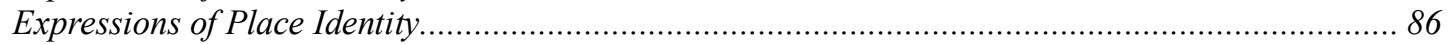

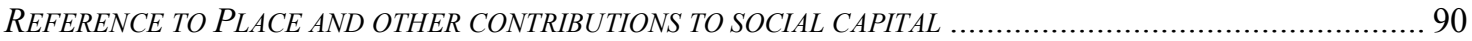

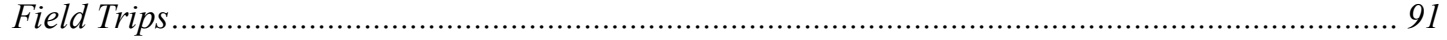

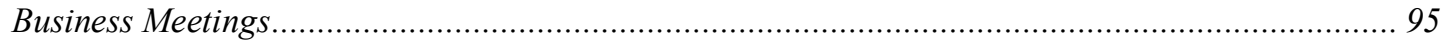


Other Non-Place Contributions to the Social Bond …...................................................................... 96

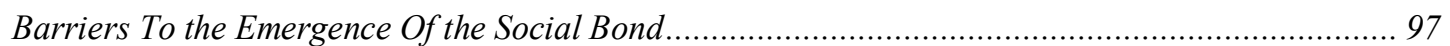

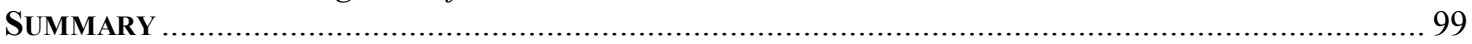

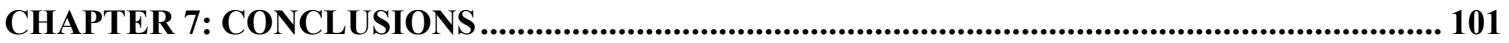

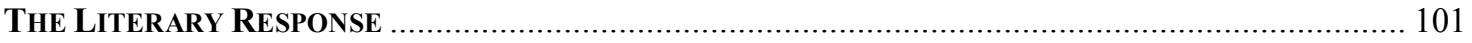

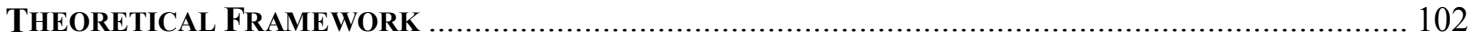

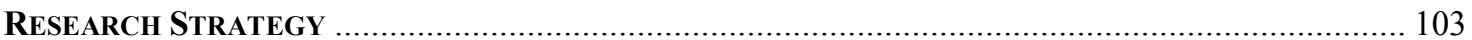

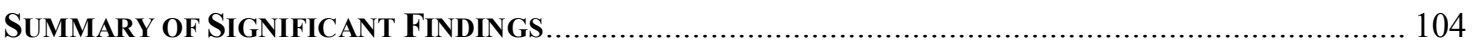

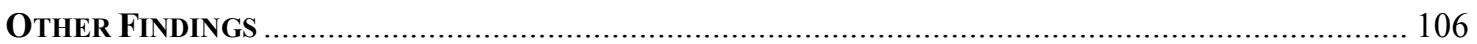

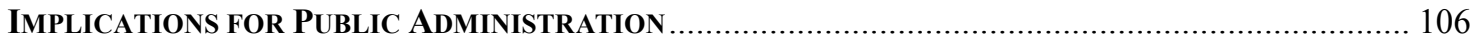

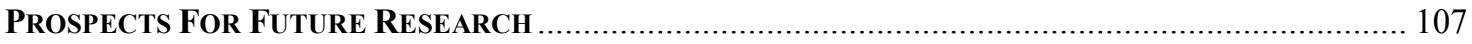

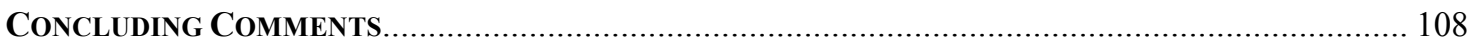

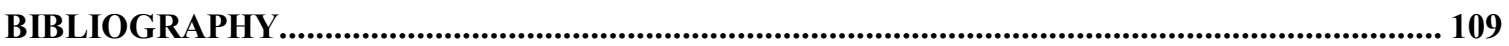

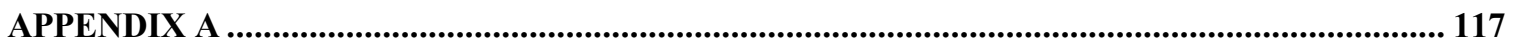

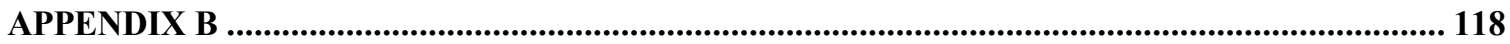

APPENDIX C

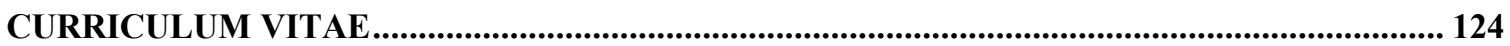

\section{Table of Figures}

Figure 1: Jung's arrangement of the four functions (Loomis, 1991, p. 29) ............................................ 51

Figure 2: Interactive Model showing relation of the Eight Cognitive Modes .......................................... 52

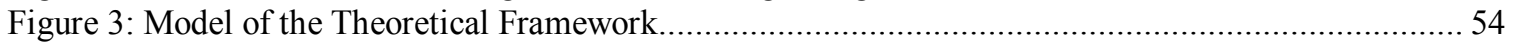

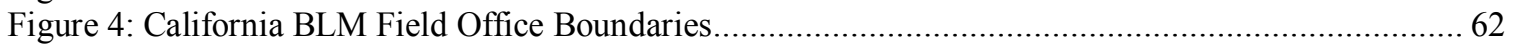

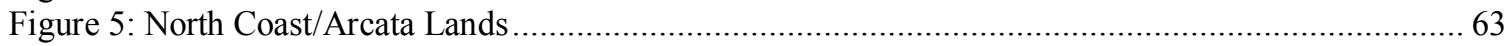

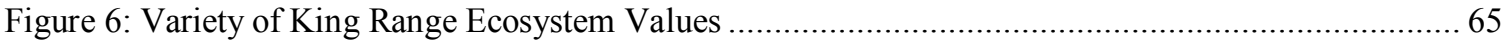

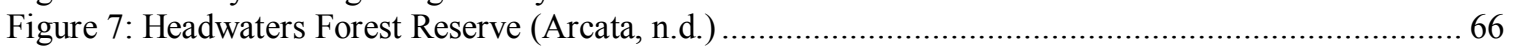

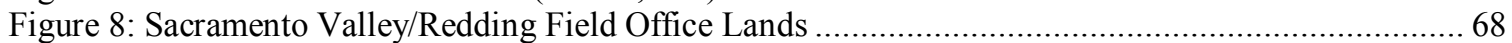

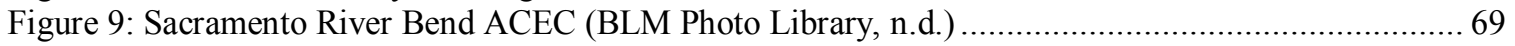

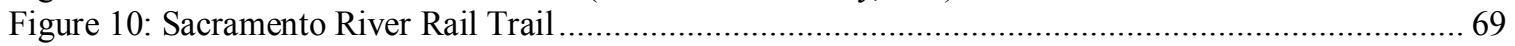

Figure 11: Clear Creek Watershed (BLM Photo Library, n.d.) ................................................................ 70

Figure 12: Clear Creek Streambed Restoration Project ……................................................................... 70

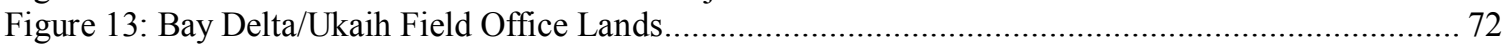

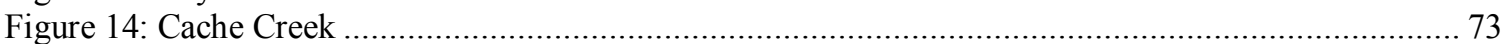

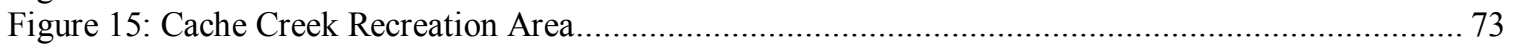

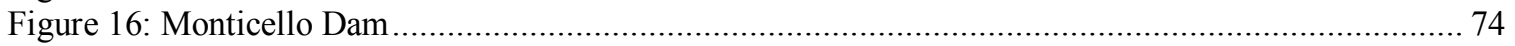

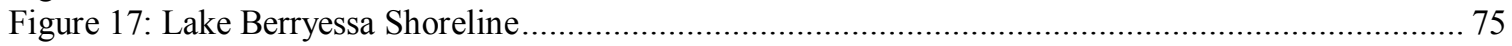

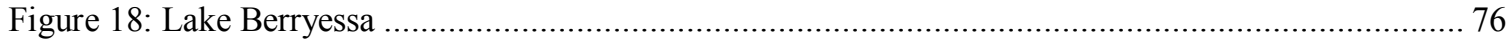




\section{Introduction}

\section{Chapter 1}

In April 1999, two teenagers walked into the high school they attended in Littleton, Colorado and committed what was perhaps the single worst incident of school violence in United States history. Several months later, riots broke out in Seattle surrounding a series of meetings between leaders of the World Trade Organization. Within an environmental movement that by and large associated itself with promoting peaceful change from within the system there has been a growing trend towards the use of violence. In 1998, as a means of protesting the Vail ski resorts' expansion into what was seen as prime lynx habitat, a radical environmental group set fire to a lodge, causing $\$ 12$ million in damages. Since 1980, there have been at least 100 major acts of violence against public and private property, causing nearly $\$ 43$ million in damages. More than half of this damage was inflicted in just since 1995. The popular press points to these and other events that began to occur as early as the 1960s as indicators of a disintegrating social fabric.

Amati Etzioni argues in the preface of his book, The New Golden Rule, that starting in the 1960s the existing moral order was undermined and that existing mores were "stretched, challenged, or abandoned"(Etzioni, 1996, p. xiv). Robert Putnam presents compelling evidence in his book, Bowling Alone, of a steady decline in group membership among all generations who have come of age since the 1940s and an equally concerning, corresponding decline in social capital. Putman's research describes a decrease in participation across a wide range of political, religious and civic organizations as well as waning incidence of altruistic behaviors such as volunteerism and philanthropic participation. Much of this change Putnam attributes to significant economic change, the growth in geographic transience as well as enormous changes in mass media and information technology.

At the same time that group membership has declined, there has been a simultaneous shift in the content and tenor of public discourse. Michael Sandel's assessment focuses on the phenomenon of rights being used as trumps in public discourse. Further, his review of the practices and institutions of the United States suggests that there is an increasing commitment to what he calls a procedural republic. That is, the United States has become a republic whose "central idea is that government should be neutral toward the moral and religious views its citizens espouse" and instead "should provide a framework of rights that respects persons as free and independent selves, capable of choosing their own values and ends" (Sandel, Id 5-6, 1996). As such, priority is given to fair procedures rather than specific outcomes. Further, Sandel's analysis indicates that Americans believe that freedom is about individual choice and that the government's job is to protect this freedom of choice and at the same time remain uninvolved in the content of those choices.

Mary Ann Glendon provides further discussion of this change to public discourse around rights and sees similar implications as well. She argues that for the first time, rights are presented as absolute, individual, and independent of responsibility. The implication, according to Glendon, is that Americans have lost the historical understanding of what rights are and as this has occurred, we have increased the level conflict in public discourse and diminished what little capacity we had for building 
consensus, accommodation, or common ground. This altered discourse of rights has created a society that lives by "its penchant for absolute, extravagant formulations, its near-aphasia concerning responsibility, its excessive homage to individual independence and self-sufficiency, its habitual concentration on the individual and the state at the expense of the intermediate groups of civil society, and its unapologetic insularity" (Glendon, 1992, p.24). This neglect of civil society and its institutions effectively weakens both civic and personal virtue.

Moreover, these trends have become more dramatic since the 1970s, with younger people far more affected than their elders. This decline in group membership according to Putnam and others (Burnham, 1982; Rahn, 1997; Capella and Jamieson, 1997) has resulted in the undermining of the social relationships necessary for effective civic engagement.

Concurrent with these trends, interest groups that purport to represent various segments of the population have become involved in an increasingly reified and polarized public discourse. Looking to environmental and natural resources policy as an example, one finds a host of statutes and policies dating back to the passage of the 1969 National Environmental Policy Act (NEPA) that mandate the means and processes that federal land management agencies such as the Bureau of Land Management (BLM) use to develop specific plans for the lands they manage. Included in these statutes and policies are detailed descriptions of the procedures by which the public can engage in the discourse of public lands management. Over the past three decades, interest groups of all varieties have become increasingly adept at using these statutory procedures to block one another from engaging in various forms of action (Rosenbaum, 1991). Daniel Kemmis describes the situation as one where, taken in total, the procedures that were envisioned as checks against tyranny have grown to the point of creating procedural stalemate. Anyone can use these processes to stop anyone else from doing what he or she wants to do (Kemmis, 1990). At the same time, groups like Earth First!, Defenders of the Earth and others have gained recognition for taking violent actions in order promote the ends of their organizations. The result of these opposing trends towards procedural stalemate on one side and violent response on the other are increasingly disconnected social relationships among those involved in the discourse of public lands and natural resources.

While it is true that one need not look far through US history to identify other outbreaks of domestic and civil violence, the current mood is such that these events and their potential causes draw substantial public interest and concern. For students of public administration and policy, questions of how to respond to these conditions and the public concern about them is particularly important as it is often public organizations, be it schools systems, police departments or the Bureau of Land Management, that find themselves in a position of having to respond to them.

\section{Response in the Literature}

A growing body of literature grouped under the label of civil society has emerged as one of a variety of responses to the social issues described above. This literature will be described in greater detail in the following sections, but for the moment it is important to note that those proposing a strong civil society as a response to these social concerns fall within three general areas. Some (Bennett, 1998; Crane, 1997; 
Palmer, 1995) suggest that the problems stem from a government that has forced its fingers into every nook and cranny of our lives, from the contents of the gasoline used in our vehicles to the mushrooming welfare state. For them, civil society offers the opportunity for self-governance through the free market without interference from the state.

Others (Glendon, 1992; Elshtain, 1997) argue that the problems lie in the hyper-consumerism and hyper-individualism flowing from the dominance of liberal, market based institutions. They suggest that civil society is a means of rebuilding the values that prevent the market from running amok.

Still others(Putnam, 1995; Walzer, 1991) lament what they identify as increasingly degraded social institutions that leave a growing portion of the population of society without voice or leverage as to the distribution of goods within society. In this case, civil society is seen as the means of building the social capacity necessary for much broader participation in the political process. Beyond the literature that flows from each of these perspectives, a variety of practical efforts to develop and use concrete processes of creative problem solving, conflict resolution and other techniques that build civic capacity also evolved out of this literature (Beem, 1996; O’Connell, 1999).

\section{Statement of the Problem}

A review of the civil society literature reveals two related issues that are relevant to practitioners and scholars of public administration. The first issue is that the traditional, self-conscious civil society literature gives little if any systematic attention to the role that public agencies have in the emergence of civil society or the relationship that such agencies can have to the institutions of civil society.

Second, while there is a collection of works within public administration that draws on theories developed within the civil society literature to strengthen citizen participation and deliberative democracy issues, these works, as well as the self conscious civil society literature, by and large, argue that the type of social bond that is necessary for civil society to function emerges from more or better discourse. The literature implies that if processes can be established that enable more and better discourse to occur, then the necessary social bond will grow and civil society will emerge. Neither the core civil society literature nor the derivative public administration literature give any attention to source of the social bond in the first place. That is, what constitutes or gives structure to the basic social bond that must exist prior to and as a foundation for any such discourse.

Current civil society literature describes the institutions of civil society as being located between the public sector and the private sector. However, neither the political institutions of the public sector nor the market mechanisms of the private sector currently have the capacity to act as the basis from which the social bond can develop. The rancor and lack of trust that characterizes contemporary American politics limits the potential of current political institutions to create the foundational social bond. At the same time, market institutions presume that the social bond can be assumed because it comes into existence naturally. As such, this naturally occurring social bond is presumed to serve as a check on excesses of the market. As a result, there is no connection of how or whether the market functions in a way that supports or hinders the development of the social bond. 
Putnam's research implies that the social bond existed in paradigmatically common cultural, religious or political perspectives. But as Putnam's and other research suggests, the commonality of those perspectives no longer remains strong enough to provide a basis for the social bond to be expressed. The research in this essay suggests that an alternative basis for the development of the social bond can be found in physical place.

\section{Theoretical Framework}

Daniel Kemmis makes a strong argument that political discourse can and should be grounded and function around the concrete institutions and issues of a particular place. He provides compelling but anecdotal evidence that place, and a shared experience of it, can have the effect of providing a seed from which the social bond can emerge (Kemmis, 1990). Several questions remain unanswered in his work. Is there any evidence to suggest that the social bond can emerge from a connection to place? If so, what is the nature of that connection? Most importantly for public administration scholars and practitioners, what actions of a public agency have the effect of fostering or hindering the emergence of a social bond grounded in place?

Before describing the strategy to be used to answer these questions, it will be useful to understand the research and theories that describe the connection between individuals or groups and place. The body of research and theory that focuses most directly this connection is primarily drawn form environmental psychology. It initially began to appear in the 1960s and 1970s as a self conscious field of study. This was simultaneous with a growing awareness of and concern about environmental quality and its potential impact on human health. Within environmental psychology, there are two specific theories -- place-identity and place-attachment -- which offer particular promise in the effort to show the connection between place and the social bond. In addition to place-identity and place-attachment, the theoretical framework also draws on Carl Jung's theory of psychological types as reconceptualized by June Singer and Mary Loomis.

Place-identity, place-attachment, Jung's typology as used by Singer and Loomis, and the research affiliated with these theories in conjunction, provide a theoretical framework that structures the collection and analysis of data from the Bureau of Land Management's (BLM) Resource Advisory Councils (RAC) and provide the means to answer questions about how the BLM builds on or impedes the development of the type of social bond necessary for collaborative governance to be effective and for civil society to emerge.

In what was among the earliest efforts to develop the main features and functions of place-identity Harold Proshansky's 1978 article entitled The City and Self-Identity, the notion of place-identity is described as "those dimensions of self that define the individual's personal identity in relation to the physical environment by means of a complex pattern of conscious and unconscious ideas, beliefs, preferences, feelings, values, goals and behavioral tendencies and skills relevant to this environment. While an individual's place-identity reflects the specific experiences and socialization unique to that individual, place-identity also reflects those experiences common to all individuals and groups of individuals living in particular kinds of settings (Proshansky, 1978, p. 155). The cornerstone of environmentally based cognitions is what Proshansky describes as the 
"environmental past" of the individual. The environmental past consists of the places and their properties that have contributed instrumentally to the biological, psychological, social and cultural needs of that person (Proshansky, et. al. 1983, p. 59)

Following on Proshansky's work, Twigger-Ross and Uzzell opperationalized place-identity by connecting an existing model of identity to the experience of place to describe the linkages of place to identity. Using Breakwell's model of identity, they propose that the four principles of uniqueness, continuity, self-esteem and self-efficacy can be used as a means of conceptualizing the relationship between individuals or groups and places. The first principle of identity is the desire to establish and retain personal distinctiveness or uniqueness. Breakwell suggests that the desire to preserve continuity of the self-concept is a second motivator of action. Twigger-Ross and Uzzell suggest that continuity is connected to place in two ways: place-referent continuity and placecongruent continuity. In the first, place-referent continuity, places act as referent to past experiences and actions in a way that provides a sense of stable and continuous identity. characteristics of the place. The desire to maintain a positive conception of oneself, or to maintain one's self-esteem, is a central theme of much of the writing about self and social identity (see Gecas, 1982; Tajfel, 1978; Hogg and Abrams 1988). Korpela's research with children has shown that a positive sense of self-esteem can be gained from being in favorite places. Self-efficacy, the final principle described in Breakwell's framework, is defined as an individual's belief in his or her own ability to meet the demands of a given situation.

Described by other theorists under a number of different headings including, community attachment, sense of community and sense of place, Shumaker and Taylor describe place-attachment as "a positive affective bond or association between individuals and their residential environment (Shumaker and Taylor, 1993, p. 233)." Milligan adds to this definition, the notion that the emotional bond has the effect of decreasing the perceived substitutability of other places for the one in question (Milligan, 1998, p. 6). Altman and Low (1992) develop comprehensive schema that describe the range of features and aspects captured under the heading of place-attachment. Although they describe several aspects of place-attachment -- including range of scales, types of actors, types of relationships and temporal aspects -- the feature of place-attachment described by Altman and Low that is most useful for this project is the nature and organization of attachments. They suggest that attachment can be understood in terms of three distinct qualities: affective, cognitive and behavioral.

The work of Singer and Loomis is especially helpful in developing an understanding of how individuals and place relate, in that their understanding of Jung provides a means of describing how individuals are oriented toward their environment as well as how they take in and process information about that environment. So, beyond helping build the understanding of human/environment connections, Jungian psychoanalytic theory offers a means of assessing various ways individuals perceive the place related aspects of agency initiated activities, and therefore enhances the effort to determine how the agency contributes to or inhibits the development of the social bond through the use of place.

There are various examples of alternative or new public lands management efforts that, while clearly not established with the intent of fostering civil society, have evolved such that characteristics of civil society have appeared in them. The Bureau of Land 
Management (BLM) is undertaking one such effort, one that is the subject of study for this research. In 1993, the concept of creating Resource Advisory Councils (RACs) arose when the BLM began an effort to reform livestock grazing policy. Over the following two years, the RAC concept became a central feature in the reform effort and the regulations creating RACs were authorized under the 1976 Federal Land Policy and Management Act (FLMPA) in August of 1995. Secretary of the interior Bruce Babbitt, in conjunction with the BLM State Directors, appointed members of the original 25 RACs situated in 14 Western states. Each RAC is composed of 12 to 15 members who represent the spectrum of people interested in and using the public lands. Membership is composed of 4 or 5 individuals from each of three subgroups: resource user groups, environmental groups and local/state government and academic organizations ${ }^{1}$. Members are nominated through a public nomination process and are then appointed by the Secretary of the Interior to serve voluntary, three-year, staggered terms.

The RACs were initially convened to develop "Standards and Guidelines" for rangeland management and livestock grazing alone. The standards are a set of measurable criteria designed to ensure rangeland health, and the corresponding guidelines are the management methods and practices used to achieve this. Since their inception and the subsequent development of standards and guidelines, many RACs have evolved to the point where they now advise and provide recommendations on the entire scope of uses for BLM lands.

There are a number of elements in the BLM's efforts that make the RACs a model for an alternative process of public lands management that is consistent with the development of civil society in the context of place. First, the agency's staff facilitates the groups' processes and does not participate as members of the groups. This suggests that the agency may have a role in opening a space for and facilitating the discourse between RAC members, while not controlling the outcomes of the process. To support this role, many of the BLM staff have been trained as facilitators, so that they would be better enabled to build the climate and social processes consistent with that described by civil society theorists. While the RAC charters prescribe more traditional decision making processes, initial study indicates that many RACs have adopted alternative processes consistent with the emergence of civil society. Although the RACs are empowered to vote on issues to be forwarded to the BLM for action, most do not work this way. Reports from BLM staff working directly with the staff indicate that most RACs forge consensus through more flexible group processes before formalizing recommendations with a pro forma vote.

Further, because the RACs are by definition focused on places, there is a greater likelihood that the type of discourse described above will be tightly connected to place. At the widest, RACs focus on issues within the lands managed by one of the BLM's state offices, but in many instances RACs focus on a much narrower region or district in a specific state. Because the interactions of individual RACs center on specific lands, place can begin to structure (in the sense of providing "common ground" for) the behavior of participants. While it is not clear if it has happened yet, there is the potential for the RACs' discourse to be structured by the lands on which they are focused.

\footnotetext{
${ }^{1}$ Membership is designed to be numerically balanced across the three subgroups. RACs with 12 members will have four members in each subgroup. RACs with 15 members will have five members of each subgroup.
} 
As noted in the previous section, in their current constitution, both political and market institutions fail to provide a basis for the social bond. It is into this void that public organizations can move and provide the structure and create the conditions from which the social bond can emerge. The study undertaken here endeavors to answer the question of how the BLM, as a public agency, resolves tensions between its historically rational model of operating with a more relational model that is required to support process which enable the development and emergence of the social bond. More specifically, this study examines the question of how an agency, in its effort to resolve this tension, builds or impedes the development of the social bond by it's symbolic use of place.

\section{Research Strategy}

In order to explore how the BLM uses or fails to use place to support the development of a robust social bond, a study of one BLM RAC and the way it has evolved since its charter was established using a logico-meaningful method is utilized. The logico-meaningful approach as described by Sorokin (1962) is being employed here because of its usefulness in investigating complex patterns of social interaction.

Data collection proceeded by first identifying one RAC in which a strong social bond has been built, thereby making civic discourse possible. Characteristics to be examined to make this determination include number of RACs within the state and the acreage managed by Federal agencies and acreage managed by the BLM. It is assumed that the smaller the area of land the RAC works on, the more likely it is that the group has found and worked from a shared sense of place. This assumption is based on the notion that individual's and group's sense of place is shaped in large part by their familiarity with that place. The smaller the area being focus on is, the greater individuals' and groups' familiarity will be, and therefore, the stronger their sense of place will be.

Once the group has been selected, the researcher observed the activities of and conduct interviews with BLM staff and RAC members. These data are used to identify indications in the RAC processes and members' experiences that place has been a factor in building the social bond and therefore allowed civil society discourse to emerge. Observations and questions to be asked of BLM staff and RAC members examined the importance of place by exploring factors including:

- The RAC members' connection to the place they focus on,

- The stories, experiences and key events of how the group and individual members came to understand the lands they focus on,

- Common experiences, perspectives and perceptions related to place,

- The nature and processes by which relationships between group members, and

- The agency's actions and role in the evolution of the group.

Beginning with the first interviews and initial observations, the data collected were reviewed and the processes of categorizing and analyzing the data initiated. This process serves to direct and focus the researcher's attention to the detail, nuance and isolated but specific information that allows categories to emerge. Further, the researcher looked for consistent as well as inconsistent meanings and perceptions described by 
interviewees. This process continued by identifying links across categories and finally examined these in order to find connections. These connections form the elements of the evolving understanding of how civil society emerges from in the RAC processes. The end result is a description of the agency's activities and processes that draw on and reference place, and in doing so, positively or negatively affect the evolution of the social bond in this group. This "catalog" of activities and processes as well as the role that the agency had in the process, will provide a preliminary understanding of what role public agencies have in supporting or hindering the development of the social bond and subsequent emergence of civil society.

\section{Organization of the Dissertation}

The intent of this dissertation is to address two related issues. First, it explicates the role that a public agency can have in fostering the development of the type of social bond necessary for civil society to emerge. Second, the dissertation describes the processes and actions that an agency can take to support or on the other hand, hinder the development of the social bond through their use of place.

As a way of understanding the intellectual context for this study, chapter two provides a chronological description of the civil society literature. This description starts with some of the oldest political and social thinking about the nature and organization of society and concludes with modern and even postmodern conceptions of civil society and related descriptions of the current condition of society. In addition to providing the contextual basis for understanding this description of current conditions and corresponding literary analysis, this review of the literature identifies two areas that have received little if any attention from civil society theorists, namely the role of public agencies and the source(s) of the social bond on which civil society is constructed.

Chapter three provides a description of the of the research strategy utilized for this study. This chapter reviews the process by which the subject of the study was identified and selected and describes the procedures followed in order to obtain University approval for the study of human subjects. Further, it includes a detailed explanation of the data collection and analysis process and the justification for the selection of these processes.

The fourth chapter describes and outlines the theoretical framework employed in the study. That is, it reviews the three theories, drawn from environmental psychology and psychoanalytic theory, that form the basis for understanding how individuals and groups are connected to place and further to assess how actions that may build or hinder that connection would be perceived. In order to do this, the chapter further expands on theories developed in environmental psychology and psychoanalytic theory introduced above. This chapter also includes some generalized examples of how these connections and perceptions may be operationalized.

Chapter five is largely a physical description of the place that the RAC has responsibility for. Before describing that place though, chapter five describes the history of the agency with particular attention to its historical use of advisory groups, up to and including the RACs. With this background in place, the remainder of the chapter focuses on the places in Northern California where the three field offices associated with this $\mathrm{RAC}$ are involved. This account gives particular attention to those places that RAC 
members identified either in describing their individual connection to place or in their comments regarding RAC activities and place.

Chapter six begins with a brief review of the theoretical framework before describinging the findings. The findings proceed by first examining the indications that RAC members do in fact exhibit characteristics of place-identity and place attachment that the agency may or may not capitalize on. This chapter continues by outlining the indications that various agency processes function in a way that they would be perceived in a manner consistent with the theoretical framework, and in doing so, build on the members' connection to place in a way that supports the collaborative efforts of the group. The chapter continues with a discussion of several processes used by the agency in working with the RAC that do not capitalize the members' connection to place and as such, fail to support and may in fact hinder the development of the social bond. Chapter six concludes by describing additional findings that may have bearing on place connectedness and the development of the social bond.

The final chapter and conclusion of the dissertation opens with a reiteration of the findings described in the preceding chapter before exploring their implications. The significance of the findings from this study offers new possibilities to administrators not only in public lands agencies, but potentially in a host of other federal, state and local agencies, as the work to craft new strategies to cope with increasingly complex issues. Chapter seven concludes with suggestions for further research, shaped by the findings of this study. 


\section{Chapter 2: Literature Review}

\section{Introduction}

Civil society has become a recurrent theme in both the popular and academic literature over the last several years. According to The Blackwell Encyclopedia of Political Thought, civil society was originally defined as "a generic term for society and state, synonymous with "political society" (Miller, 1995, p.77). Walzer describes it as "the space of uncoerced human association and also the set of relational networks formed for the sake of family, faith, interest, and ideology - that fill this space" (Walzer, 1991, p. 293). Its more contemporary definition has evolved to mean those "social and economic arrangements, codes, institutions apart from the state... In general usage today civil society... refers to the non-political aspects of the contemporary social order" (Miller, 1995, p.77).

In order to understand the contemporary literature, it is important to first examine the range of thinking that laid its conceptual foundations. This, to a great extent is the work of philosophers and political theorists. By and large, these early thinkers are interested in questions related to nature and reason, if and how they are connected, and what the answers imply for how one should live the good life. Although they do not specifically address the role that the state or its agencies had in promoting or supporting the good life, the force of their arguments can be traced to the contemporary literature.

This review of the literature proceeds in three broad sections. The first examines the long history of civil society thought as it has evolved in western political philosophy, paying particular attention to the arguments that contribute to current understandings of civil society. The second section examines a cross section of contemporary literature, and highlights what, if any attention is given to public agencies and their role in supporting the emergence of civil society. The final section turns its attention to the contribution this study seeks to make to the civil society literature.

\section{History}

Discussions about the history of civil society literature in western societies often begin with the most well known authors of the Scottish Enlightenment: John Locke and Adam Smith. While these thinkers are critical to the evolution of thought about civil society, Adam Seligman argues that the foundations of thinking about civil society begin much earlier with the Stoics'. The Stoic idea of oneness with the moral perfection of the natural order is among the key ideas that later influenced European thinkers. Consistent with the Stoic position, Cicero argued that there is a "true law (namely right reason) which is in accordance with nature, applies to all men and is unchangeable and eternal" (Seligman, 1992. p. 17). Human law therefore, should be consistent with natural law and to create laws that are otherwise is not morally correct. It is in this conception of axiomatic principles of behavior grounded in a natural order that Seligman finds the early conceptions of natural law, so influential later in western notions of social order.

One clear shift from Stoic notions of natural law to early Christian conceptions is its denaturalization. That is, rather than being immanent in the physical world, natural law is seen by the Christian philosophers as a matter of divine will. This move creates an 
apparent contradiction between nature and grace. St. Thomas Aquinas resolves this contradiction by arguing that reason and natural law are necessary steps that move man toward the Christian vision. At the same time, Aquinas was able to subordinate the political order and laws of man, created consistent with reason and our experience of nature, to the laws of God and the moral ends of Christianity. The result is a State in which the political ends are connected to and in fact further the moral ends of God (Seligman, 1992, pp. 18-19). Further, for Aquinas, the supreme purpose of the state was the good of the group (Frost, 1962, p. 190). Consistent with his notions of reason and order and with his belief that the state is of divine origin, Aquinas also argued that change in government should come only through legal means.

The next clear shift in thinking bearing on civil society occurred with the theorists of the Scottish Enlightenment. Key to the shift in thinking made by Locke, Smith and others is the move way from divine will as the organizing feature of the political system. While they did not abandon their belief in God, the Scots argued that God does not establish political power, nor is human action driven by subservience to God. For these thinkers, individuals possess God-given rights and have the capacity to exercise free will. At the same time, individuals are innately social creatures and interactions in the social sphere shape morality. For Locke, efficient social life demands that individuals submit themselves to the authority of the majority (Frost, 1962, p. 197). Self-interested action, according to Smith, was tempered by the moral sentiments of society. That is, because self-interest is imbedded in the context of a socially conscious mind, individual action would always be tempered by the sentiments of others in society. In this way the interests of the individual and the society are advanced simultaneously.

Richard Boyd argues that Edmund Burke adds further associational aspects to the concept of civil society that are often overlooked or underrepresented in contemporary understandings of classical liberalism. In opposition to the atomistic conception of the individual, Burke argues that when taken to extremes, an emphasis on the values of reason, consent and wholesale emancipation from relationships threaten liberalism's commitment to liberty. Further, the rigid distinctions between public and private, obscure the intimate relationship between our ties to family, church, party or locality and the larger political order. The result of such rigid distinctions is a denial of the political character of social man. In contrast to the classical definitions of civil society as synonymous with political society or contemporary definitions that place civil society between the public and the private, Burke attempts to find an intermediate domain, describing a "civil and political scheme," a "civil and political mass" and "civil social man." Burke also argues that civil society entails more than a society of vibrant groups and reminds us there is inevitably a moral and evaluative nature to the (neo)Tocquevillian associationalism (Boyd, 1999).

Seligman continues his discussion of the evolution of civil society by suggesting that English rationalist David Hume introduces an alternate conception of Reason that would lay the groundwork for modern liberalism. According to Seligman, Hume makes the argument that morality has no basis in reason, but rather is related to passions. Reason, by contrast, is concerned with the discovery of universal truths. In addition to separating reason and passion, Seligman suggests that Hume further establishes the foundations of liberalism by identifying what he describes as necessary conditions for the calculation of the good. These were the stability of professions, the transfer of goods by 
contract and the performance of promises, all of which are consistent with the notions of a secular civil society dominant today.

Although Kant made a variety of contributions to the thought around civil society, the key concept to be noted here is his work aimed at salvaging the connections between the individual and the social. As the thinkers of the Scottish Enlightenment move to secularized theories of civil society and place an emphasis on individual reason and the pursuit of self interest, they simultaneously face a difficult separation of universal from particular or social from individual. Kant begins from a position, similar to the Scots, where freedom and equality are central elements of his philosophical position. He works through the problem of the social versus the individual, positing that it is through the exercise of practical reason within the public sphere that man's autonomy could be guaranteed. One important consequence of Kant's conceptualization of the public sphere however, is that it had the effect of disconnecting the public juridical Right from the private ethics (Seligman, 1992).

For Hegel, and Marx later, Kant's final cut separating the juridical from the ethical leads to the project of reconnecting the Right and the moral. To some extent, Hegel reflects the thinking of the Scottish Enlightenment in his argument that it is the exchange of property that creates mutual recognition and the construction of individual self-consciousness. His attempt to re-unite the legal and the ethical comes in the notion of the universal, in the Idea of Freedom, working through the particular, or the livelihood and legal status of each individual.

Tocqueville's attention to the importance of equality and the role of voluntary associations in the expression of political sentiments in the United States is often discussed. He wrote, "nothing struck me more forcibly than the general equality of condition among the people" (Tocqueville, 1945, v.1, p. 3). Tocqueville saw this as an enabling feature of the political environment in the US. That culture was embodied in the political life in New England. He sees the participation of the people in public affairs as the "life and mainspring" of American liberty. He continues by describing the role of voluntary associations in fusing personal interest and the common good (Ehrenberg, 1999). This aspect of his work became particularly important in the 1990s as concern about an apparent decline in civic participation attracted renewed attention.

Another aspect of Tocqueville's work that must be addressed is his concern with the subversion of the public sphere to the private in the US. The elevation of the particular or private sphere to a status that is somehow representative of the social whole is but one aspect of the loss of a public sphere wherein individuality, as a component of ethical solidarity, is constituted. The "universal" subject is the counterpoint to a devalued public sphere within which society and its constitutive relations are presented. The absence of a shared public space within which critical reason could exert its influence struck Tocqueville as one of the most dangerous aspects of American life (Seligman, 1992). Tocqueville states:

The first thing that strikes the observation is an innumerable multitude of men all equal and alike, incessantly endeavoring to procure the petty and paltry pleasures with which they glut their lives. Each of them living apart is as a stranger to the fate of the rest- his children and his private friends constitute to him the whole of mankind; as for the rest of his fellow-citizens, he is close to them, but he sees them not; he touches them, but he feels them not; he exists but in himself and for 
himself alone; and if his kindred still remain to him, he may be said at any rate to have lost his country (Tocqueville, 1945, v.1 p. 350).

In the end, according to Tocqueville, unless the public sphere is preserved, everything in modern society has the potential to look alike and the specific characteristics of each individual become indistinct from the general aspects of the world (Seligman, 1992).

To this point in the literary history of civil society, the possible role of public organizations in fostering civil society remains well outside the consciousness of any of its contributing thinkers. The connection of this literature the contemporary discourse can be identified in one of the conceptual themes found throughout the literature described so far. This recurrent theme can best be described as a tension between general and specific or as an effort to answer the question of whether the good life is attained through expression of the general or the particular and it appears across the literature. Emerging primarily from the thinking of the Scottish Enlightenment, the contemporary literature in the United States continues this theme, emphasizing the tension between public and private and proposing civil society as an alternative to or existing in the space between public and private.

\section{Contemporary Literature}

\section{Revival of the Literature and Social Critique}

The literature of civil society remained primarily the province of but a few philosophers and political theorists until the 1980s, when a variety of world and national events occurred, bringing the interest in civil society to the fore not only in the ivory tower of academia but to the muck and mire of street level policy makers and community activists. With the fall of communism in Eastern Europe and substantial cultural changes in the US, the volume of writing, thinking and discourse regarding the promise of civil society increased.

Works like Glendon's Rights Talk, Sandel's Democracy's Discontent, Putnam's Tuning In, Tuning Out, and a host of others all describe from various perspectives the problems faced by modern western society in general and the US in particular. The result of these trends, say many thinkers, is the undermining of the civic engagement and weakening of connections people establish to each other and the lives of their communities. The result of this reduced engagement is a weakening of the trust that feeds and builds the social capital on which individuals base their notions of effective and satisfying political participation -- and, in turn, diminished social capital.

\section{The Idea of "Public" in Contemporary Literature}

The notion of public in much of the early civil society literature referred to the expression of moral values in relationship to others outside of oneself and his or her immediate family, and included other individuals or the community or the society. The idea of public began to change with the thinking of the Scottish Enlightenment and this change is clearly reflected in civil society's embodiment the US. "Public" has now come 
to refer to the government, or those institutions that are authorized and created as a part of a state and its administrative structures.

The current conception of civil society, as it was revived in the 1980's in Eastern Europe and the US is characterized by this later conception of public. Civil society by this logic is marked by those forms of communal or associational life that are organized neither by the coercive potential of the state, nor the self-interest of the market.

The contemporary literature of civil society reflects this conception and can be broadly organized into two loose categories. The first and less numerous collection can be understood as proposing civil society as a response to what is seen as growing intrusions of big government into private life. This collection of work suggests that the institutions and processes of civil society can and do act as a bulwark against the impositions of government that at the same time encourage and assist altruistic activities.

The second body of literature can be loosely understood as proposing the institutions and processes of civil society as a means of shoring up or rebuilding the morals and virtues necessary for a vibrant democratic society. This literature broadly argues that institutions such as religious, civic and other voluntary organizations as well as the family are the mechanisms by which the necessary moral foundations for democracy are conferred from one generation to the next. Those working from this general perspective also suggest that civil society, as supported by these institutions and processes, is necessary in the face of an overactive market. Absent in this large and growing body of literature however, is any reference to the role of the public agency in facilitating and supporting the emergence of civil society.

Another change in the contemporary literature of civil society can be found in the audience to which it is written and the authors who undertake the projects. Whereas the classical literature is written by philosophers and political theorists, the contemporary literature is characterized by a much more populist tone. That is, community activists, policy makers and political commentators have all become involved in the most recent round of interest. Beem argues that for the first time, civil society has taken center stage in public political discourse. Among the distinguishing features of much of the new, less academic work is its lack of theoretical contention. Social critics, be they from think tanks, foundations, the media or the political establishment all start from the position that the theoretical dimensions of civil society have been worked out or if they have not, doing so is not a prerequisite for the applying the idea. Even among academics entering the fray, such as Sandel, Elshtain, Putnam and others "arcane language and conceptual argument" is replaced with the more substantive questions of application (Beem, 1996, pp. 4-5).

\section{The Literature Emphasizing Individual Freedom}

The first of the two strands of literature is generally organized around the idea that civil society is the means by which individual freedom is increased and government involvement is curtailed. Edward Crane, in his 1997 speech at Fudan University, in China, argues this point. He suggests that there are in essence two ways to order society. The first, political society establishes a relationship between the individual and the state wherein the state coercively makes decisions for the individual. The second way to order society is through civil society, based on the private interaction of individuals, 
associations, religious organizations, businesses and institutions other than the state. Crane asserts that in political society, government involvement in decisions stifles economic growth and ultimately denies the sense of individual achievement and fulfillment that can only come through the freedom of choice afforded by civil society (Crane, 1997) .

Consistent with a libertarian perspective, David Boaz, Executive Vice President of the Cato Institute suggests that limited government is not just anti-government, but instead is an "appreciation of the complicated network of institutions and associations that bind us together and provide us with much of what makes life worthwhile(Coats, 1996, p. )." Boaz argues for a shift in charitable spending from government to individuals and private organizations. Boaz also asserts that grants do not create strong, creative, vibrant private organizations, but instead lead to rule-bound, ineffective games of grantsmanship and bureaucratic empire building. Simply put, social engineering is social engineering regardless of whether it is liberal or conservative. Boaz continues by arguing that government is one primary reason institutions of civic association have atrophied. To revitalize these institutions, he suggests that taxes should be dramatically cut, "so that people have more money to spend, both on their own families and on charitable efforts (Coats, 1996, p. 31)." Beyond a reduction in taxes, functions of civil society should be returned to the lowest level at which they can be adequately performed - the individual, the family the church the neighborhood the school the community and if necessary, the state government.

Simultaneous with the growth in interest around civil society in the United States, the fall of the Iron Curtain has generated new interest in civil society throughout Eastern Europe and China as well. Ernest Gellner, in his examination of Poland and Hungary in particular, sees civil society in Eastern Europe as parallel structures built alongside but independent from the state. It is these structures that allow individuals to associate freely and thereby to increase their power, strength and dignity relative to the state. In this role, civil society attempts to tame the power of the state and direct it toward peaceful ends. Not only do the structures of civil society check the power of the state, but also they enable the individual to flourish in the face of the smothering effect of clans, tribes and castes. Gellner tries to make his conception of civil society more distinct by pointing out that civil society is neither just a pluralist state nor is it a condition of individualized or atomized populations. Such has been the case with various premodern and Islamic states respectively, and neither is an example of civil society (Palmer, 1995). It seems clear that formal democracy is not enough. Democracy will degenerate into authoritarianism unless the process of debating what to do and organizing to do it are established in the institutions of civil society (Ignatieff, 1995). In his treatment of the atomized individual, Gellner also suggests that civil society offers the mechanisms to avoid the hyperindividualism seen in modern market focused welfare states (Palmer, 1995). He goes on to suggest that in is in connection with the state that civil society can mitigate the ill effects of the market. Without civil society it is impossible to debate what sort of market to have (Ignatieff, 1995).

W. Lance Bennett, in his Ithiel De Sola Pool lecture, does not directly argue for civil society as a protector of individual freedom, but does add further complexity to the kind of data Putnam presents in Tuning In, Tuning Out as evidence of a shrinking public space. Bennett, employing an extensive review of participation and economic data, 
argues that Americans are continuing to engage in civic and political activities, albeit of a very different sort than in the past. Moreover, he posits that what changes in civic engagement have taken place are in response to changing and uncertain economic conditions rather than the fragmenting effects of mass media technologies. In such an environment individuals do not have the resources to participate in traditional structured activities and groups, but are still interested in the political issues that affect their lives. As a result, they instead participate in what Bennett describes as lifestyle politics, which allows them to contribute limited resources on their terms to issues they feel most strongly about. Bennett argues that declining participation in political processes is a result of these uncertain economic conditions in combination with the growing public sentiment that large, comprehensive or collective government programs fail to achieve their goals. He concludes that if, in fact, participation has not declined, but changed, the critical challenge is not to recreate previously existing civic institutions and processes, but rather to shape communications processes and technologies in such a way that the deliberation, interest formation and decision-making requirements of societies may be better positioned for experiments with direct democracy, which is needed now more than at any other time in modern history (Bennett, 1998)

Don Eberly surveys the contemporary civil society discourse in his 1998 article "Civic Renewal vs. Moral Renewal," and suggests that there are two themes: one which focuses on the civic life of the nation and another which is concerned with the nation's culture and moral underpinnings (Eberly, 1998, p. 45). In other writing from his work as the Director of the Civil Society Project, he argues that current public policies are now being directed at asserting institutional authority, social obligations and moral requirements over the individual. Moreover, one of the primary contemporary problems is the collapse of character shaping institutions, resulting from hedonistic mass culture that is increasingly characterized by violence, incivility and a flagrant disregard for human dignity. Eberly argues for a reinvigoration of a civil society whereby the authority in the noncoercive realm of civil society would be restored, as opposed to defaulting that authority to the coercive realm of the state. He assesses the current political climate by saying further, "Most will rejoice to know that a vast majority of Americans now acknowledge that government, and especially the central government, may never again be embraced as the engine that drives American progress" (Eberly, 1998, p. 46). He is interested in social renewal and in originating in our "hearts, homes and local communities." Further, he suggests that civil society has the ability to contribute to the restoration of real and functional local communities and that this happens in a vibrant third sector, civil society, that departs from our "current obsession with either the state or the market as instruments for social progress." If, according to Eberly, this third sector is lost, there is the possibility that what is left is not the other two sectors, but eventually only one, the bureaucratic state.

Berger and Neuhaus, in To Empower People, propose the use of a collection of mediating structures as a means of strengthening democratic governance and rethinking the institutional means by which the government exercises its responsibility. While they acknowledge that there are likely other such mediating structures, those that Berger and Neuhaus focus on include the neighborhood, the family, the church and the voluntary association. Although Berger and Neuhaus, perhaps more than other writers in this segment of the literature, are not openly critical of government intrusiveness, the do see 
the structures or institutions they describe as mediating against megastructures such as huge corporate entities like General Motors, interest organizations such as the AFL-CIO, and, most especially, the government. They see these mediating structures as the value generating and maintaining agencies in society and propose that they be used as a means of and source of social welfare programming that does not require direct governmental involvement. Operationalization of this proposal would occur in one of two ways: Minimally, public policy should protect and foster these mediating structures, and maximally, public policy should directly utilize these mediating structures for social purposes (Berger and Neuhaus, 1977).

Moving from mediating structures that limit the intrusiveness of Berger and Neuhause's megastructures to a philosophical defense of the enlightenment project, James Schmidt argues that the enlightenment project has been misrepresented and that, further, Immanuel Kant's thought leads to fewer difficulties in the conceptualization of civil society than does the use of works by critics of the enlightenment. Schmidt's article begins from the oft cited criticisms of the enlightenment, namely that:

- The Enlightenment's indifference to traditional norms and values destroys the connections between individuals and societies and opens the way to oppression or anarchy,

- The Enlightenment fails to see the limitations of its on use of reason and essentially replaces faith in religion with faith in rationality, and

- The Enlightenment's critique of religion was the first step toward a broader critique of science, morality and reason, the end result of which is nihilism and the promise of a "new enlightenment" wherein the ideal of aesthetic selffashioning would replace the drive to uncover universal values.

In response, Schmidt turns to Outram's overview, which suggests that the conception of the Enlightenment that leads to these criticisms is based on an overly narrow notion of what comprises the Enlightenment. She indicates that a more current historical survey of the literature as made it increasingly difficult to speak of the Enlightenment as a discrete phenomenon with particular objectives. In their analysis, both Schmidt and Outram suggest that the Enlightenment project is incoherent for those that reject it, while those who study it more closely find that it breaks down into a host of particulars that are inconsistent with the criticisms (Schmidt, 1998, p. 423). Schmidt goes on to use Kant's arguments as an alternative that avoids some of the difficulties encountered by the enlightenment critics. Kant's notion of civil society is characterized by forms of association in relation to a state that is governed by laws that pass a universalization test, a test which requires them to respect attributes of "lawful freedom," "civil equality," and "civil independence" (Schmidt, 1998, p. 429). In comparing Kantian civil society with Edward Shils' civil society and civic virtues, Schmidt believes that Kantian civil society avoids concerns of excessive emphasis on individual rights while at the same time avoiding the possibility of state intervention in pursuit of a common good. Further, Kant's use of practical reasoning avoids the need to calculate chains of causal connections and potential effects on less than clearly defined communities. Finally, Kant recognizes the necessity of considering actions within state borders and those involving the international community. 
Taken in total, this collection of literature describes a conception of civil society that envisions its institutions functioning in a way that limits the intrusion of state authority into individual freedom and autonomy. By and large, this collection of work is openly opposed to, or implicitly ambivalent toward, the possibility of positive government involvement in efforts to foster the emergence of civil society. Although there is some implication that moral foundations can perform this function, this literature is also essentially silent on the topic of the nature and source of the social bond that is necessary for civil society to emerge and function.

\section{The Literature Concerned with Social and Political Fabric}

In contrast to the literature described above, which proposes civil society as a means of limiting the incursions of state power into private realms, the next segment of literature argues that civil society represents a means of rebuilding the kind of social and moral fabric that is necessary for effective democratic processes to function. Much of this literature draws directly and indirectly on the social conditions described in the first chapter and moves forward by proposing both philosophical and technical strategies for addressing what these authors see as a disintegration of the fabric that comprises our social and political lives.

In an article that obliquely argues for civil society as a way to build the social and moral fabric, Alan Wolfe starts with the question, "Is civil society obsolete?" The answer to that question, not surprisingly, is an indirect one. Wolfe sees changes in the fabric of society which do not necessarily hearken the death of civil society. Civil society he says, has the ability to change with respect to changes around it. The term and the concept are constantly evolving and being reinvented. One way that the current debates can be understood is as a tension between nostalgia and change. On the one hand, some feel a certain nostalgia for a social environment where there was greater consensus about norms and values and less instability. The urge for change, in contrast, centers around the desire to overcome the substantial remaining social challenges. In examining two sets of countries that have separate notions of what civil society is as well as the role of the state, both neglect the role of the third sector (Wolfe, 1997).

Still another perspective is offered by Jean Bethke Elshtain, who takes up the discourse of authority vs. liberty, and in the process describes the importance of civic institutions for maintaining the social fabric and avoiding the descent into despotism or totalitarianism. Elshtain reminds us that Tocqueville argued that liberty and authority go together. "He realized that the resort to tyranny is an indication that legitimate authority has broken down and given way to brute force"(Elshtain, 1997, pp. 11-12). Further, Tocqueville understood that there was a distinction between authoritarianism on the one hand and authoritative rule or governance on the other. The former takes the form of despotism, which is generally far different than authoritative civic organizations and institutions without which democracy cannot function. Elshtain goes on to argue that such organizations are growing weaker and as a result, citizens are becoming increasingly distrustful of both the government and each other. As the mistrust grows, Elshtain sees subjectivism growing to the point where everything is up for grabs. It is under such conditions that democracy slides into despotism or totalitarianism. Quoting Hannah Arendt, "The ideal subject of totalitarian rule is not the convinced Nazi or the convinced 
Communist, but people for whom the distinction between fact and fiction and the distinction between true and false no longer exists (Arendt in Elshtain, 1997, p. 11)." For Elshtain, civil society and its institutions are the means by which standards, norms, claims and counter claims can be measured, established and maintained.

Moving from authority v. liberty to public v. private, Evan Charney draws on the work of John Rawls to argue for the need to retain the distinction between what Rawls describes and public and nonpublic. In contrast to what Charney sees as a general trend in the civil society literature to break down the barriers between public and private as a means of improving social discourse and strengthening the social fabric, he draws on Rawls' public/nonpublic distinction in order to ensure the sort of plurality necessary for robust democracy. To begin, Charney uses Rawls definition of public, which, rather than the broad public space characterized by the sort of associational life typically linked with civil society, can be understood as a more restricted space that most importantly includes the legal sphere and its related institutions. This public space, and the type of public reason exercised there, is attributed:

To the judiciary and what the supreme court-called the "exemplar" or public reason; to political officials when they "speak in official forums"; to the executive in its public acts and pronouncements; to members of political parties and candidates in their campaigns; as well as to citizens when they "engage in political advocacy in the public forum" and voted on issues concerning "constitutional essentials and matters of basic justice." (Charney, 1998, p. 99; Rawls, 1993, pp. 215-216)

By contrast, nonpublic is used to identify the types of associational life that Rawls, in $\underline{A}$ Theory of Justice, calls "social unions." Included in this sphere are institutions such as the family as well as the associations that carry connotations of civil society, such as clubs, churches and universities (Rawls, 1971, pp. 520-529). With these definitions in place, Charney goes on to argue that while these two spheres are not entirely distinct and subject to constant reevaluation, the theoretical distinction between them must be maintained in order to ensure the viability of a robust democratic society. In an example that he uses on several occasions, Charney argues that if these spheres collapse, and the separation of church and state disintegrates, it threatens the possibility of both state incursion into the affairs and perspectives of the church and the possibility of incursion of the church's values into the state's actions. Both alternatives are seen as threats to the maintenance of the sort of plurality necessary for robust discourse and democratic processes to occur.

The nature and means of achieving the good life has been a recurrent theme throughout the writings of Western philosophers. Michael Walzer identifies four strands of literature that discuss specific ways of achieving the good life. From the left, he identifies two strands. One places emphasis on the importance of a democratic state in which individuals are freely engaged and are committed decision-makers. A second, leftist strand focuses on economics and highlights the importance of a cooperative setting in which production is set free. The third strand is based in the capitalist conception of the market, where the good life is defined through personal choice. The final strand, nationalism, and with it an emphasis on the bonds of blood and history, is seen as the 
means to achieve the good life. Walzer's notion of civil society responds to these four in a way that both refutes and incorporates elements of each. Walzer describes civil society as "people freely associating and communicating with one another, forming and reforming groups of all sort, not for the sake of any particular formation... but for the sake of sociability itself.(Walzer, 1991, p. 298)" In response to the leftist strands of thought, he sees a version of civil society in which neither production nor citizenship is all absorbing. That is, citizenship is seen as a more fluid associationalism. At the same time, the system is also more open to competition and means of production subject to pluralist ownership. The market, according to Walzer, would be politically constrained and open to the collective as well as private initiatives. As such, civil society would allow for the limitation of the gross inequities of an unrestrained market. Further, Walzer's civil society adds pluralist tendencies to the nationalistic notions of the good life. Civil society holds out the hope of "domesticated nationalism" where the stakes are lower, people are less ready to take risks that threaten peace and coercion is used only to keep the peace (Walzer, 1991). The state, in this conception of civil society, is still an active player because the networks of association cannot do without the agencies of state power. The state both frames and occupies space with civil society because, left to itself, civil society has the potential to generate radically unequal power relationships. In Spheres of Justice, Walzer attempts to answer what he sees as key questions of distributive justice. While not directly addressing the idea of civil society, Walzer does take a philosophical position that informs his understanding of civil society. He rejects taking a position based on philosophical idealism and instead turns to a more contextual pragmatism. He suggests that our notions of justice take the form of a sort of 'gold standard' by which other claims of justice are measured. In time alternate conceptions of justice are offered up, ones that argue that the monopoly the existing standard holds is unjust or that the dominance of any standard is unjust. This reinforces Walzer's advocacy of a civil society characterized by pluralist and fluid associationalism as well as state involvement and that is limited to maintaining peace and framing the space for discourse.

More recently, Walzer examines the breadth of civil society theory and suggests that there are two necessary forms of civil society. The first is the "civic republican, Jacobian, stateist model, which hods that there is only one really important community, the political community (Walzer, 1999, p. 62). This model of civil society comprises active citizens who are engaged and devoted to debating the issues of concern and leave administration to a professional civil service that serves everyone. Walzer describes the second model as the "pluralist, multiculturalist model, which holds that there are many communities, based on class, religion, ethnicity, neighborhood and so on" (Walzer, 1999, p. 62). Under this model though, members are focused less on debate and decision making, and more on mutual aid. Rather than a professional civil service that is whole responsible for administering the decisions of citizens, members of the pluralist community act also as recruiters, organizers, teachers, etc. They become administrators themselves, and support the work of the professional civil servants. Walzer suggests that these two models, and the communities that emerge from them, are both necessary to cope with three features that he attributes to civil society: inequality, fragmentation and fitfulness. He suggests that society will necessarily be characterized by some degree of inequality because of variation in resources and capacity. Both models of civil society 
must function to cope with conditions of inequality; the civic republican model in order to craft state strategies and the pluralist model to provide self help and mutual aid. Similarly with the conditions of fragmentation, the pluralist model provides a nearly infinite opportunity for individuals to come together around concerns and interests. As these pluralist groups become stronger though, the effect is one of increased distinction between them. At the same time, the stateist, civic republican model provides a unifying umbrella under which civil society may find common goals. Finally, Walzer points out that civil society is marked by a fitfulness of part time engagement and occasional and undisciplined work. Certainly, the organizations and associations of the pluralist model provide some structure to the work done in civil society, but at the same time, face challenges of recruiting members who will work for little or no monetary compensation. In these conditions, it is necessary for the civic republican model to be strong enough in will and resources to support and provide the means and structure which support consistent and extended engagement. Walzer contends that for civil society to truly flourish, the current trends that oppose state involvement or at least the state's fiscal involvement, must end.

Michael Sandel recognizes the phenomenon of rights being used for the first time as trumps by the Supreme Court. Going further in his review of the practices and institutions of the United States, Sandel contends that they express a commitment to what he calls a procedural republic. That is, it has become a republic whose "central idea is that government should be neutral toward the moral and religious views its citizens espouse" and instead "should provide a framework of rights that respects persons as free and independent selves, capable of choosing their own values and ends" (Sandel, 1996, Id 5-6,). In such a republic, emphasis is placed on fair procedures over specific outcomes. Sandel argues that Americans believe that freedom is about individual choice and that the government's job is to protect this freedom of choice and at the same time remain uninvolved in the content of those choices. Sandel suggests that this conception is both new and faulty. Instead, he wants to reinvigorate the traditions of civic republicanism. In making this argument, Sandel takes on what he sees as the primary challenges to civic republicanism, that in our current large and complex society, civic republicanism is not possible and that even if it were possible, it is not desirable, as it tends toward exclusivity and coercivness. In addressing the first issue, size and complexity, Sandel sees hope in the possibility of dispersing sovereignty, as is already part of the American political tradition in the form of Federalism. Sandel suggests that, "federalism is more than a theory of intergovernmental relations... it suggests that self-government works best when sovereignty is dispersed and the citizenship formed across multiple sites of civic engagement." (Sandel, p. 347) Despite the nationalization of politics and political discourse in the US, Sandel argues that there is hope for a renewed civic life in the particular communities within which we reside. Moving then to the exclusivity and coerciveness challenge to civic republicanism, Sandel suggests first that the argument for exclusivity is based on the assumption of human incorrigibility. That is, the argument for exclusivity is based on the idea that only some citizens have the capacity for the type of civic virtue necessary for a vital civic democracy. If however, civic virtue can be taught and is not an inherent personality trait, the claim of exclusivity disintegrates. Once one embraces the formative project of teaching civic virtue, the possibility of coerciveness then looms larger. Sandel's response to this concern argues that if one adopts 
Tocqueville's notion of a clamorous, dispersed, and differentiated form of civic practice, as opposed to Rousseau's view of a unitary and incontestable common good, the possibility of coerciveness is diminished. Sandel acknowledges that it does not however, disappear, which reinforces the need for the formative project of teaching and building civic virtue.

Glendon describes the change in the discourse around rights and the implications of this change. She argues that for the first time, rights are presented as absolute, individual, and independent of responsibility. The result according to Glendon is that Americans have lost sight and understanding of what rights are and in the process have heightened conflict and hindered the discourse that moves towards consensus, accommodation or common ground. This altered discourse of rights has created a society that lives by "its penchant for absolute, extravagant formulations, its near-aphasia concerning responsibility, its excessive homage to individual independence and selfsufficiency, its habitual concentration on the individual and the state at the expense of the intermediate groups of civil society, and its unapologetic insularity" (Glendon, 1992). This neglect of civil society and its institutions undermines both civic and personal virtue.

In her book Rights Talk, Glendon describes the extensive changes that have occurred in the nature of our political and social language. For Glendon, 'Rights Talk' has taken on a series of characteristics that severely curtail our ability to engage in effective political discourse. According to Glendon, our discourse has embraced a language in which rights are absolute, rights place individuals in a radically autonomous position relative to others, rights contain no corresponding language of responsibility or sociality and is insular or isolationist in its world view. The consequence of this type of language is a "stark, simple rights dialect (that) puts a damper on the processes of public justification, communication and deliberation upon which the continuing vitality of a democratic regime depends (Glendon, p. 171)". Further, the language Glendon describes accommodates the economic, short term and individualistic aspects of the problem while neglecting the social and long-term concerns of society. After her exhaustive discussion of how the discourse of rights has changed over time and what the implications of that change are, Glendon suggests that there is an opportunity to move toward a new discourse that acknowledges civil society, as she sees it, in the space between the individual and the state. Her focus remains on the language used, and she argues that there is a need to refine the rhetoric that promotes a more public conversation about political ends. She argues that because the sources of the social bond that once structured our political discourse are now largely gone, we need an new language, but the source of this new language can be drawn largely from the few remaining pockets of cooperation and relationship. Among these pockets of relational language are the family, the law and our collective sense of American ideals. From the family, Glendon looks to draw on the language of the household and family as well as drawing out that language that is characteristic of women and mothers, that is, a language that enables the inclusion of non-rational features in discourse. From the law, Glendon sees the source of a language of responsibility. She suggests that while there has been much change in the litigious nature of our culture on the whole, much of the law, and contractual relationships particularly continues to enforce a language of both rights and corresponding responsibilities. Further, the language of the law has the capacity to better cope with the complexities of modern society and issues than does our current language of rights. 
Finally, Glendon looks to American ideas as a source of a renewed and revitalized language. Here she finds a language that reinforces tolerance, respect, public deliberation, freedom and responsibility and the rule of law. Here again, the adoption of a new language that embodies these characteristics, Glendon argues, will move our discourse in more functional directions.

Christopher Beem argues that while it is necessary to develop (re-develop) the institutions of civil society, doing so is not sufficient for the invigoration of civil society as a whole. A well-ordered democratic society also needs rough agreement about a basic set of moral principles. "If, despite our differences, we cannot agree to a common foundation of virtues, values and norms, our society literally cannot function." (Beem, 1996). For Beem, the institutions that are most important to rebuild are those which reinforce and cultivate that moral foundation. Importantly, Beem breaks from Sandel and others in recognizing that the difficulties faced in growing civil society are more than merely political. In addition, they have an ontological dimension. That is, he acknowledges the breakdown of the ontological consensus that existed from the Founding up until the 1960's, but believes that we can return to some sort of consensus around a set of foundational morals from which to build civil society.

Robert Putnam in his 1995 Tuning In, Tuning Out, presents compelling evidence of a growing disengagement from group membership since the 1940s. His data, though they can and have been questioned and challenged, indicate that recent generations of Americans have joined public groups in smaller numbers, displayed less social trust and voted in smaller numbers then ever before in American history. Other researchers have noted similar trends, including the following:

- Declines in the identification with political parties (Burnham, 1982; Wattenberg, 1994).

- Intergenerational reduction in loyalty to party among those born following World War II (Inglehart, 1996).

- Reductions in the level of social trust, knowledge, national identification and voter turnout (Rahn, 1997; Rahn and Transue 1997).

- Public cynicism and dissatisfaction with government and politics (Capella and Jamieson, 1997, Chalupka, 1999).

Growing vigor and bitterness in cultural and moral politics generating animosities among citizens and between citizens and government (Gitlin, 1995; Hunter, 1991). Gertrude Himmelfarb, Professor Emeritus of history City University of New York, argues that devolution of power and authority to state and local governments is necessary but not sufficient. Further, transfer of power to all levels of civil society is also necessary but not sufficient. Instead, what is critical is the reconstruction of the moral fabric of culture. Himmelfarb argues that policies such as affirmative action and trends including multiculturalism and outcome-based education have undermined the institutions of civil society. For Himmelfarb, family is the bedrock of civil society. (Himmelfarb, 1998) In order to avoid bifurcating life into separate realms of private and public virtue, it is not only necessary to "eliminate laws and social policies that have illegitimatized traditional values... (but) must also devise laws and social policies that will legitimize traditional values (Himmelfarb, 1996, p.30)" For Himmelfarb, it is these traditional values, located 
or grounded in traditional institutions such as the family, from which functional civil society can emerge.

Beem's 1996 assessment that Sandel and most if not all of the other contemporary civil society theorists fall short in the prescriptions to return to or attain civil society by addressing political elements of the social system appears to be correct. He also seems correct in his assertion that the problem is in fact an epistemological one. He goes so far as to quote Glendon, saying "We have all become postmodernists." Yet his response fails to acknowledge the very conditions that exist if we have really become postmodernists, namely the public resistance to the discourse of morality and religion and a resulting value relativism (or public silence).

Taken in total, this segment of the literature argues that there is the possibility to rebuild the social fabric through shifts in the content and quality of our public and political discourse. The focus of these efforts is on the nature and character of the discourse (Sandel and Gledon), as well as the attributes of contemporary society which shape it (Putnam and Himmelfarb). These efforts do not, though, give attention to the possibility that there are other promising factors that may be available to support the development of a robust social bond in the absence of common political, religious or cultural values. Further, while some of these works do imply a role for public organizations, most likely in support of civic education, they give no systematic attention to the possibility of a broader and more substantive role that public organizations could play in building the social bond and facilitating civic discourse.

\section{Literature Critical of the Civil Society Movement}

While there is a wide range of proposals encompassed by the contemporary literature of civil society, there are several themes that seem to underlie much of the work. By and large, civil society is viewed as filling the space between the individual and the state. It is proposed as a check on the excesses of radical, atomistic individualism, overbearing market mechanisms or a heavy handed, intrusive state. In each scenario, the individual is either too strong or too weak to overcome the barriers he comes in contact with. That is, the individual has either become too strong in terms of his demands and expectations based on what are perceived to be inalienable rights, or the individual is too weak to overcome the barriers of huge and impersonal market actors (corporations) on the one hand and giant, unresponsive, and intrusive public bureaucracies on the other, to engage in the political process under current conditions.

Advocates argue that civil society offers the means to cope with these conditions by building new or stronger civic associations that allow individuals to have great voice and influence on both the market and the state. Such associations will do so in a way that enables individuals to engage and have an impact in ways that they are currently prevented from doing or are reluctant to do. Further, it is claimed that these organizations, because they are engaged in the discourse of governance, will also help individuals learn and practice the skills they need to be responsible members of the polity.

Critics of civil society argue that it falls short in a variety of ways. Berman (1997) suggests that while the cultural and societal elements of civil society are important to principles of liberal democracy, the study of these elements in isolation from a 
society's political institutions leaves substantial gaps in our understanding of contemporary political dynamics. Encarnacion, in his examination of civil society internationally, takes an even more critical stance, stating, "The notion that civil society can serve as the engine for the democratic transformation of formerly authoritarian and totalitarian societies, however appealing, is deeply flawed" (Encarnacion, 2000). Such assertions are flawed, he writes, because they are neither feasible nor sustainable and in many cases and have the unintended consequence of hindering rather than facilitating the growth of democracy.

\section{Civil Society Themes in the Public Administration Literature}

Although the main body of thought about civil society contains few if any references to the role that public administration can play in the emergence of civil society, there is a collection of works in the public administration literature that does draw directly -- though in some cases implicitly -- on the core concepts of civil society theory and thinking. Primarily focused on the democratization of public administration or the improvement of participatory processes, this literature warrants closer examination, as it reinforces the trend emphasizing more or better discourse as the means of fostering the emergence of civil society.

In his article entitled "The Recovery of Civism in Public Administration," $\mathrm{H}$. George Frederickson starts from the same basic description of the social condition that Putnam, Glendon and others lament and concludes from this description that our institutions are in trouble. Further, whether it is the family, the behavior of larger organizations, diminishing influence of churches, increases in crime, increases in the greed, self-interest and primitivism, government is at the center of many of these problems. Citizens are acutely aware of these conditions and are reacting by expressing their lack of support and confidence.

Frederickson argues that a recovery of civism in public administration is the means by which we can counter these trends. The roots of civism in American public administration can be traced, according to Frederickson, to the early writings of Wilson, Waldo and others. From these thinkers, Frederickson draws the ideas "efficient contributions of public opinion" and "the science of politics and the sciences of organization and management." Following WW II however, Simon and others shifted the focus to an attack on the "principles" of administration and moved to concepts of efficiency and rationality.

In an effort to rebuild and strengthen civism, Frederickson draws on the literature of democratic theory and the literature of organization theory. More specifically, from the democratic theory literature, he is interested in the concepts of citizenship, justice and freedom. From the organization theory literature, he looks to ideas of hierarchy and authority. In the end, it is through the development of these ideas in public administration education and practice that civism can be recovered and the slippage in our institutions stopped.

There are several ideas from these areas that call on themes addressed in the core civil society literature. The first is his discussion of high and low citizenship. In

describing high citizenship, Frederickson draws on the work of a variety of classical and 
modern thinkers to develop the idea that "citizens are free, equal and engaged with one another in pursuing matters of high and distinctive import." The critical theme here, though, is the notion of being engaged with one another. This is one of the critical aspects of civil society. Proponents of low citizenship by contrast argue that high citizenship is neither possible nor advisable because attempts to build high citizenship are both distracting and destabilizing. However, the possibility of developing high citizenship allows for the scenario that Frederickson advocates for, where "effective public administration (in) the future should be intimately tied to citizenship, the citizenry generally, and to the effectiveness of public managers who work directly with the citizenry (Frederickson, 1982, p. 502)."

Frederickson also addresses the often used criticisms that attempts at high citizenship or more direct forms of democracy are often slow, cumbersome and risk averse. He acknowledges that this can be the case, but goes on to point out that administrators who are skilled in working effectively with citizens and elected officials can overcome such tendencies. Frederickson does not elaborate further how this would change the nature of public administrators and how they work, but it would seem that such efforts would lead administrators to be facilitators of processes rather than content or technical experts. This too seems to be an important aspect of what can bee seen as civil society.

Moving on to the role of freedom in the recovery of civism, Frederickson makes the argument that the role of government is to protect the freedom of individuals. He goes on to suggest that, in fact, large scale organizations actually free us in that, for example, we are better educated and healthier than at any other time in history. Further, the crux of the issue for organizations and freedom is the ability to create organizations that are changeable and responsive. He goes on to argue that a relatively powerful government is necessary to allow for the corporate system we have.

Turning to his arguments regarding organization theory and the recovery of civism, he argues against rigid, hierarchical, rational authority structures in favor of flexible organizations that are rapidly responsive to changes in their environments. Further, such organizations would be open to greater levels of citizen association, would be decentralized and would avoid or reject ways of working that are punitive. These characteristics are important to organizations in a civil society in that they emphasize openness and democratization as the grounding principles.

Frederickson departs from the civil society literature in his advocacy of a positive role for public administration in social discourse. Further, his arguments draw in many of the principles and characteristics developed in the civil society literature. However, his arguments are also consistent with the core of the civil society literature in that they emphasize the development of more or better discourse as the means of recovering civism or, in other words, supporting the emergence of civil society.

Camilla Stivers extends the exploration of public administration's relationship to the citizenry in her 1990 article entitled "The Public Agency as Polis: Active citizenship in the Administrative State." In this work she argues that when active citizens interact with professional administrators in substantive ways, that it is possible to create a polis, "a public space in which members act together in order to achieve limited ends and to lead a virtuous life (Stivers, 1990, p. 86)." Already, this notion of engagement within a 
public space connects to conceptions of civil society. Continuing, she describes four key attributes of active citizenship.

1. Authoritative action - the direct engagement of citizens in governance that is both authorized in law and acted out with others in society. While it is limited, this form of action is decisive within the realm for which it has been assigned responsibility.

2. Consideration of the Public Interest - The authoritative action described above is shaped by a concern for and attention to the public interest.

3. Learning - By developing their judgment in line with the public interest, citizens learn, develop and develop the skills of a 'political person'

4. Relationship - In acting with one another, with the public interest in mind, citizens for a polis, or the area in which members of the group or community attain common goals, cope with disagreement, develop shared values and enact a virtuous life. (Stivers, 1988)

Combining these attributes with the characteristics that she and the other Blacksburg theorists ascribe to public organizations, fosters the development of the polis. Stivers states, "it is suggested that interaction between lay citizens and administrators, when normatively grounded in an agency-specific understanding of the public interest, creates and maintains a public space that enables participants both to live and to live well." It is this notion of interaction in and about a public space and about the public interest that suggests the polis and civil society are one in the same. More importantly however, Stivers' work introduces a distinction between two disparate models of the public agency. The model described by Stivers, one that relies on active and substantive participation by the public, one grounded in agency context and focused on the public interest, is a departure from the rational agency model, one that has traditionally dominated the discussion of public organizations and their behavior. Although Stivers argues that public agencies do have a role in the emergence and functioning of civil society, as the polis, she does not give attention to the basis or source of the social bond from which a shared understanding of the normative foundations or public interest is determined.

More recently, Frank Anechiarico examined what he sees as a split between the public administration and civil society. Anechiarico's article examines this disjunction and suggests that it can be bridged through attention to administrative culture.

Anechiarico suggests that American political culture and by implication, administrative culture, diverged from conceptions of civil society because our political culture developed as an outgrowth of the progressive era. He argues that the focus on professional and technical specialization had the effect of cutting off the citizen from public administration and in effect, blocking discourse and engagement. He goes on to suggest that a shift in administrative culture in the U.S. to one that fosters civic engagement and is oriented to support citizens' active participation would contribute to the reconnection of public administration and civil society (Anechiarico, 1998).

Cheryl King, Kathryn Feltey and Bridget Susel's 1998 article shifts the focus slightly from civism to what they describe as authentic participation. The article, like the those above, is noteworthy in that there are several points at which the authors' description of authentic participation is consistent with process based civil society efforts. 
This article addresses the question of how to make public participation efforts more effective and satisfying based on findings from interviews and focus groups. The study was comprised of a population of subject matter experts and citizens who took part in a reframed participatory process described a model of what the authors call a "Context of Authentic Participation." These interviews and focus groups also enabled the authors to identify a series of barriers to authentic participation and then propose what they see as various means of overcoming these barriers.

Among the concepts in this article that make the link between citizen participation and process based civil society efforts was the authors' description of authentic participation. "Authentic participation is deep and continuous involvement in administrative processes with the potential for all involved to have an effect on the situation." Here, it is the notion of "deep and continuous involvement" that seems consistent with my conception of civil society. Further, the authors describe administrators as focused on process as well as outcome. One reading of the call to focus on process would indicate an understanding of the importance of inter-subjective processes. However, it is not entirely clear from the content of the article whether the authors are referring to interpersonal processes or to administrative processes here. Another indicator that there is a move towards a process based model of participation is the authors' awareness of moving the administrator away from a reliance on technical and expertise models of administration. The authors recognize that this means a shift in the kind of work that administrators do, from making and re-making decisions to enabling decisions by participants. Further, the authors recognize that this shift also means that administrators must develop communication skills that will enable them truly to hear what citizens are saying and convey their own messages in ways that will be understood by others.

While there are indicators that the authors understand and are arguing for a shift toward process based citizen participation, the article focuses much of its attention on more technical aspects of how to involve citizens in participatory efforts that avoid stalled, litigated or otherwise failed policies. Like the Frederickson article, it supports a positive role for public administration, but it also focuses its attention on the nature, quality and quantity of discourse while missing the importance of the inter-subjective processes that build a positive foundation for successful ongoing civil society, i.e. the social bond.

In a similarly focused article, Ned Crosby, Janet Kelly and Paul Schaefer describe the use of citizen panels and a mechanism to enhance citizen participation. In this article, the authors suggest that citizen panels as developed by the Center for New Democratic Processes can help overcome some of the short falls of many contemporary participatory efforts. Among the shortcomings identified by the authors are lack of representativeness, success inversely related to expertise, limited overall impact of citizens groups, and a tendency for participatory efforts to be geared to intervention at the local administrative or delivery level, leaving most of the agenda setting and policy prescription efforts unaffected.

The article has two intents: First is to identify and describe the characteristics or criteria that all participatory efforts or citizens panels should ascribe to and share, and Second, the article applies these criteria in effort to examine a panel experience dealing 
with water quality and agriculture that occurred in Minnesota. The former intent holds greater interest for my purposes and this review focuses primarily on the criteria.

The six criteria for successful citizen participation method are:

1. The participants should be representative of the broader public and should be selected in a way that is not open manipulation,

2. The proceedings should promote effective decision making both in terms of how the decision is structured and carried out,

3. The proceedings should be fair so that participants will support the decisions made by the group,

4. The citizen participation process should be cost effective, in that it attempts to internalize as many of the costs as possible and also considers non-monetary costs and benefits,

5. The process should be flexible and adaptable to a number of different tasks and settings, and

6. Recommendations from the citizen participation process should have a high probability of being heeded by appropriate public officials.

The authors recognize that authentic participation, consistent with that which is characteristic of civil society, will require changes in the stance of public administrators towards their duties and roles. First, they suggest that in situations and processes where citizens do in fact have control, administrators would no longer retain control, something administrators may be reluctant to relinquish and a dramatic change from traditional administrative discourse. However, they state that the likelihood that the "recommendations" of the group will be followed depends in part on how well administrators and other gate keeps relinquish their perceived control. They suggest that the more legitimate a process is perceived as being, the more likely the process is to succeed.

Like much of the literature described thus far, this article evolved from the same procedural foundations that shape the public discourse currently taking place. It is characterized by the same language and frameworks intended to improve that discourse in some way, and leads to the same or similar dead ends.

In an article that focuses its attention more narrowly on policy processes specifically rather than administrative discourse more broadly, Peter de Leon advocates for the democratization of the policy development process. In this article, the author argues for the establishment of participatory policy analysis as opposed to broader conceptions of participatory democracy. According to de Leon's arguments democratic policy analysis should make for much more effective policy because it would be operating under the recipients' values and needs hierarchies as opposed to those of the removed analyst and policymaker. Consequently, rather than directing one's efforts toward the more ambitious goal of participatory democracy, the realization of a policy science of democracy is a more discrete objective, and one with significant advantages for all concerned. The concept of a democratized policy analysis is relatively straightforward. Instead of involving every citizen in decision making, the idea is to increase citizen participation in the articulation and formulation of public policy programs. Rather than having the many engage in the actual policy decision, it asks that 
policy analysts devise and actively practice ways to recruit and include citizens' personal views in the policy formulation process.

In his effort to develop a theory of democratic or participatory policy analysis, deLeon is quite critical of traditional policy analysis. First, he notes that there has traditionally been a tendency for the relationship between the analyst and policy maker to be a closed one. That is, policy knowledge tended to be exclusively in the hands of experts and decision makers, and this resulted in an undermining of the democratic ethos. Further, he is critical of the economic traditions of many policy analysis efforts. First, while being touted as "objective," econometric analyses such as cost-benefit analysis have been demonstrated to be subjective at all but the most rudimentary level, "i.e. almost nowhere of interest." Further, econometric methods could not retain their theoretic rigor and still incorporate personal and political values into its analysis. There was an inherent difficulty in reconciling rational effectiveness of programs with their political palatability. From this perspective, one of the insights in this article is the emphasis on social process and social creation in contrast to modernist tendencies toward rational, mathematical calculation of the public good.

There are a number of points raised by deLeons' argument that demonstrate his connection to civil society theory and literature. One is the notion that it is not necessary that people be particularly well informed or knowledgeable about the policy issues at hand. The key ingredient is not sufficient citizen knowledge, but rather that they are willing to express their perceptions in an open public policy forum. It is this last characteristic, willingness to express their perceptions, or at least rudimentary participation in public discourse, that first connects this work to the civil society literature. This argument rejects a privileged position for knowledge in policy analysis and seems consistent with his criticism of econometric methods. It instead emphasizes the importance of engagement in substantive discourse.

Interestingly, after arguing that the characteristics of participatory democracy make it practically impossible to achieve, he describes his idea of issue sharing in a way that is consistent with general notions of civil society. Under policy sharing, citizens have some confidence that their individual and aggregated opinion on a specific subject will be heard and considered within the policy councils that make decisions. That is, citizens have confidence that when they engage with others in the policy process, their concerns and issues will be acknowledged and influence the decision process. Further, de Leon suggests that this will place a new burden on government institutions and analysts to seek out and solicit public opinion regarding matters under policy consideration. Where he falls short, however, is understanding that it will take more than just opinions to achieve either participatory analysis or participatory democracy. Rather, it also requires ongoing, committed engagement to the task of maintaining the relationship of citizens and administrators in governing.

In the end, deLeon's notion of participatory policy analysis remains consistent with the literature described so far. It again implies a positive role for public administration in engaging in public discourse, but only advocates a shift in the stance of public administrators that allows for improved discourse. It, neither in quality and quantity, conceptualizes nor implies anything about the seeds of the social bond nor the agency's role in its development. 
In an article from a slightly different perspective than the one described above, Camilla Stivers advocates for the importance of a 'listening bureaucrat.' She begins from the perspective that the public administration literature emphasizes the need for responsible bureaucrats over responsive bureaucrat. That literature, from Wilson, to Finer to Rourke, describes the responsible bureaucrat as "a proactive agent, one who causes things to happen, in charge of his or her own conduct, trustworthy, capable of moral judgment, reliable and politically answerable (Stivers, 1994, p. 365)." The responsible bureaucrat is "reactive, sympathetic, sensitive and capable of feeling or suffering (Stivers, 1994, p. 365)," not, according to Stivers, the sort of qualities that call one to the public service, and not what the bulk of the public administration literature calls for. Stivers calls for a shift in the stance of bureaucrats, to one that emphasizes listening. This amounts to a fundamental shift in role orientation of individuals in public agencies, a shift that opens discourse as opposed to the closed nature of speech grounded in professional knowledge. Listening opens the individual to other experiences and makes one aware of the other's perceptions of the world. It "promotes the development of moral sensibilities because it models the reciprocity inherent in the ideas of justice (Stivers, 1994, 366)." Such a stance is critical to the ability to engage in the sort of substantive discourse characteristic of civil society. Harkening back to the work described above, she suggests that as citizens and bureaucrats work together, enabled through the openness fostered by listening, programs goals and objectives can be better tailored to meet community needs. That is, listening enables the emergence of civic discourse, through which collective strategies can be developed and implemented.

While the possibility of developing a responsive bureaucracy through listening would support the sort of substantive public discourse characteristic of civil society, here again, no attention is given to the means by which the social bond is established in the first place. Such a bond, even if only in rudimentary form, must exist in order for the discourse to emerge in the first place. Listening, though important for facilitating discourse, does not create it.

As was the case with the segments of the literature examined earlier, the public administration literature that draws on the civil society literature does not give attention to the nature and source of the social bond. Like the other segments of the civil society literature, the PA literature focuses its attention on the charactaristics of the current discourse and how that discourse can be improved. Again, while such efforts can yield positive results, giving attention to the nature and creation of the social bond has yet to be addressed.

\section{The Literature Gap and Contribution of the Dissertation}

An underlying theme that appears throughout the literature of civil society, regardless of political or epistemological perspective, is a tension between general and specific. This tension can be described using various terms including universal/individual, public/private and a variety of others. Regardless of the descriptor used, the possibility of attaining the good life through expression of either the general or the particular is a consistent theme throughout the literature. For the Stoics, this was expressed in an effort to unify the laws of nature with the laws of man. Later, Locke and Smith explore the possibility of individual freedom and rights tempered by the authority 
and morals of the majority. Kant works to maintain a closer relationship between social and individual in developing the notion of practical reason expressed in the public sphere as a means of maintaining individual autonomy. Hegal and Marx continue to reflect the tension that characterizes the continental literature in their efforts to reconnect the juridical and ethical.

Developing largely from the foundations laid by early liberal thinkers like Locke and Smith, the contemporary literature in the United States continues this theme, shifting it from a tension between social and individual to tension between public and private. As described earlier, contemporary definitions of civil society describe it as an alternative to or existing in the space between public and private. Thinkers like Cane and Gellner argue that civil society offers a means of raising and addressing social issues instead of doing so through government intervention. Others, including Walzer and Glendon, see civil society as a means of building social relationships that stop or prevent the deterioration of a functional social order.

Throughout this contemporary literature, whether it proposes civil society as an alternative to government intervention or as a means of buttressing a functional social order, at least one primary aspect of civil society stands out as having received little, if any systematic attention. Little theoretical attention has been given to what elements can function in a way as to adequately structure the social bond such that civil society can emerge. The existing literature does not acknowledge that some basic social bond must exist in order for any discourse to be possible, but rather implies that through more or better discourse, agreement around key values can be achieved and civil society can develop. However, a social bond must pre-exist discourse and this is a prerequisite for the emergence of civil society. Without the existence of the social bond, no effective discourse would be possible in the first place. Within the field of public administration, the work of scholars like Frederickson, Stivers, King and others that draws on the civil society literature focuses largely on issues like effective citizen participation and how to address the discontent with government voiced by much of the public. Like the broader civil society literature, the public administration literature turns its attention to the quality and quantity of discourse and how both might be improved.

Daniel Kemmis, in his description of how politics can be successfully grounded in specific places, looks to the traditions of civil republicanism championed by Montesque and Jefferson. Drawing from them, Kemmis explores the notion that character and civic skills necessary for face to face democracy are learned and honed through practice. Citizens with these skills and character would understand that personal welfare is dependent on the general welfare (Kemmis, 1990). According to Bellah et. al., developing this understanding requires practice in instances where this coincidence of personal and public concern can be experienced. (Bellah, et. al., 1985) Drawing again from Jefferson, though in this instance from Jefferson's insistence that centering the new American nation in the culture and practices of agriculture and the land would maintain civic virtue in America's political culture, Kemmis develops the argument that the habits necessary for civic republicanism are shaped by places (Kemmis 1990). That is, the demands that places put on inhabitants shape the ways that they interact as they make decisions about their community. This was particularly true earlier in American history when the frontier character of the land required people with widely varying perspectives to work together to ensure each others' survival. Although that frontier character is 
largely a thing of the past, explicit and symbolic reference to place can be a key factor in structuring the social bond in such a way that civil society can emerge. Kemmis provides enticing, but anecdotal, evidence that place can in fact play such a role.

This dissertation seeks to contribute to the body of civil society literature by illuminating how a public agency can foster the development of the social bond by drawing explicitly and symbolically on place and in doing so, contributes to the emergence of civil society - or on the other hand, fails to foster it as effectively as it could by being attentive to the role that place can play in creating the social bond.

Beyond the work Kemmis has done, there is a large and growing collection of research and theory that describes how individuals and groups connect to and interact with the physical environment. Expanding on the work done by earlier theorists, June Singer and Mary Loomis refine Jung's theory of types in a way that allows for a more comprehensive explanation of human/environment interactions at and below the level of consciousness. Further, there are two specific theories drawn from the field of environmental psychology, place-identity and place-attachment, which offer particular promise in the effort to show the connection between humans, place and the social bond. A more extensive explication of each of these theories and their value in this project is the focus of the next chapter. 


\section{Approach:}

\section{Chapter 3 - Research Strategy}

The basic approach used for this study is Sorokin's logico-meaningful method, one which adapts and reflects the principles of grounded theory techniques described by Corbin, Glaser and Strauss and is conjoined with those of Rubin and Rubin's in-depth interview method. The intent of this project is to examine the role of a public agency in creating a context in which civil society can emerge and to determine whether an emphasis on place can provide an enhanced grounding -- a social bond-- for civil discourse. In order to do this, a study of a single BLM RAC and the way it has evolved since its charter was established was carried out. The logico-meaningful method, as described by Sorokin (1962) and Sjoberg and Nett (1968) is being used in this study because of its usefulness in investigating complex patterns of social interaction. Sjoberg and Nett suggest that researchers using this method practice what is described as "disciplined insight" as means of exploring what is communicated, i.e. the discourse, that takes place within the setting being studied, via the complex processes of interaction among stated goals, prior knowledge and experience as well as what participants perceive as taking place (Sjoberg and Nett, 1968. p. 291). They suggest the logico-meaningful method as an approach to understanding and ordering social processes that are complex and subtle and involve more factors than can be managed by traditional forms of measures, especially predictive methodologies, which focus on a limited set of predetermined variables. As such, generalized research questions would include explorations of how meanings are joined into systems and what the nature of such relationships might be. It becomes possible then, to develop new understandings of how the agency utilizes place as a means of building the social bond.

Turning then to the adaptation of the principles of Grounded Theory, there are two key elements of grounded theory that are not appropriate in the context of the study described here and that therefore demanded modification. First, Grounded Theory would typically be used in situations where little information is available and little is known about a particular phenomenon. Therefore, it is likely that little or no theory has been developed to describe that phenomenon.

Second, Grounded Theory prescribes a particular process of coding the data for analysis that supports the development of theory. For the purpose of this study, coding data as it is collected and analyzed must be done to support the continued development of an emergent theory rather than the construction or development of new theory. The coding scheme used for this study is consistent in many ways with that developed by Glaser, Strauss and Corbin, but it is modified to reflect the unique circumstances of this study.

A review of the literature suggests that there has been no systematic study of the symbolic use of place by public agencies and therefore no developed theory describing or supporting a basic understanding of it. However, based on literature from other areas of study, the basic elements of the theory have already been developed. The value of adapting elements of Grounded Theory in this study is that it allowed flexibility and sensitivity in the conduct of each interview, as it was not entirely clear what the substance of data collected would be and how the data would support the development of the theory. 
One of the key aspects of Grounded Theory for this study is the notion of theoretical sensitivity. Strauss and Corbin define theoretical sensitivity as an awareness of the subtleties of the meanings of data. Theoretical sensitivity is critical to grounded theory development because unlike theory verification, it is not known or presumed prior to the research what the evidence will be or to what that evidence will point. Such awareness can be drawn from a variety of sources including related literature, personal or professional experience and the analytic process itself. It is the ability to recognize what is important in the data and to give it meaning (Strauss and Corbin, 1990, p. 46). It is not however, merely seeing something new or first. It is recognizing and making solid connections between something already known and something here-to-fore unknown( Strauss and Corbin, 1990, p. 44). As noted above, the relationship between place and successful process has not been examined and the connections are as yet unknown. The flexibility and adaptability of the Grounded Theory method allows for refinement of the study as the specific nature of connections begins to emerge.

The awareness and sensitivity captured in the notion of theoretical sensitivity will be critical to identifying and understanding the details of the subject of study. In the case of this research, a broad but essentially empty theoretical framework was proposed as a way of understanding the phenomenon under study. This initial framework was developed through the examination of literature and some anecdotal professional experience. In some sense, this literature and experience were the initial data upon which provisional categories were developed. From this perspective, this dissertation is then the continuation, both theoretical and in the field, of the data collection already begun, the goal of which is not to confirm or deny the validity of the proposed theory, but rather to develop the theory into a useful, grounded understanding of the phenomenon.

Although the principles and coding techniques are clearly defined, the literature describing grounded theory is largely silent on the specifics of how one collects the data. As a result, this study used in-depth interviewing to collect data -- or as Robert Stake describes it, "to obtain descriptions and interpretations of others (Stake in Rubin and Rubin, 1995, p. 9)," in support of the elements of grounded theory. Rubin and Rubin develop a model of qualitative interviewing that modifies ordinary conversations to draw out what others know and think about the subject of study while minimizing the extent to which the interviewer imposes his or her own views. Working from the idea of a conversation, the authors highlight the active role of the interviewee in shaping the direction of the conversation. The interviewer and interviewee work together in an effort to develop a shared understanding (Rubin and Rubin, 1995, p. 11).

The researcher, in order to bound the scope of the research, starts the interview with a broad, open-ended question that is broad enough to prompt interviewees to share their opinions and experiences. This "main question" as Rubin and Rubin describe it, is at the same time, narrow enough to delineate the subject of study. It is within these bounds that the interviewer and interviewee actively shape the content and direction of the interview. In this study, because of the complexity of the research questions and theoretical framework, a small set of main questions was used.

Based upon the response to these main questions, the researcher then formulates additional questions intended to draw out the details, depth and richness of the interviewees original response. The interviewer then probes further in an effort to clarify response, fill in additional or missing information, draw out longer or more detailed or 
give specific examples and experiences (Rubin and Rubin, 1995, p.148). These followup queries to the main question were used to add depth to the original responses and allow the interviewer to pursue themes that are uncovered, elaborate the context of answers and explore the implications of the interviewee's answers (Rubin and Rubin, 1995 , p. 150). Looking back to grounded theory, the notion of theoretical sensitivity is useful again at this point because the researcher must not only be sensitive to the responses of the interviewee, but must also maintain an awareness of what he or she has learned from the relevant literature and experience as well as any previous interviews.

As a result of the researchers sensitivity to the array of experience, literature and data, the process of data collection must be open to adaptation. The processes described by Rubin and Rubin are flexible as well as iterative and continuous, thereby providing a way to collect rich data that enables the researcher to build theories that can describe the complexity of a setting or phenomenon (Rubin and Rubin, 1995, p. 43 \& 56). As the interviewer conducts each successive interview, he or she is actively engaged in the process of collecting the data, analyzing it and testing it (Rubin and Rubin, 1995, p.46). The information that is added by each interviewee become the blocks upon which the emergent theory is built. Through each succeeding interview, the process of analyzing and testing elements of the emergent theory are examined so that elements of the theory that are unsupported by the data drop out (Rubin and Rubin, 1995, p.62). This process continues until a point of "theoretical saturation" occurs, at which point no new data arises and the collection of perspectives offered by the interviewees wholly describes the instance being studied(Rubin and Rubin, 1995, p.48 and 63).

Subject of Study and Procedures:

\section{Site Selection}

The level of analysis for this study is a single RAC. This level is selected because the in depth examination of a single case helps facilitate the development of the emergent theory.

The first step was the selection of a single RAC to work with, based on the apparent existence of a strong social bond, indicated in part by its success in dealing with contentious issues. Success for the purposes of this study, has been defined as the ability to genuinely engage members of the RAC who bring to the process substantial diversity of perspective and are able to make recommendations to the BLM that all members can support. This definition raises some potential problems. First, there is a question of how one determines what genuine engagement is and if it has occurred. It is unclear if there are any external measures that are useful in making this determination or even if there are such measures, whether the data to make such an assessment could be collected. For the purposes of this study, it is adequate that the assessment of genuine engagement is largely self-determined by participants familiar with the unique dynamics of the particular RAC to which they are connected. While there are general criteria such as perceived influence on outcomes, sense of membership in the process or respect afforded by other members of the group, RAC members themselves assess their own experiences and perceptions of each of these criteria.

A second difficulty is related to determining what substantial diversity in RACs is. A great deal of variation exists in the makeup and diversity of the 24 RACs currently in 
place. Initial conversations with other researchers suggests that there is substantial diversity of opinion in some groups and far less in others. For the purposes of this research, absolute diversity is less important than the relative diversity of a group within the context of the specific situation. That is, there are potentially some groups that a wide range of membership that would be less useful to study than one with less diversity but greater tension and contextual challenges to overcome (i.e. potentially in places like Northern Nevada). Therefore, diversity was assessed in the political and social context of the particular RACs being examined. Data gleaned from the first round of interviews was used, the details of which are described in more detail below.

A final problem relates to the definition of consensus. Interviews conducted with BLM staff indicate that any recommendations from the RACs to the BLM are consensual in that most if not all RACs have agreed to work on the basis of consensus even though they are not required to do so by their charters. However, anecdotal evidence suggests that there are instances where this agreement is disingenuous in that members, for various reasons, give in to the recommendations of other RAC members or that issues to be addressed are relatively uncontroversial and "consensus" is more or less meaningless. The development of the theory developed here requires that the group studied will have addressed contentious issues and developed more genuine consensus, meaning that there was true disagreement but a solution was forged that all members could live with and support. Here again, it is not clear if there are external measures of such consensus. Instead, the level of consensus achieved by the RAC was assessed through an internal review and reflection of the RAC's members.

Given the difficulty and commitment of resources necessary to conduct an on site study of all RACs in order to identify one for more in depth study, a tiered process was used to narrow the number of RACs for in-depth study. As noted above, it is assumed that the smaller the geographic area the RAC focused on, the more likely it would be that RAC members were connected to place and more importantly, the more likely it would be that the BLM would be able to refer to place in such a way as to build a collective attachment to place. Based on this assumption, the first tier of the selection process was a review of the number of RACs that had been created under each BLM state office. This review revealed that there were three RACs each in California, Colorado, Idaho and Nevada.

In order to narrow the list of potential sites further, the next tier of the review process drew on the knowledge of a researcher who is already familiar the RACs, their makeup and experience. In addition, the Public Affairs Officer (PAO) from the BLM's Washington Office who is the national contact for RAC activities. Based on discussions with the researcher and the PAO, a 'short list' of 3 RACs that were most likely to meet the criteria necessary for this study was developed. The three RACs that emerged as possible candidates for study were the Northwest California RAC, the North East California RAC and the Front Range RAC in Colorado. These three RACs had diverse memberships, had taken on issues beyond the development of rangeland Standards and Guidelines and had informally moved to a consensus based model of decision making.

Once this list of three RACs was developed, BLM Field level PAOs were contacted in order to collect additional information about the character of the RAC in his or her area and to determine what issues the RACs were working on. In terms of the character of the $\mathrm{RAC}$, it was assumed that a RAC that is more rigorously engaged and which had 
developed strong relationships between and among the members was more likely to be fertile ground for place to be a factor in the group's dynamics. At this stage, rigorous engagement was defined as the group's use of unanimous consensus rather than the procedural consensus specified by the groups' charter. Turning then to the nature of the relationships between and among members, it is believed that the more members are genuinely engaged with one another, the stronger their relationship will be to one another. Genuine engagement was defined as a sustained focus on the issue in the face of potential or known opposition.

Turning to the use of issues as a selection criterion for the group, it seems likely that the more diverse the RACs range of issues are, the more likely members of the group will engage with one another. The assumption is that if the group focuses on a variety of issues, no one interest, collection of issues or knowledge about an issue can become "captured" by a single member or group of members. Once information about these issues was collected, it was used to identify a single RAC that was the subject of study.

It was decided that, based on the issues up for discussion at upcoming meetings and the recent tenor of discourse and relationships within it, the Northwest California RAC was the most promising candidate for further study. One additional factor that added weight to the decision to select the North West California RAC was the possibility of conducting and interview with a member who was leaving the RAC, but who had been a member of various BLM advisory boards for 40 years $^{2}$. The possibility of gaining insights from someone with 40 years of institutional memory of not only RAC but other advisory group work was a rare opportunity.

\section{History, Culture and Processes}

In addition to the research done in order to select a single RAC as the subject of this study, much of the existing research and literature previously conducted on the BLM was also examined. This was done in order to gain a more extensive understanding of the agency's background, processes and culture. Particular attention was given to the agencies long standing practice of using advisory groups in various aspects of its planning and management processes.

\section{On Site Procedures}

Based on this research strategy, the investigator traveled to Northwest California in order to become as immersed as possible into the physical and social environment of the agency. The study procedures used on site broke into three sets of activities: in-depth interviews/conversations, observations of RAC meetings and activities and a review of available BLM and RAC documents.

A series of in-depth interviews/conversations taking place in the following manner was conducted. It should be noted that consistent with a hybrid Grounded Theory/ indepth interview approach, data collection procedures were iterative and required time

\footnotetext{
${ }^{2}$ It should be noted here that although the RACs have been in existence since the early 1990s, the BLM has a long history of using various forms of citizens' advisory groups. A brief description of some of these groups can be found in Chapter 5, but for a thorough description of the BLM's use of advisory groups, for an extensive description of the BLM's history, see Foss, 1960.
} 
between interviews to review and organize initial data from which adjustments to interview questions reflecting any learnings from initial interviews can be made. Two sets of interviews were conducted:

1. Interviews with the BLM staff that served several purposes.

A) Provided sense of agency and RAC history - continuity of participation.

B) Expanded the understanding of the agency perspective - i.e. the politics and processes in and around the RAC, the Field Office, State Office and Agency, and

C) Yielded data that helped further develop an emergent theory of place, and from which questions and strategies for the interviews to be conducted with current members of the RAC of study could be better focused.

2. Conduct in person, in-depth interviews or structured conversations with RAC members. These interviews took place on site, over the course of approximately two weeks and were intended to collect further data for the development of a theory of place. Data collected from these interviews was taken off site and integrated into data already collected and used to further develop the theory of place. Further, these data were used to refine, again, the questions and strategies for the final set of interviews.

As noted above, the organization, flow and format of these interviews/conversations was fairly unstructured, so that participants were free to make their own associations and follow their own intuitions as to what was important. To begin the interview, a loose parameter of the type of information garnering interested was established. It was indicated the researcher wanted to understand two related issues of the RAC function. The first was how the context for the group's work was established. Second, I wanted to understand how the relationships between and among the members was established and maintained.

Before asking any questions that explicitly pursued information about these two issues, each person was asked to describe their background and connection to the area, and to the BLM. Posing this question had two benefits. First, it helped establish a comfortable social interaction and built a rapport between myself and the RAC member. Further, the background information that each RAC member shared yielded significant information about their personal sense of place. Although it was not expected that individual connections to place would make collective connections to place more likely, developing an understanding of the types of personal connections extant, did provide clues as to the range actions the agency could take that RAC members would be more responsive too. That is, knowing what connections individuals had, provided some sense of the 'building blocks' that the agency could draw upon in their activities.

After the RAC member had the opportunity relate their background, the conversation was guided back to the two broad issues of context and relationship. Although individual conversations took a wide range of paths and covered a huge breadth of issues, there were some common types of questions that were recurrent across conversations. In simplest form, these questions included:

1. What has the RAC been working on?

2. What experiences have stood out?

3. What issues have you been successful with/had the most challenges with? 
4. How did you (personally and as a group) make sense of the issue? OR What did you do to understand the issue you were dealing with.?

5. What helped the group be successful/what hindered progress?

6. What has the agency's role been in building understanding?

7. What has the agency's role been in facilitating the processes?

Where possible, an effort was made to draw out specific and detailed examples, anecdotes or experiences. As each of the questions, or variations of them, were asked and answered, follow-up questions were asked, in an effort to draw out impressions and experiences related to developing an understanding of the agency's role in the RACs processes and work.

The second set of activities that occurred during the investigational visit to the site was the observation of two days of RAC meetings and activities. The first day comprised a field trip to a collection of sites that the RAC was to discuss during the following day's business meeting or that had been a subject of discussion in previous meetings. During the course of the day, the formal and informal proceedings that took place were observed. These observations were primarily focused on how the participants and BLM staff interacted during formal and informal portions of the field trip (i.e. during formal briefings and presentations as well as during informal times such as car trips between sites, lunch and walks to and from site visits and vehicles). These formal and informal interactions were observed with an eye toward gaining a sense of how diverse the interactions were (i.e., were there 'cliques' or alliances), what the topics of conversation were, what did the BLM do to support or impede the quality and character of the interactions. Data collection during this set of activities took the form of note taking and photos of the group and the sites visited by the RAC.

The second day comprised a business meeting as well as a variety of informal social experiences. At this point, it is adequate to understand that the RACs business meeting is dedicated primarily to updates on current projects, reports from each of the field managers, open/public comment periods and time for finalization and approval of recommendations from the RAC to the BLM. As was the case during the field trip the previous day, data collection was in the form of note taking, supported by the formal minutes compiled by the BLM staff.

The final set of activities that took place both during and after my visit to the site was a review of BLM documents related to the RAC. This included materials that were explicitly related to the RAC, such as prior meeting minutes and RAC products including the Standards and Guidelines for rangeland management. This review also included the examination of documents that were provided by the BLM to the RAC at various points in time. These documents included briefing pieces designed to help build a common base of knowledge among members, maps, Field Office updates, materials compiled or created by other organizations. These materials were reviewed for content that explicitly or symbolically referred to place and would build a connection to place.

\section{Analysis:}

As described above, data analysis begins to some extent during the process of collecting the data. That is, the data are reviewed and placed into propositional categories prior to each interview so that modifications to subsequent interviews to reflect 
new learnings could be made. This process allowed not only the opportunity to focus the questions and conversations more directly, but also revealed unexpected, shared experiences that became the subject of later conversations and questions. This enabled later conversations to more quickly move from abstract conversations about topics such as context to specific conversations about particular experiences.

Final analysis began following the last interview. At that point, data were reviewed and categorized into themes. These data were then compared, both within and across themes. This allowed the identification of any new themes that were previously unrecognized.

The coding processes described by Rubin and Rubin is consistent with that described by Strauss and other grounded theory methodologists. However, axial coding described by Strauss and others is more highly structured and allows less flexibility than does the coding scheme and process of Rubin and Rubin. Following these schemes, similar ideas were grouped so that one can figure out how to relate the ideas to each other and to the theoretical framework that drives the research question. Further, it allowed the noting of core ideas, concepts, stories and themes. Noting and grouping these themes helped build a broad foundation for the overall theory.

Like the interview process described above, coding was an iterative process of categorizing and re-categorizing. Each time new categories are generated, the data must be re-coded to reflect the changes. This process served to direct and focus attention to the detail, nuance and isolated but specific information that allowed categories to emerge. The process occurred in two stages. In the first stage, consistent meanings and perceptions as well as inconsistency between interviewees' meanings and perceptions were pursued. In the second stage, links across coding categories that were consistent with the theoretical framework were identified. At that point, categories were reviewed with the research question(s) in mind to determine if the data supported the proposition that the BLM could use place to support the development of a strong social bond, in its collaborative governance efforts.

\section{Conclusion:}

Before going on to discuss the findings from the strategy described here, it will be helpful to describe the literature and research that is the basis for the theoretical framework that gives substance to this strategy in some detail. This is the topic of chapter 4. 


\section{Chapter 4: Theoretical Framework - A Theory of Place}

\section{Introduction}

There is a large and growing collection of research and theory that describes how individuals and groups connect to, interact with and are affected by physical environments. Much of this work can explicitly or implicitly be tied to environmental psychology, a field of study that began to emerge in the late 1960s and early 1970s. It first began to appear as a self-conscious field simultaneously with the growth of general social awareness of and concern about environmental quality and its potential impact on human health. Two characteristics of environmental psychology are of particular importance to this current study. First, environmental psychology has attracted interest and contributions from a wide range of professions and fields from architecture to zoology (Proshansky, 1976, p. 1). Second, because of the relative youth of the field and because of the wide range of studies contributing to it, more attention has been paid establishing scientific credibility than to the critical theoretical issues confronting it (Proshansky, 1978, p. 150). The implication is that although there is a vast body of empirical research that falls under the umbrella of environmental psychology, there are comparatively few overarching theories connect existing research findings. These features notwithstanding, there are two specific theories, place-identity and placeattachment, which offer particular promise in the effort to show the connection between place and the social bond.

It should be noted here that although the concepts of place-identity and placeattachment appear at first glance to be fairly well developed and grounded in agreed upon definitions, there is some variation in the detailed conceptualizations and corresponding research carried out under each theory's name. There is also some overlap across various theories. Altman and Low suggest that, "place attachment subsumes or is subsumed by a variety of analogous ideas, including topophilia, place identity, insidedness, genres of place, sense of place or rootedness, environmental embeddedness, community sentiment and identity to name a few (Altman and Low, 1992, p. 3)". Which theories do the subsuming and which are subsumed remains an open question. However, for the purposes of this research, this apparent lack of theoretical consensus is more beneficial than problematic in that it suggests a wider range of potential data to collect in the field.

Beyond drawing on place-identity and place-attachment, the theoretical framework described in this chapter also draws on Carl Jung's theory of psychological types as reconceptualized by June Singer and Mary Loomis. The addition of psychoanalytic theory, particularly Singer and Loomis' conceptualization of Jung, is that it provides a dynamic and sophisticated understanding of how individuals and groups perceive the world, including the physical environment, especially in unconscious ways.

Taken together, place-identity, place-attachment, Jung's typology as understood by Singer and Loomis, and the empirical studies associated with each of these theories provide a theoretical framework. This framework can guide and enable the collection and analysis of data from the RACs, and suggest how public agencies use place to build on or hinder the social bond necessary for collaborative governance and civil society. This chapter describes the main concepts and elements of each theory, examines a 
snapshot of the empirical research by which researchers have opperationalized the theories in ways that can more easily apply in the field and offers suggestions for how all three shape the field research for this study.

\section{Place-Identity}

Harold Proshansky's 1978 article entitled "The City and Self-Identity" was the first attempt to develop the main features and functions of place-identity. Place-identity is discussed as,

"those dimensions of self that define the individual's personal identity in relation to the physical environment by means of a complex pattern of conscious and unconscious ideas, beliefs, preferences, feelings, values, goals and behavioral tendencies and skills relevant to this environment. While an individual's placeidentity reflects the specific experiences and socialization unique to that individual, place-identity also reflects those experiences common to all individuals and groups of individuals living in particular kinds of settings (Proshansky, 1978, p. 155)."

The core of these environmentally based cognitions is what Proshansky terms the 'environmental past' of the individual. This past consists of the places and their properties that have contributed instrumentally to the biological, psychological, social and cultural needs of that person (Proshansky, et. al. 1983, p. 59)

Drawing on existing self-identity theory, Proshansky goes on to theorize three of the major dimensions of place-identity. The first is the cognitive-descriptive dimension, which are the substantive and content aspects of a person's place-identity. This includes images and memories of places as well as conceptions and beliefs about distances, size color and any number of other physical attributes of a place. Conscious and unconscious beliefs and expectations about how one interacts with physical settings are included in this dimension.

A second dimension is described as the affective-evaluative dimension. This includes expectations about a particular setting as well as the range of feelings and preferences for the content of that setting. Preferences for particular colors, sounds, light patterns, shapes, sizes and so forth, make up a portion of the elements of this dimension. Further aspects of this dimension encompass how these elements are combined in the real world settings experienced by individuals and groups. It is worth noting that Proshansky acknowledges that these dimensions apply to groups as well as individuals, suggesting that although there are aspects of place identity unique to the individual, there are other aspects which would be common to or shared by groups. One way that this dimension is embodied is the everyday expressions such as "my favorite room," "my type of city," and so on. Such evaluations reflect the conscious and unconscious expression of the affective-evaluative dimension of place-identity.

Proshansky describes a third dimension as the setting and object requirements of place. For any given role an individual may play, the physical setting related to this role is represented by a collection of expectations, beliefs, feelings, ideas and aspirations about that setting. This dimension is most clearly understood in instances where an individual's role and the physical and setting expectations or requirements of that role do 
not match. Examples of such mismatches include physicians who practice out of strip mall storefronts or improvised classrooms in warehouses.

Two key assumptions bear noting as well. First, Proshansky approaches place differently from other conceptualizations, in that he sees them as a "differentiated but unified physical system rather than as a socio-cultural physical context", which influences the formation and development of place-identity (emphasis in the original). Place-identity understands the physical environmental as something other than either a container or context for human behavior and meaning construction or purely a stimulus that generates responses. Proshansky's approach to place differs also in its concern with "those environmentally related tendencies, beliefs, dispositions, values and expectations of which the individual is unaware," but never-the-less contribute to the definition and expression of the individual's identity (Proshansky, 1978, p. 162). Here again is an indication of the mechanisms by which place-identity operates below the level of consciousness.

Place-identity, according to Proshansky and other's continued work, can be understood partially in terms of a collection of functions that serve to maintain and protect an individual's self-identity. The first of these functions, the recognition function, provides the means by which the individual judges or assesses their environmental past against their immediate physical setting. In terms of maintaining and protecting the individual's self-identity, this function enables the individual to develop a sense of stability or constancy across time and setting. From this sense of stability, the individual validates a belief in their own continuity across time (Proshansky et. al., 1983, p.66). One way that this function can manifest itself is when an individual experiences radical changes in his or her physical environment. This may take the form of moving the individual into a new and different environment or by making significant changes to the current environment. Lifton describes the loss of self identity experienced by some prisoners of war held in Japanese POW camps (Lifton, 1961). Similar experiences have been described by those incarcerated through the criminal justice system as well as long term patients in psychiatric facilities (Proshansky et. al., 1983, p. 66). The implication of this function for the current research is the possibility that potential and substantial changes to place and its historical use may threaten an individual's or group's sense of self. Public administrators may mediate or exacerbate that threat by their efforts (or lack thereof) to incorporate elements of an existing setting into new proposals.

The second function, the meaning function, operates in the processes by which individuals assign meaning to a given setting by virtue of their understanding of what should happen in it, what the setting is supposed to be like, and how the individual and others are supposed to behave in it. According to Proshansky, while the recognition function reflects one level of meaning attributed to place, the meaning function refers "to a much higher level of attributed meaning; one which goes well beyond recognition or familiarity with a physical setting in that it establishers its purposes, its properties and what is to go on there." The individual is able to use these meanings to help solidify their own understanding of role and behavior in that setting. The types of places noted above, such as prisons or psychiatric facilities, work on the level of the meaning function as well as the recognition function in that they serve to disrupt the individual's sense of role and behavior in that setting. While the meaning function as described by Proshansky is easier to observe in built environments, it functions in subtle ways in natural environments as 
well. The meaning associated with lands which have historically be dedicated to specific uses such as timber production or grazing arguably have developed strong meanings and associated roles connected to specific settings and places. Perceived threats or changes to those uses and the places' meanings and users' roles could be perceived as a significant threat to both place and self-identities. Agency officials have the opportunity to approach collaborative management in such a way as to minimize this perceived threat.

While the recognition and meaning functions are described as providing a basis for diagnosing or assessing a setting and how well it matches a person's place-identity, simply making such a diagnosis is inadequate if it becomes apparent that there is a mismatch between the setting and the individual's place-identity. The next several functions, beginning with the expressive-requirement function, can be viewed as being more active or 'problem-solving' in nature. That is, these functions serve to support an individual's efforts to affect changes that bring the setting and his or her place-identity into closer alignment. The expressive-requirement function operates in two ways. First, there is the expression of the tastes and preferences the person has for what the place should be like. Such preferences can include elements such as levels of light, level of complexity and space and general landscape type. One way that this aspect of the function is expressed is through efforts to personalize places (Proshansky, 1983 p 69). Clearly it is more feasible to personalize built places, such as an office, than natural places such as a tract of forest or rangeland. It is conceivable that perceived threats to the recognition or meaning of such places, combined with an inability to effectively change that place would lead to great resistance to the threat.

The second way that the expressive-requirement function operates is through attempts to control the requirements that must be met in order to occupy and use a particular place. Again in built environments, such requirements include amount of space available, necessary equipment or furniture, levels of light or other elements needed to fulfill the purposes of the place. (Proshansky, 1983, p.70) In natural places, requirements may include things like levels of biological diversity or extent of human access. Adding to the complexity of the expressive-requirement function is the fact that expressed desires and requirements reflect sociocultural factors as well.

The implication of the expressive-requirement function for public agents is the need to be aware of how participants in public processes express their desires and perceived requirements. Such awareness allows the public agent to craft strategies or courses of action that reflect those expressed desires and perceived requirements and that can bridge discrepant desires and requirements or construct new, common ones.

The next function, the mediating change function, is more active still than the previous function. Like the previous function, the mediating change function is expressed in two ways. The first way is in the set of skills that the individual develops to actually change the physical setting such that it better matches his or her place-identity. In many situations, the individual will find himself in a setting with other people. The second set of skills related to the mediating change function are those that enable the individual to understand and influence the behavior of others. In part this is knowing and understanding the range of appropriate behaviors in a given place, but also involves being able to communicate one's own desires such that the setting can be configured to those desires. This may be a matter of establishing informal boundaries and property lines such as leaving an ashtray in a particular place to designate what the individual sees as "his 
spot" or relying on historical uses, both formal and informal, applies to either built or natural places. The final way the mediating change function is expresses is in changes to the individual himself so that place-identity/setting discrepancies are minimized. One example of such a personal change might simply take the form of leaving a particular setting. Another example would be making changes to one's own stance in a public place such as a bus or subway in order to influence those around him, perhaps prompting others to stand farther away.

The final function of place-identity Proshansky describes is the anxiety and defense function, which serves to make the individual aware of potential threats or dangers in places they inhabit. Just as the recognition and meaning functions serve to define what place should be like to the individual, the anxiety and defense function serves in part, to prompt the individual to what the setting should not be. At the next and slightly higher level of analysis this function may serve to allow an individual to disassociate from a setting that is widely discrepant from the individual's place identity but that cannot be avoided. This may take the form of the individual fantasizing or withdrawing mentally from the setting. The third and even more complex level of analysis is based on the notion that an individual's self-identity is determined in part by a series of evaluations of how well that person is doing in his various roles and then determining some sense of self-worth and self-identity based on those evaluations. Because self-identity is closely related to place-identity, these role evaluations tend to distort a person's views and judgements about the settings in which the role is played. In this scenario, the setting can begin to be seen as inadequate for the role and may itself begin to generate anxiety and discomfort (Proshansky et. al., 1983, pp. 73-74). The consequence of this function for the public administrator is the possibility that as changes are proposed to the use particular lands or the role that can be played on those lands, community members may begin to experience anxiety and will exhibit aspects of this function. The public administrator may have the opportunity to predict and preempt maladaptive expression of this anxiety and defense function and propose policy and use changes that minimize its expression.

More recently, Twigger-Ross and Uzzell have attempted to connect an existing model of identity to the basic concept of place-identity. Using Breakwell's model of identity, they propose that the four principles of place identity: uniqueness, continuity, self-esteem and self-efficacy can be used as a means of conceptualizing the relationship between individuals or groups and places. The first principle of identity is the desire to establish and retain personal distinctiveness or uniqueness. Twigger-Ross and Uzzell point to research which shows self-perceived distinctiveness associated with being a "city," "town" or "country" person. They show further that such place grounded distinctiveness can become even more narrowly associated with a specific setting, such as a particular town, as opposed to a generalized urban or other type of setting.

Twigger-Ross and Uzzell's study of London dockland's residents revealed a strong localized self-perception and the tendency of to describe themselves and others by their residency in or outside the docklands community. They felt themselves to be distinct in particular ways from others outside of their community. Individuals and groups may likewise develop an association with other types of places, such as particular tracts of land, which would support their sense of distinctiveness. 
One means by which individuals and groups distinguish themselves is by place identification. Breakwell suggests that the desire to preserve continuity of the selfconcept is a second motivator of action. Twigger-Ross and Uzzell say that continuity is connected to place in two ways: place-referent continuity and place-congruent continuity. In the first, place-referent continuity, places act as referent to past experiences and actions in a way that provides a sense of stable and continuous identity. According to Korpella, "place can remind one of one's past and offers a concrete background against which one is able to compare oneself at different times.... This creates coherence and continuity in one's self-conceptions (Korpela, 1989, p.251)." While place-referent continuity works based on references to specific places, place-congruent continuity is more generic in that it refers to the maintenance of continuity via characteristics of places that are similar enough to be transferable from one place to another. This suggests that those who have spent significant portions of their lives in and around public lands or specific tracts of public land would draw some sense of their own continuity from those lands. As was the case with the principle of distinctiveness, the desire to maintain continuity should be expressed in association with places other than those like the docklands. Looking to the RACs and their association with the public lands, this may be expressed in participants comparisons of the area the RAC is associated with, with other lands that share similar characteristics. The principle of continuity may also be expressed as a resistance to relocation or to what might be perceived as radical changes to the characteristics of the place.

The desire to maintain a positive conception of oneself, or to maintain one's selfesteem, is a central theme of much of the writing about self and social identity (see Gecas, 1982; Tajfel, 1978; Hogg and Abrams 1988). Korpela's research with children has shown that a positive sense of self-esteem can be gained from being in favorite places. It seems likely that users of the public lands may develop a similar sense of selfesteem, grounded in part, in their relationship to the lands they associate themselves with. Expressions of place related self-esteem would include a sense of status, pride or achievement associated with that place.

Self-efficacy, the final principle described in Breakwell's framework, is defined as an individual's belief in their own ability to meet the demands of a given situation. Drawing on the work of Winkel and manageable environments, Twigger-Ross and Uzzell suggest that one's sense of self-efficacy is maintained if the environment facilitates or in the least, does not hinder that person's everyday lifestyle. Their study indicates that a sense of self efficacy might include individuals' sense that they can move in or out of the place, their ability to control or ensure their own safety and their influence on and from neighbors, visitors or other community members. Again, for those who use the public lands in any number of ways, their ability to function effectively and to influence the development and implementation of management plans would contribute to their sense of self-efficacy.

\section{Place-Attachment}

Described by other theorists under a number of different headings including community attachment, sense of community and sense of place, Shumaker and Taylor describe place-attachment as "a positive affective bond or association between 
individuals and their residential environment (Shumaker and Taylor, 1983, p. 233)." Milligan expands this definition by conjoining with it the idea that the emotional bond has the effect of decreasing the perceived substitutability of other places for the one in question (Milligan, 1998, p. 6). Altman and Low (1992) develop comprehensive schema that describe the range of features and aspects captured under the heading of placeattachment. Although they describe several aspects of place-attachment, including range of scales, types of actors, types of relationships and temporal aspects, the feature of place-attachment described by Altman and Low that is most useful for this project is the nature and organization of attachments. They suggest that attachment can be understood in terms of three distinct qualities: affective, cognitive and behavioral. Altman and Low trace the roots of place-attachment to the phenomenological work done by Bachelard, Tuan, Eliade and others. It is these scholars who first described the positive affective experiences and emotions associated with the relationship between person and place. Tuan, in describing his notion of topophilia, notes that affective bonds to place can vary greatly in range and intensity and can include a fondness for place because it evokes pride in ownership or creation. Both of Tuan's examples are likely to be evident public lands discourse because of user's perceptions of ownership, use, stewardship, management and possibly other connections. More recent works have also demonstrated that negative affective associations can also exist, often resulting from traumatic individual or collective experiences. Although such negative associations seem less likely to be apparent in the experiences of public lands users, it is possible that negative associations could arise out of policy and management debates that are perceived to have failed.

While the affective features of place attachment are quite clear through much of the literature, many writers have also shown that the emotional aspects are often connected to cognitive processes as well. Chawla and Cooper Marcus, among others, describe the relationship between places and memories as well as their connection to thought processes. Others such, as Ahrentzen, demonstrate the relationship between place and individual and social knowledge and beliefs. It seems likely that the sorts of connections that Ahrentzen illuminates in her discussion of women and the home as a workplace could help shed light on the nature of place-attachment as it is experienced by those who spend their lives on and in some cases make a living on the public lands.

Altman and Low also point out that in addition to the emotional and cognitive aspects of place-attachment, it affects behaviors and actions in reference to place as well. Altman and Low's volume includes work that describes, for example, repeated rituals, daily events and various ongoing activities that contribute to a sense of place-attachment (Pellow, Lawrence and Low in Altman and Low, 1992). In another study, Reiley highlights how the activities by which people cope with environmental demands affect attachment to place. Research conducted by Mazumdar goes further in exploring the connections between important activities or rituals and place attachment in his study of Hindu houses and the activities by which the home becomes a sacred place. In each of these works, the shared ritual, activities and experiences are both the expression and the foundation of the individual's and group's attachment to place. Turning to public lands and the unit of place, it is easy to conceive how similar behavior-place relationships would be evident in the connections between public land and those who use the lands. Shared rituals or experiences such as horse back field trips (such as those used by some 
agency facilitators), may provide the basis of shared experience to develop or enhance place attachment and the social bond.

Milligan, in his study of place-attachment to a university coffee house, adds two additional processes to the concepts described in Altman and low: the interactional past of a site and the interactional potential of a place. Milligan defines the interactional past as "the past experiences associated with a site, or, in a word 'memories' (Milligan, 1998, p. 2)." That is the interactional past of any particular place and the strength of the relationship or attachment to place is related to the degree and meaningfulness of the experiences. The more important the experiences are or are perceived to be, the stronger the place-attachment will be.

The interactional potential of a place refers to the specific features of a place that shape, constrain and influence the activities that are perceived as able to happen. It is the collection of conscious and unconscious expectations for what can, should and/or will happen in and around a particular place. For the purposes of this study, the concepts of interactional past and potential provide a means for the researcher to first hear and then explore with participants their memories of prior experiences and expectations of future experiences associated with particular places. Doing this is aimed at gaining a sense of how strong an attachment has become to that place. Further, the research assesses the extent to which the agency facilitators are aware of and take into consideration the experiences and expectations of RAC members in the facilitation of the group. The more facilitators recognize and acknowledge place-attachment of RAC members, the more likely he or she is to build an effective collaborative group.

Mesch and Manor's study of place attachment in Israel reveals a number of different factors. First, their research confirms the social aspect of place attachment and indicates that the strength of the attachment to place is related at least in part to the number and strength of local relationships. That is, the more relationships one has (and the closer they are) within a specific place, the greater the attachment. Their study also indicates that the place attachment is related to the perceptions one has of the local environment, including one's satisfaction with open spaces, satisfaction with the quality of the place and the safety that the place provides. Safety here is defined as physical, social and economic safety. Again, such perceptions are both conscious and unconscious, both objective and subjective and occur both individually and collectively. Potential expression of these aspects of place attachment could play out in terms of RAC participants' rootedness in the local community and lands as well as their expressions of comfort, safety or satisfaction.

Brown and Werner's study of neighborhood level attachments to place suggest that attachments are expressed and can be observed in three ways. The first is in individual and group attitudes toward place, in this case, a cul-de-sac. Drawing from other place attachment literature, this would most likely be a positive affective attitude and bond towards place, but it is also possible that attachment could be expressed in negative terms as well, such as being trapped, or otherwise connected counter to the expressed preferences. Brown and Werner also found that attachment is expressed in terms of contact and intimacy with others at or in that place. The greater the individual or group's attachment to place is, the greater was the frequency of interaction and intensity of the relationships of those in the place. The final expression described by authors was participation in group activities and rituals. The level of participation in such activities 
was related to level of attachment to place. Turning again to the RACs, it is possible that one, two or all three of the ways Brown and Werner observed the expression of place attachment might be observed within the RAC's community. It would not be unexpected to hear expressions of affective relationship to the place, or to find some level of relationship between RAC members related to the BLM lands or the local community. Because of the disparate perspectives of the RAC participants, it seems less likely that participation in shared rituals would be observed, but not impossible. It is related to this last expression of attachment that the BLM staff seem most likely to hold a shared attachment. Potential shared rituals or experience that the BLM might facilitate range from the field trips that all RACs organize, to the more specific horseback field trips some groups have taken part in, to the simple meetings that members attend. It appears that there are ample opportunities for the BLM staff to recognize and foster a collective attachment to place, though it remains to be seen if they actively take steps to capitalize on them so as to deepen their relationships.

\section{Singer-Loomis}

In addition to the theories described above, which explicitly link humans to their environment, there is a third theory, drawn from a Jungian psychoanalytic framework that is also valuable in conceiving how humans and the environment are connected. This theory also suggests ways in which agency staff can employ place to enhance the social bond necessary for civil society to emerge and collaborative efforts to be successful. The work of Jungian analysts June Singer and Mary Loomis is particularly useful in the effort to understand how individuals and place relate, in that their understanding of Jung provides a means of describing how individuals are oriented toward their environment as well as how they take in and process information about that environment.

Jung's theory of psychological types is based on the idea that there are two opposing attitudes, introversion and extraversion, and two opposing pairs of functional types, thinking/feeling and sensation/intuition. Prior to the development of the SingerLoomis Personality Test, it was generally assumed that these oppositional pairs were bipolar, or mutually exclusive in nature. That is, any given individual is either introverted or extraverted, but not some combination of both. Singer and Loomis' research and clinical experience suggested that this is not the case. Based on this new conception of Jung's theory, Singer and Loomis developed a new personality test which measures each factor independently, producing a score for each of the eight factors.

A complete description of Jungian psychoanalytic theory is both unnecessary and beyond the scope of this study. However, a brief description of each of the eight factors are useful for understanding how Singer and Loomis' understanding of Jung can be used to assess if and how BLM staff employ place symbolically to build or strengthen the social bond. The first psychological dimension described by Jung is the introversionextraversion dimension. The extravert focuses attention primarily on the outer or physical world, including human relationships and the physical environment. Introverts by contrast, focus largely on their inner or subjective world. Their personal experiences, ideas, visions and thoughts tend to be of greater import that what occurs around them. 
Jung's theory further suggests that in addition to a preference of introversion or extraversion, humans have four psychological functions inherent in their psychological makeup.(Loomis, 1991, p. 28)

These functions allow and enable the individual to interact, comprehend and understand the environments in which they live.

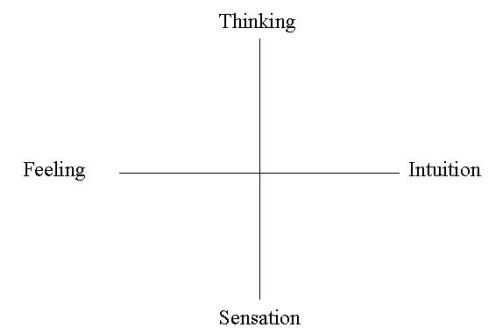

Figure 1: Jung's arrangement of the four functions (Loomis, 1991, p. 29)

The four functions are organized into two pairs, one described as the perceiving pair and the other described as the judging pair. The first of these four dimensions, associated with the perceiving pair, is sensation. As the common connotation of the word might suggest, sensation is connected with one's awareness or sense of what is going on in and around him. It is the kinesthetic experiences and bodily awareness of what exists in the present.

The second function, intuition, is what Jung called perception via the imagination. It is the function by which one is able to transcend the present into the past or future. Intuition allows one to conceive of the realm of possibilities through one's imagination.

The judging pair of functions consists of thinking and feeling functions. The thinking function, according to Jung, entails the logical thought processes of cause and effect reasoning. Feeling, by contrast, is not the emotional feeling the connotation of the term might suggest, but rather is the process by which value judgments are made. Both are considered rational by Jung, because both result in judgments being made. Both are predictable methods by which people make decisions. The complete model looks as follows: 


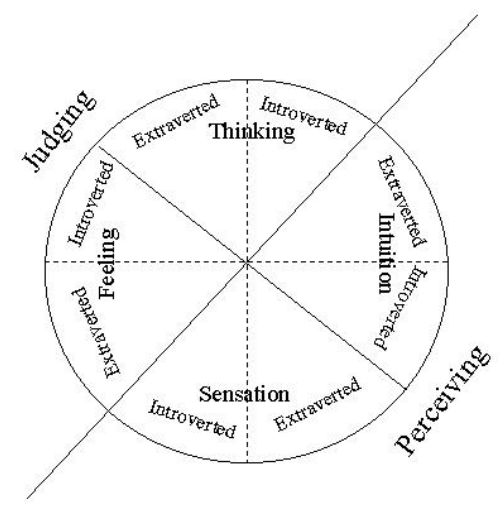

Figure 2: Interactive Model showing relation of the Eight Cognitive Modes (Loomis, 1991, p. 47)

It should be noted that the description of the four functions thus far is fairly consistent with the predominant interpretation of Jung. Singer and Loomis' interpretation differs in its emphasis on the dynamism of the model. Singer and Loomis suggest that the oppositional cross model above was a teaching model used to explain his theory of types as well as their possible interactions and was a simplification of the more complex theory. Singer and Loomis rely on later works to argue that Jung's notion of individuation or individual growth necessitated a dynamic understanding of the four functions. The implication is that while one might behave in was that are consistent with one psychological category in a particular situation, the individual should not be assigned a type for all situations over time. In his later lectures, Jung stated, "Do not think I am putting people into this box or that and saying, 'he is an intuitive,' or 'he is a thinking type'... It is no use at all putting people into drawers with different labels (Jung, 1935, par. 34)." The importance of this more dynamic interpretation is that it suggests that individuals may behave in ways with different functions at different times and that place is one of the factors associated with which function is the dominant.

For example, Tony Hiss describes the inherent coordination and cooperation that occurs in particulary crowded places such as Union Station in New York City. Huge numbers of individuals unconsciously adopt patterns of behavior and interaction that are consistent with one another given the demands of the place. Regardless of one's dominant psychological type, when located in a particular place, another function or functions come to play and in this example an unconscious awareness of patterns and symbols encourages or sets up tendencies toward particular types of behavior.

The interplay of these two dynamics (introversion/extraversion) and the four functions combine into eight cognitive modes. These eight or arrayed in the following table: 


\begin{tabular}{|l|l|}
\hline Mode & Description \\
\hline Introverted Sensation & $\begin{array}{l}\text { This mode draws on kinesthetic and proprioceptive bodily } \\
\text { sensations - i.e. the sense of physical states such as stress, } \\
\text { relaxation, excitement, etc. }\end{array}$ \\
\hline Extraverted Sensation & $\begin{array}{l}\text { This mode relates to the physical connections to life through } \\
\text { senses - auditory, tactile, visual, etc. }\end{array}$ \\
\hline Introverted Intuition & $\begin{array}{l}\text { This mode recognizes symbols of the unconscious, beggar, } \\
\text { father/hero, etc. - it is the inward imagination that generates } \\
\text { ideas and suppositions }\end{array}$ \\
\hline Extraverted Intuition & $\begin{array}{l}\text { This mode allows for seeing the possibilities in a situation. } \\
\text { Tends to be aware of ambiance over specifics of décor, tenor } \\
\text { of a conversation over the specific of the topic - the source of } \\
\text { hunches }\end{array}$ \\
\hline Introverted Thinking & $\begin{array}{l}\text { The conceptual problem solving mode - focused on ideas, } \\
\text { concepts or symbols - characteristic of philosophers and } \\
\text { mathematicians }\end{array}$ \\
\hline Extraverted Thinking & $\begin{array}{l}\text { The logical problem-solving mode that is focused on the outer } \\
\text { or physical world. }\end{array}$ \\
\hline Introverted Feeling & $\begin{array}{l}\text { The mode that draws connections to inner values, be they } \\
\text { personal, family, societal - even abstract, spiritual, mystical or } \\
\text { potentially even conflicting with other held values. }\end{array}$ \\
\hline Extraverted Feeling & $\begin{array}{l}\text { The mode that draws connections to others through shared } \\
\text { experiences and recognized intrinsic value - it is the mode } \\
\text { that draws in the human factor of decisions. }\end{array}$ \\
\hline
\end{tabular}

The value of using Singer and Loomis' interpretation for this project is several fold. First, the use of Jung is helpful in understanding the ways place can be perceived as well as the range of senses or understandings of place that can be held and influence behavior. While Singer and Loomis recognize many of the more obvious and conscious shared experiences of a physical place, such as those described by the extraverted sensation mode (sense of place through, for example auditory or tactitile sensation), They also provide a framework for understanding that there are other means of experiencing and reacting to place below the level of consciousness. This would include the recognition of symbols at an unconscious level (introverted intuition), such as symbols of 'opportunity' or 'space' or 'rugged individualism' that have come to characterize the American West. The notion of perception of place below the level of consciousness would also include modes like introverted-feeling, by which place would call on connections to inner values. Here again this may include values like economic selfreliance or environmental preservation. Another mode of perception that operates below the level of consciousness is introverted sensation, by which one might experience particular emotional states related to the physical environment. One well known example of introverted sensation would be a sense of anxiety about the configuration of a room that is inconsistent with its intended use, such as a class room style room for a participatory teaching experience. Associated with other places on the public lands, this might be experienced as a sense of joy while visiting a particularly pristine wilderness or 
potentially even a mining or logging operation. Other important perceptions that Singer and Loomis' schema give structure to include how one may conceive of himself as being part of place or a recognition of the human factor in decisions related to place (extraverted feeling). Again, Singer and Loomis' interpretation is of particular value because of their recognition of the dynamic nature of Jung's theory, which allows for the possibility of different modes operating for an individual at various times or in different situations. The purpose of the theory is not to predict behavior or to attempt to determine the personality types of study participants, but rather to provide a theoretical framework by which data from the field study can be organized. More specifically, the use of Singer and Loomis's work provides a means of understanding the range of ways individuals perceive a given situation both at and below the level of consciousness and then uses that understanding to examine the processes used by the BLM in order to assess which may contribute to the strength of the social bond and which may hinder its development.

The following model represents the way in which the concepts described above (Place Identity, Place Attachment and Singer-Loomis) fit together and operate.

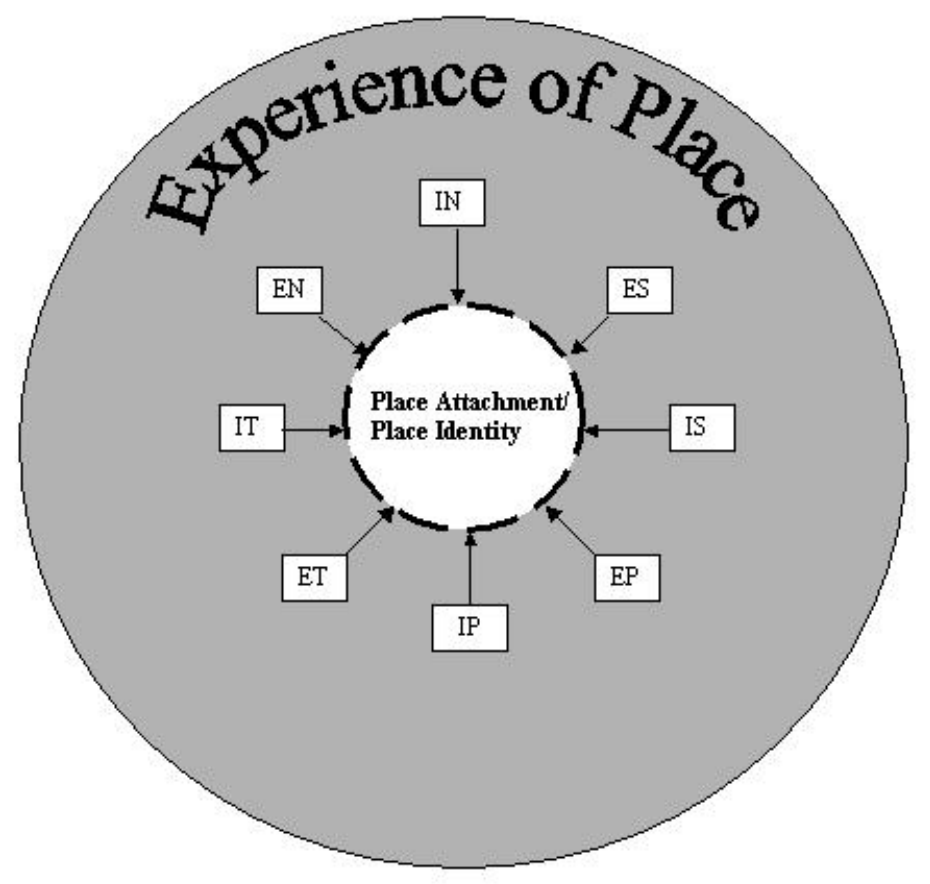

Figure 3: Model of the Theoretical Framework

\section{Model of Agency Action}

The presentation of this theoretical framework implies more than just a means of assessing the activities of single public agency. It suggests that an administrator, aware 
of the framework, should be able to craft strategies that capitalize on group members' connections to place and thereby contribute to the development of a robust social bond, which in turn enables the emergence of civil society.

In order to effectively craft strategies under a place based mode of action, a public administrator would need only know that individuals can and may in fact already be connected to place. As a starting place, the public administrator would conduct an informal assessment of the issues and concerns of members of a group, from which some sense of members' connection to place would emerge. Connections would emerge in the form of individual or group, personal or professional, histories as well as voiced or implied issues and concerns. More specifically, place identity might be expressed in terms of distinctions drawn to other cities, regions or places, personal and professional histories that indicate stability of location or type of location, or expressions of members' sense of safety, comfort or pleasure associated with place. Similarly, place attachment may be expressed in terms of desires to retain an association with particular places, and affinity for place or a reluctance to depart or see changes occur in it.

Once an assessment of the types and range of connections is complete, the administrator then would have the opportunity to craft a strategy that builds on individual connections to place or that perhaps even engenders a collective connection to place. Such strategies might include opportunities to share prior experiences and histories with one another in order to identify and show commonalties. It may also include the development of new opportunities to experience places as a group, and in doing so build new connections and create a shared social bond from that experience. 


\section{Chapter 5 - Historical, Institutional and Physical Context}

Before describing the findings of the field study, it is useful to have a sense of the historical, institutional and physical context within which the RAC works. In order to establish such a context, this chapter proceeds in two broad sections. The first portion of this chapter describes the historical and institutional context of the agency. The second section of this chapter describes the specific lands or place that the Northwest California $\mathrm{RAC}$ is responsible for, emphasizing those tracts of BLM that have received the most attention from the RAC.

\section{The Agency}

The contemporary Bureau of Land Management is housed within the U.S. Department of the Interior, manages the remainder of the public domain -- a once vast expanse of land held in ownership by the United States Government for the American people. The stated mission of the BLM is to sustain the health, diversity, and productivity of the public lands for the use and enjoyment of present and future generations.

Of the original 1.8 billion acres of public domain, which stretched from the Appalachian Mountains to the Pacific Ocean, two-thirds were transferred from Federal ownership to individuals, corporations and States. Other land was set aside for national forests, national parks and other public purposes, leaving the BLM responsible to manage 270 million surface acres and 570 million acres of sub-surface mineral rights. These 270 million surface acres make up one-eighth of America's land surface and amount to 41 percent of the land under Federal ownership.

Formed in 1946 as a part of a government reorganization, the BLM is a successor to two former Federal agencies, the General Land Office and the U.S. Grazing Service. With the exception of some small holdings scattered throughout the East, the bulk of the lands managed by the BLM are located in 12 Western States.

The Bureau is headquartered in Washington, D.C., and has about 9,000 employees, most of whom work in field offices throughout the 12 Western States (BLM California, n.d.).

\section{History and Institutional Context of the BLM}

As the nineteenth century drew to a close, the first questions about what to do with the remaining lands in the public domain began to arise. Starting around 1875, a collection of comments from Presidents Grant and Hayes as well as a report from the General Land Office acknowledged that the existing homestead laws failed to work for the lands west of the $100^{\text {th }}$ meridian. It became clear at that time that these lands had too little water and arable land to make the small homestead tracts viable for agricultural purposes.

In 1901, the cattle growers proposed a bill that introduced the notion of permits and leasing for the federal lands at a rate of $\$ .02$ an acre. Though the bill was criticized and eventually blocked because it favored large existing landowners and grazers, it began a series of proposals and counter proposals for how the western public domain, especially 
those lands used for grazing, should be managed. Between 1901 and the eventual passage of the Taylor Grazing Act in 1934, no fewer than eight bills were introduced in Congress proposing one management scheme or another for the Federal grazing lands. Issues under debate at this time included which agency management of the grazing lands was to fall under, as well as the means by which the grazing lands were to be administered.

In a move that foreshadowed management strategies that would become crucial to the fledgling Division of Grazing and would also shape management process to this day, a 1928 bill was proposed allowing the Department of Interior to enter into agreements with ranchers in Montana. This was to be facilitated through the creation of a stockman's association. These agreements allowed for and enabled the collaborative determination of management processes for tracts of land, including the determination of carrying capacity and oversight of leased lands. These collaborative agreements made for functional and successful administration of the lands in Montana (Foss, 1960).

Among the other interesting proposals that arose during this time was a 1929 recommendation from President Hoover to turn ownership of the federal lands over to the states. At that time, the states opposed the possibility of acquiring the public lands, as they generated very little revenue and required the additional administrative structures to manage.

In 1934, Colorado Congressman Edward Taylor reintroduced what had been Colton Bill in the prior session of Congress. This proposal had made it through the House but had died in a Senate committee the year before. The bill dealt with the entire public domain and in the words of the House Committee on Public lands, would "stop injury to the public grazing lands by preventing over grazing and soil deterioration, to provide for their orderly use, improvement and development, to stabilize the livestock industry dependent upon the public range (Foss, 1960, p.51)". The original Colton Bill and later the Taylor Grazing Act also created the Division of Grazing within the Department of Interior.

Following the passage of the Act, the first director of the Division of Grazing, Farrington R. Carpenter, immediately faced an extraordinary challenge in that there was no corresponding appropriation of funds to administer the Taylor Grazing Act nor to operate the Division of Grazing. Farrington was loaned 17 men from the General Land Office and two men from the Forestry Service who had experience with grazing issues. Beyond the problems of resources and personnel, there were no maps of the 142 million acres (221,875 square miles), eventually designated as grazing districts, which were to be administered by the new agency. In Carpenter's own assessment, "the only people who knew where the remaining public plans were and what they were, were the stockmen who used them and they had first hand and accurate knowledge (Carpenter in Foss, p 79)."

The answer to the challenges the new agency faced was devised in the form of advisory boards. These boards would have a two fold benefit. First, they would be able to provide much of the information necessary for the administration of these lands. Second, they could provide assistance in the decision making process on both technical matters as well as broader policy matters. A further benefit of these boards was the likelihood that they would improve local compliance and support for the agency. Among the reasons that Carpenter felt that the advisory boards were the best strategy were: 
- To let carefully filtered local advice have great weight, but not to ever let the boards "get the bit in their teeth,"

- To give the permittees a democratically constructed machine and warn them that "eternal vigilance" and attendance at the polls was the price of retention, and

- To keep the service civil and cooperative but with a firm hold on all final decisions and an eye to the long range policy. (Carpenter in Foss, p. 81)

To add to the second point above, it should be noted that the members of the advisory boards were not appointed by the agency or the stockmen's associations, but rather were elected by the permittees. Further, once elected, these stockmen were required to take the same oath of office as did regular federal officials (Foss, p. 81).

Just as the creation of the Division of Grazing had been contentious and politicized, the early history of the agency could be described in the same vein. In 1939 the agency was reorganized into the Grazing Service, at least in part in an effort to centralize power to Washington D.C. Within two years, the agency was decentralized and the headquarters was moved from Washington to Salt Lake City. In 1945, then director C.L. Forsling attempted to grow the agency further with the proposal to conduct an extensive range rehabilitation program. Unfortunately, not only did this initiative fail to increase the efforts and size of the agency, but within one year, the agency was reduced to a "paper" organization. In July of 1946, the Grazing Service was consolidated with the General Land Office into the current Bureau of Land Management. In the course of these changes, total personnel were reduced by $79 \%$, four regional offices and several field offices were closed. As was the case following the enactment of the Taylor Grazing Act, advisory boards would once again be the mechanism by which the agency was able to achieve what it could of its mandate. In this instance, the advisory boards provided approximately $\$ 200,000$ of range improvements funds to cover the costs of salaries in 1947 . At that time, $50 \%$ of the grazing fees collected were distributed to the state governments in which the grazing districts were located. In most instances, these funds were then allocated to the advisory boards for range improvements. During this period however, a large portion of the funds were used to pay the salaries of agency staff in the field. This also created the unique situation in which the agency which was to provide oversight was, in effect, overseen by those it was supposed to regulate.

From the creation of the first advisory boards following the passage of the Taylor Grazing Act until 1960, the local, state, and national boards were entirely or almost entirely occupied by livestock interests. Selection of board members at each level was driven by the selection process at the most local level. District board members were elected by permit holders in each district, i.e. by the stockmen in the district. Members of the state boards were selected by district board members. That is, each district board selected two members to serve on the state board. Similarly, each state board selected two members to serve on the national board. Between 1939 and 1949, only the district boards had statutory authorization. The state and national boards were only tacitly recognized by the agency. In 1949, the state and national boards received formal administrative recognition, but in gaining that recognition, were required to add one wildlife representative to each state level board and three representatives at the national board level (Cawley, 1980, pp. 100-101). 
Although the composition of the state and national boards would change significantly following the election of President Kennedy in 1960, the district boards did not undergo substantial change until the passage of the Federal Advisory Committee Act (FACA) in $1972 .^{3}$ This act required that:

1. Advisory committees must have statutory authority, presidential authority or be created as a matter of formal record such that it is in the public interest as a part of an agency's statutory duties,

2. Recommendations and/or reports generated by advisory committees must be presented by an officer of the Federal Government,

3. Advisory committee meetings must be open to the public,

4. Advisory committee meetings must be called by a Designated Federal Officer (DFO), who either chairs or is present at the meeting, and

5. a charter for the advisory committee which defines its scope and functions must be filed with the agency, Congressional oversight committee(s) and the Library of Congress (Cawley, 1981).

Further, the Act required that all existing advisory boards either be terminated or reconfigured to comply with the Act's provisions. At the same time, the Department of the Interior expanded the multiple use representation and philosophy to the district boards, dictating that membership of the boards be balanced in terms of the perspectives represented (43 CFR, 14784.7, 1979).

The next change to the structure and composition of the BLM's advisory boards came in 1976 with the passage of the Federal Land Policy and Management Act (FLPMA). At the district level, FLPMA had the effect of creating a dual advisory board structure. Section 403 of the act created advisory boards that exactly resembled the grazing boards created by Carpenter following the establishment of the Division of Grazing in 1934. However, section 309 of the Act created a second board that would advise the agency on multiple use plans and programs and that further, these boards would be balanced in their membership to reflect the various interests reflected in those multiple use plans (Cawley, 1981).

The most recent iteration of the BLM's use of advisory boards was unveiled in 1992 with the creation or Resource Advisory Councils (RACs) which were created to facilitate the Clinton administration's rangeland reform initiative. Although the focus of the RACs has since expanded beyond the establishment of Standards and Guidelines for rangeland management, their basic structure, function and operations remains largely unchanged since their original charter in 1992.

There are two issues associated with the agency's history with advisory boards worth noting at this point. First, the Bureau has a long history of substantive involvement with and use of advisory groups. Moreover, the connection of these groups to place, and the

\footnotetext{
${ }^{3}$ It is worthwhile to note that the changes to the national board composition resulted in dramatically broader representation of interests other than livestock. Wildlife representation was increased from three to ten, mining and local government gained two representatives each and Alaska, Washington, Forestry, Oil and gas, outdoor recreation, urban/suburban development, soil and water conservation, and state governments each gained one representative each. This was the first example within the BLM of broader diversity in membership that would later be seen in the RAC's composition (US DOI, 1967, Appendix 1).
} 
agency's use advisory group members' place bound knowledge was established with Carpenter's creation of the first advisory boards after the passage of the Taylor Grazing Act. The second issue of note is the increasing diversification of interests and representation among advisory board members over time. Though initially composed only of stockmen, current RAC membership covers a wide range of interests and perspectives.

\section{Advisory Group Meetings - An Historical Account}

Philip O. Foss describes a series of the 1955-56 District Advisory Board meetings in Politics and Grass, and provides an interesting point of comparison to contemporary RAC meetings. Foss indicates that at the first of the three Advisory Board meetings he describes, the single topic for discussion was the status of the district's physical plant facilities and potential for improvements to that physical plant.

The second meeting was focused primarily on the review of and action on grazing permits. Other topics considered during the second meeting included the possible need for changes in grazing capacity, uses and allocation of range improvement funds for the district and a continuation of the physical plant discussion from the previous meeting. When considering the grazing permit applications, the district manager proceeded by recommending that the board consider applications in two large blocks. One block of applications considered were those that contained changes from previously approved permits. The second block of applications were those that were unchanged from previous years. In dealing with those that were unchanged, the district manager made the assumption that because nothing was different from previous years, "everything was O.K." and no discussion was needed on individual cases. After the district manager read a list of 80 to 90 names of applicants on the unchanged list, the board asked that two of these applications be considered further, the remaining applicants were approved without board discussion.

The third and final meeting of the season was scheduled for hearing protests from the prior meeting's decisions and to finalize decisions and recommendations regarding the district's physical plant. The one individual who attended in order to lodge a protest did so not to protest a permitting decision but rather to lodge a complaint against another permittee. Finally, following the presentation of additional information regarding the possible purchase of property and construction of new facilities for the district offices, the board recommended that the district manager proceed with the purchase of property, but delayed any decision regarding the construction of new facilities.

While the topics of discussion during these three meetings are of interest in their own right, Foss' more important observations related to the processes that were used during the course of the three meetings. First, no formal agenda was prepared for any of the three meetings and no written materials were prepared or presented to the board members. The district manager did have a brief list of notes that he periodically referred to, but the range manager (who facilitated the discussion of permit applications) had only a stack of case files and no notes. The size of many of the case files made quick reference to them difficult if not impossible. Further, the district and range managers' responses to questions were often from memory and were couched in terms such as, "as I recollect," "I figure," "around about that." Board members themselves also tended to 
rely on generalizations, approximations and memories. A map of the district was available in the meeting room, but it was placed so that it could not be readily referred to by the BLM staff or the board members. In the discussion of the carrying capacity of the range in the district, no reference was made to range surveys, dependent property surveys, range utilization checks or range conditions and trend studies.

Interestingly, the connection of this group to place or its use of place bound knowledge is not expressed in any recognizable form. In part, this may result from the character of the meetings' agendas and the focus of the record keeping. That is, it may well be the case that place does not appear as a theme in these meetings because it was not Foss' research focus and also because the agenda for these meetings did not include items that would likely draw on place oriented discourse. Further, the lack of place oriented discourse is perhaps not surprising in that the composition of the advisory group in this case was entirely stockmen. While there is some indication that members were not in agreement about each and every issue to come before them, it seems likely that as stockmen, there was a core of commonality among them that mitigated any need to drawn on place as the factor which would shape productive discourse.

\section{The BLM Today - The character of place for the BLM}

The BLM currently manages 270 million surface acres, ones which are increasingly recognized for their ecological, aesthetic and economic values. By its own account, the BLM is working to improve the way it manages the land. One of the ways the agency is doing this is by taking what it describes as a "big picture" or ecosystem approach to land management. This style of management is aimed at promoting and or maintaining biological diversity and sustainable development simultaneously. This ecosystem approach to management is consistent with the BLM's mandate under the Federal Land Policy and Management Act of 1976, which requires the agency to administer the lands it is responsible for in a way that accommodates many uses, including recreation, resource extraction, and species protection.

\section{Northwest California}

The Northwest California RAC is organized around three Field Offices comprised by the Ukiah district prior to the Bureau's reorganization in 1992. Because of the differentiation of uses and land holdings between Northeast and Northwest California, the Bureau made the decision that the two regions should have separate RACs. The three Field offices falling within the area of responsibility of the Northwest RAC are Arcata, Redding and Ukiah. Lands managed by the Arcata Field Office range from the Oregon boarder south along the Pacific coast, and include Del Norte, Humboldt and Mendocino counties. The Redding Field Office has responsibility for lands inland from the coast, but that also run from the Oregon boarder south. They include Siskiyou, Trinity, Shasta, Tehana and Butte counties. Finally, the Ukiah Field Office has responsibility for lands running north from the San Francisco Bay area north. Lands within the Ukiah Field Office's area of responsibility include those BLM lands located in Marin, Sonoma, Napa, Solano, Lake, Yolo, Colusa and Glenn counties. Taken in total, the area comprises 
the bulk of the Northwest corner of the state of California, from the San Francisco Bay to the Oregon state line.

The following sections proceed by first providing a brief overview of the lands managed by each respective Field Office and then a more detailed description of the tracts of land that receive the greatest amount of attention from the Northwest RAC.

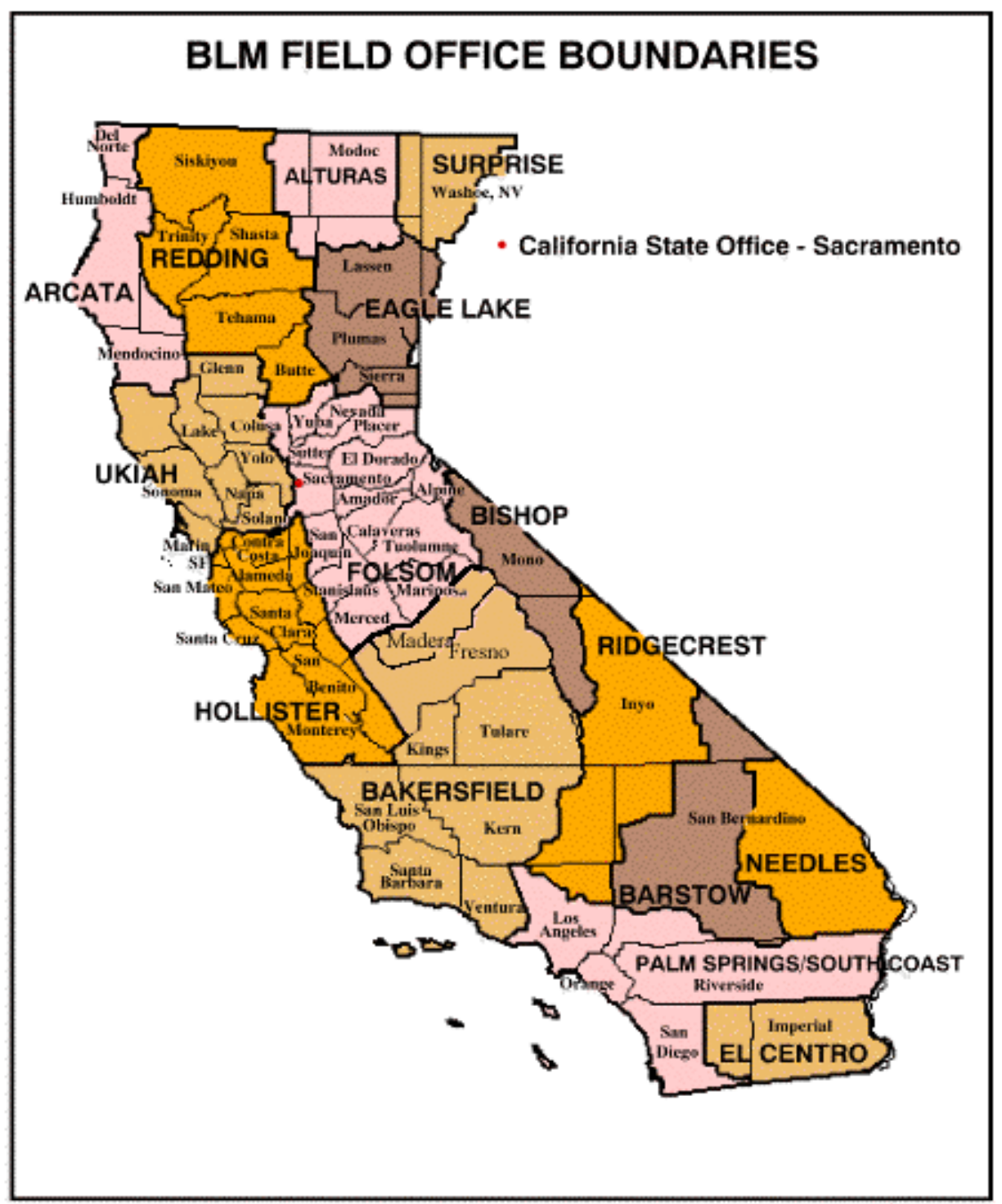

Figure 4: California BLM Field Office Boundaries (BLM California Home Page, n.d.)

Arcata

The Arcata Field Office is responsible for the administration of natural resources, lands, and mineral programs on approximately 200,000 acres of public land in Northwestern California, from Mendocino County north of San Francisco to the Oregon border. The character of the BLM lands in this are is quite diverse and includes redwood 
forests, coastal ecosystems and habitat critical to several endangered species. The Area includes the 60,000 acre King Range National Conservation Area and the 7,400 acre Headwaters Forest Reserve (BLM Arcata Field Office [Arcata], n.d).
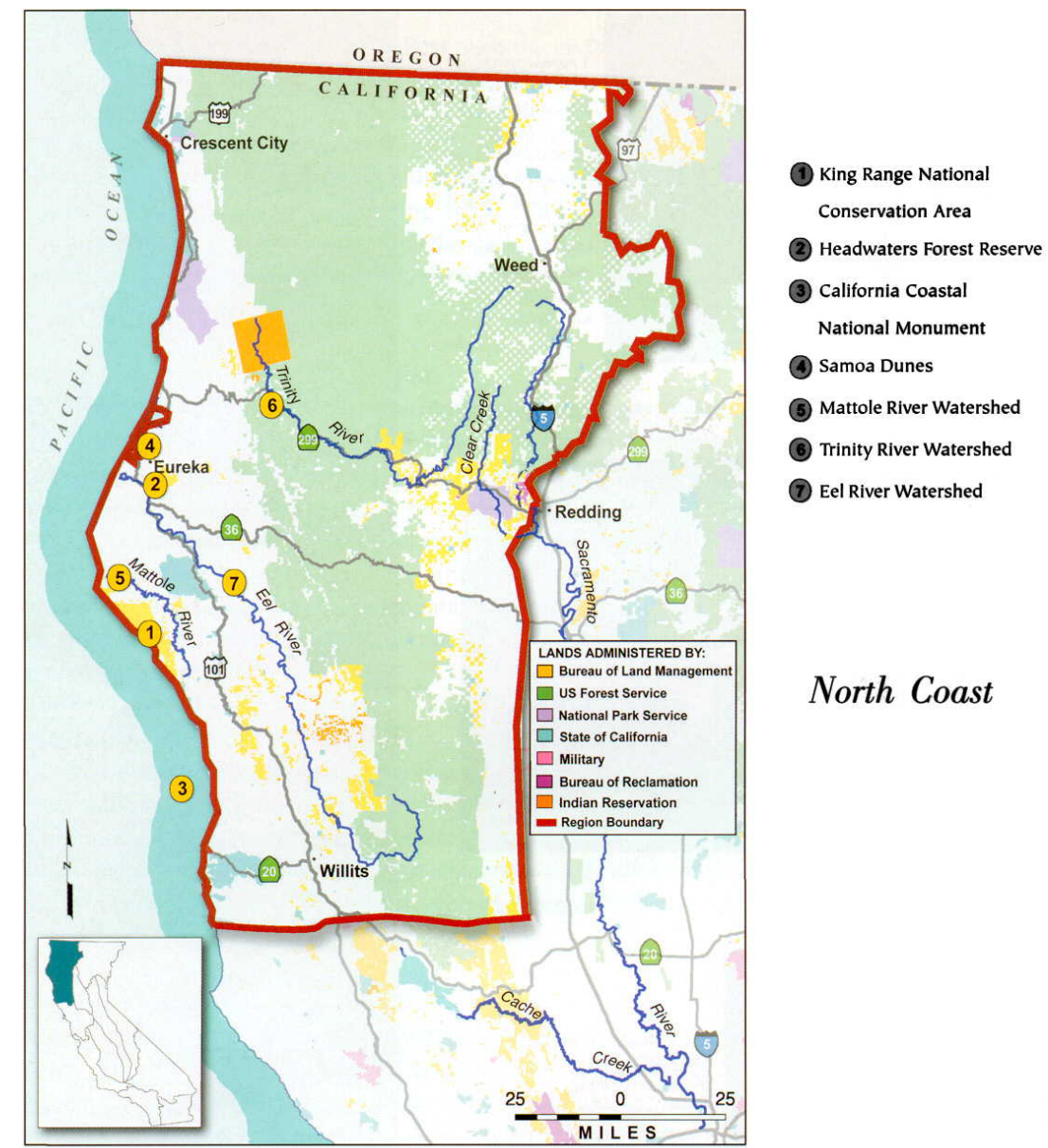

North Coast

Figure 5: North Coast/Arcata Lands

(BLM North Coast, 2000, p. 4)

\section{King Range National Conservation Area}

Located South of Eureka, California, along the coast of the Pacific Ocean, the King Range National Conservation Area (NCA) is a 26 mile long range of geologically folded and faulted ridges at the point where three of the large tectonic plates meet just offshore. The King Range is at the edge of the North American Plate, which is being forced upward from the two offshore plates. The ridges here have risen 66 feet over the last 6,000 years. The rock in this range is primarily is graywacke, a dark gray crumbly sandstone. The King Range includes a stretch of Black Sands Beaches, which are made up of this rock, rather than volcanic rock, which is common to black sand beaches in other areas.

The coastal ecosystems include offshore rocks, tidepools and kelp beds that are inhabited by seals, sea lions and a wide range of marine birds. The inland ecosystems are a mix of Douglas fir forest, chaparral and grassland. These areas provide rich habitat 
values for black tailed deer and black bear, as well as a herd of Roosevelt elk that ranges from the area around Chemise Mountain south into Sinkyone Wilderness State Park. All told, nearly 300 species of native and migratory birds have been spotted in the King Range. Further, the old-growth forest in this area provides important habitat for the northern spotted owl, bald eagle, and Coopers hawk. The area is open to a various public uses, including backcountry hiking and backpacking (BLM Arcata Field Office, n.d). 

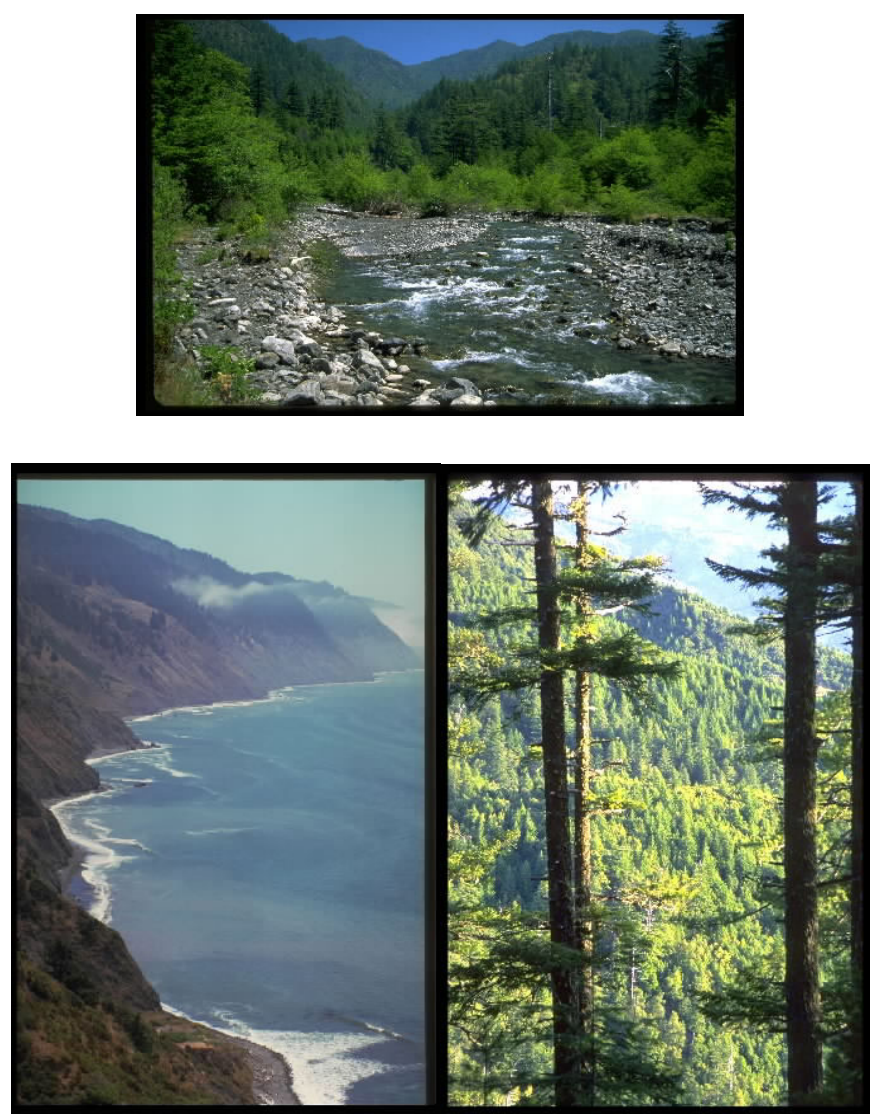

Figure 6: Variety of King Range Ecosystem Values (Bureau of Land Management Photo Library [Photo Library], n.d.)

\section{Headwaters Reserve}

Acquired from private owners by the U.S. Bureau of Land Management (BLM) and the State of California in March of 1999, the Headwaters Forest and surrounding lands totals some 7,400 acres in central Humboldt County, California, just a few miles southwest of Eureka. The Headwaters Reserve is co-managed by the BLM and the State of California in order to protect one of the last stands of old-growth redwoods that provide habitat for a threatened seabird, the marbled murrelet, as well as the aquatic systems that serve as a habitat for the threatened coho salmon and other fisheries.

Public access into the Headwaters Forest Reserve has been obtained by BLM as part of the acquisition. A five and a half mile trail follows an abandoned logging road to the old-growth forest, but access is limited to day hiking only because of the resource sensitivity. The acquisition included the remains of the historic town of Falk, which is located one mile from the trailhead. Built in 1884, the town had approximately 400 people until its decline in 1937 . Very little remains of this once booming mill town. 


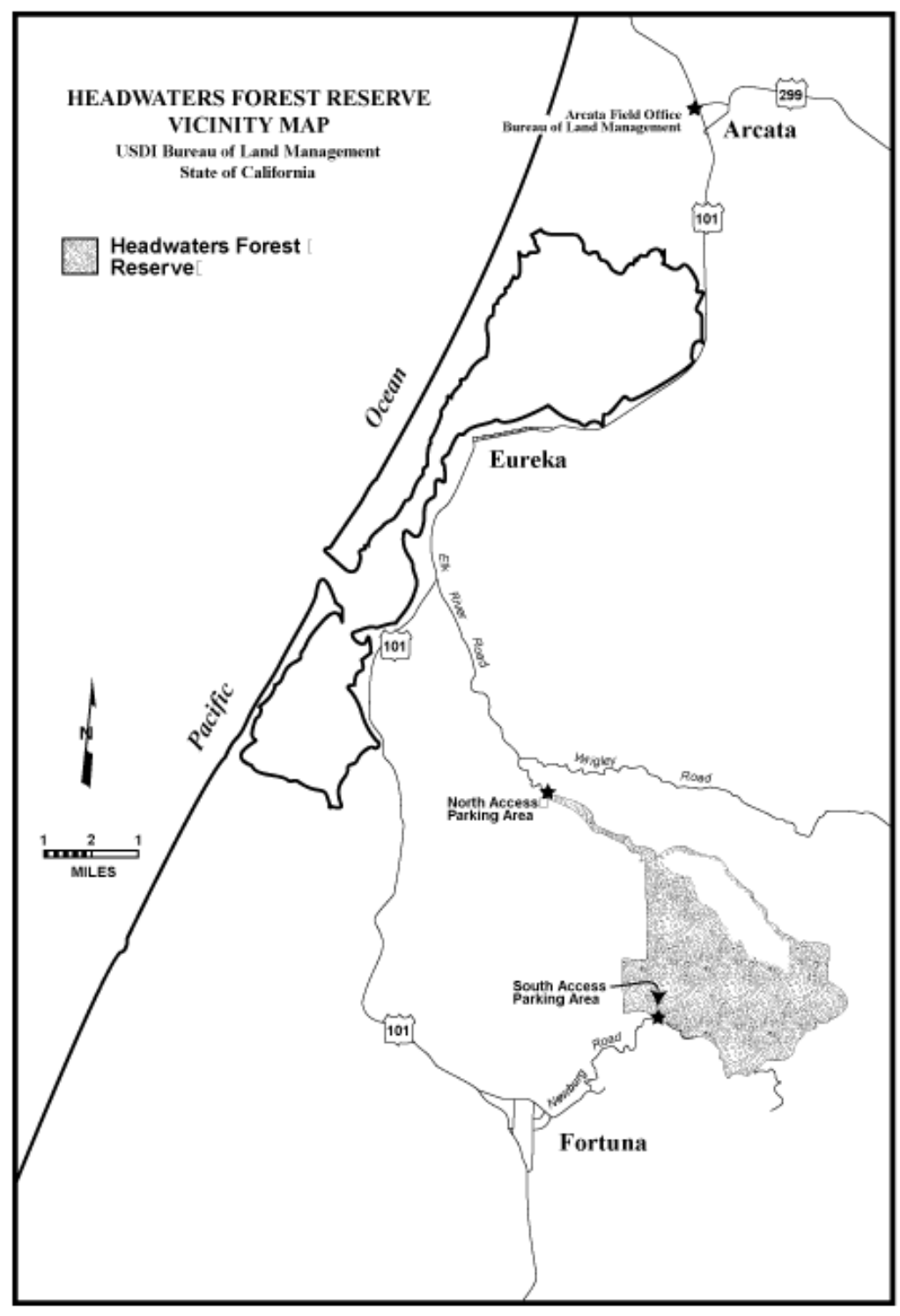

Figure 7: Headwaters Forest Reserve (Arcata, n.d.)

Concern and awareness around the Headwaters Forest began to grow in 1986, when the MAXXAM Corporation acquired Pacific Lumber Company, the previous owner of Headwaters. The company developed plans to harvest timber in the area, which immediately became very controversial, with public protests and disagreements over potential impacts to the habitat of the threatened marbled murrelet. Some 10 years later, the Federal and State Governments negotiated an agreement that paid \$380 million to acquire the Headwaters Forest. The Federal Government appropriated \$250 million and the State another $\$ 130$ million to be paid to Pacific Lumber Company and the Elk River Timber Company, the adjoining landowner, in return for Headwaters and a buffer, totaling about 7,400 acres and including more than 2,700 acres of old growth redwoods in the heart of what is now the reserve. The acquisition also included just over 300 acres of old-growth at Elkhead Springs. In addition to the lands acquired from Pacific Lumber, 
the Elk River Timber Company agreed to sell approximately 9,600 acres of its adjacent lands at a cost of $\$ 80$ million. This acquisition included a roughly 1,700 acre buffer for Headwaters Reserve (Arcata, n.d.).

The BLM and the State of California are developing a coordinated management plan in cooperation with other interested agencies, private groups, and individuals, to guide the future management of this special area. Although some initial restoration work, signing, and other necessary steps will be taken immediately, the cooperative management planning process, which will guide all other activities, is expected to take about a year. As a part of this planning process, the BLM and other agencies are crafting a Habitat Conservation Plan (HCP) and the Sustained Yield Plan (SYP) for the area. This will also affect the rest of Pacific Lumber Company's holdings, which are under the jurisdiction of the U.S. Fish and Wildlife Service (FWS), the National Marine Fisheries Service (NMFS), and the California Department of Fish and Game (CDF\&G). Timber Harvest Plans on the private lands authorized in conjunction with the HCP/SYP are under the jurisdiction of the California Department of Forestry and Fire Protection (CDF). Although there are a range of state and federal agencies involved in the management of the Headwaters Reserve, the BLM remains the lead agency (Arcata, n.d.).

\section{Other North Coast Holdings}

The North Coast area managed by the BLM includes a variety of other holdings, including Gilham Butte and the Soma Dunes. Gilham Butte is an area of just over 5,000 acres of old growth, low elevation Douglas fir forest lands lying between the Eel and Mattole watersheds. Samoa Dunes is an area around the Samoa Peninsula, the management plans for which are developed in a coopeartive effort between local environmental groups, off-highway vehicle (OHV) enthusisists and the agency. Although the BLMs holdings include these and other lands, the King Range and Headwaters lands have received the most attention from the RAC.

\section{Redding}

The Redding Field Office is responsible for the administration of natural resources, lands, and mineral programs on approximately 250,000 acres of public land in northern California. The Area includes the 17,000 acre Sacramento River Bend Area of Critical Environmental Concern, the Clear Creek watershed area, Payne Ranch and the Shasta-Chappie OHV area (BLM Redding Field Office [Redding], n.d). 


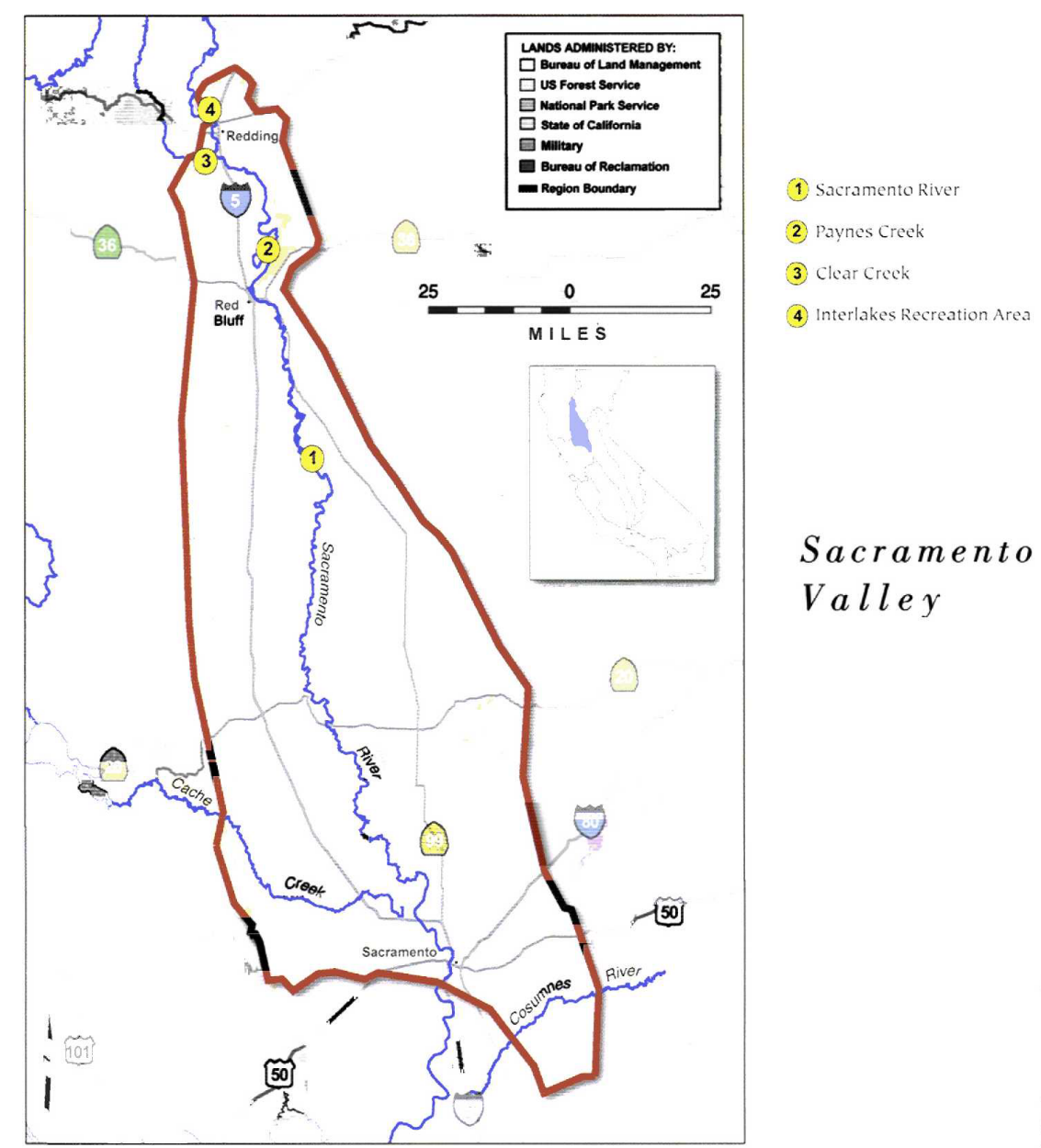

Figure 8: Sacramento Valley/Redding Field Office Lands

(BLM Sacramento Valley, 2000, p. 4)

\section{Sacramento River Bend ACEC and River Designation}

Public lands managed by the BLM in the Sacramento River Bend Area of Critical Environmental Concern (ACEC) in Shasta and Tehama counties, provide public access to river corridor lands, which remain in pristine condition. The BLM has created 100 acres of wetlands, and maintains 600 acres of nesting habitat for shorebirds and waterfowl. Public lands provide habitat for a diversity of wildlife including the bald eagle, fairy shrimp, and river otter. The river, along with tributaries, Paynes Creek and Battle Creek, support four runs of salmon, which include two federally listed endangered species, the winter run Chinook salmon and the spring run Chinook salmon. 


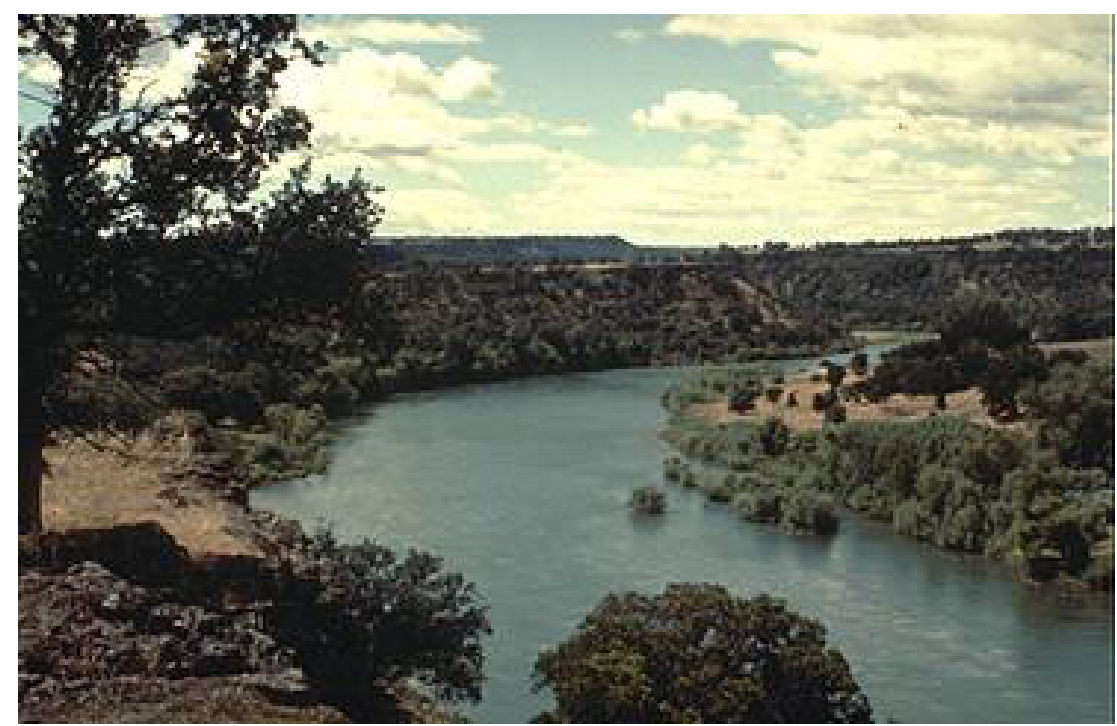

Figure 9: Sacramento River Bend ACEC (BLM Photo Library, n.d.)

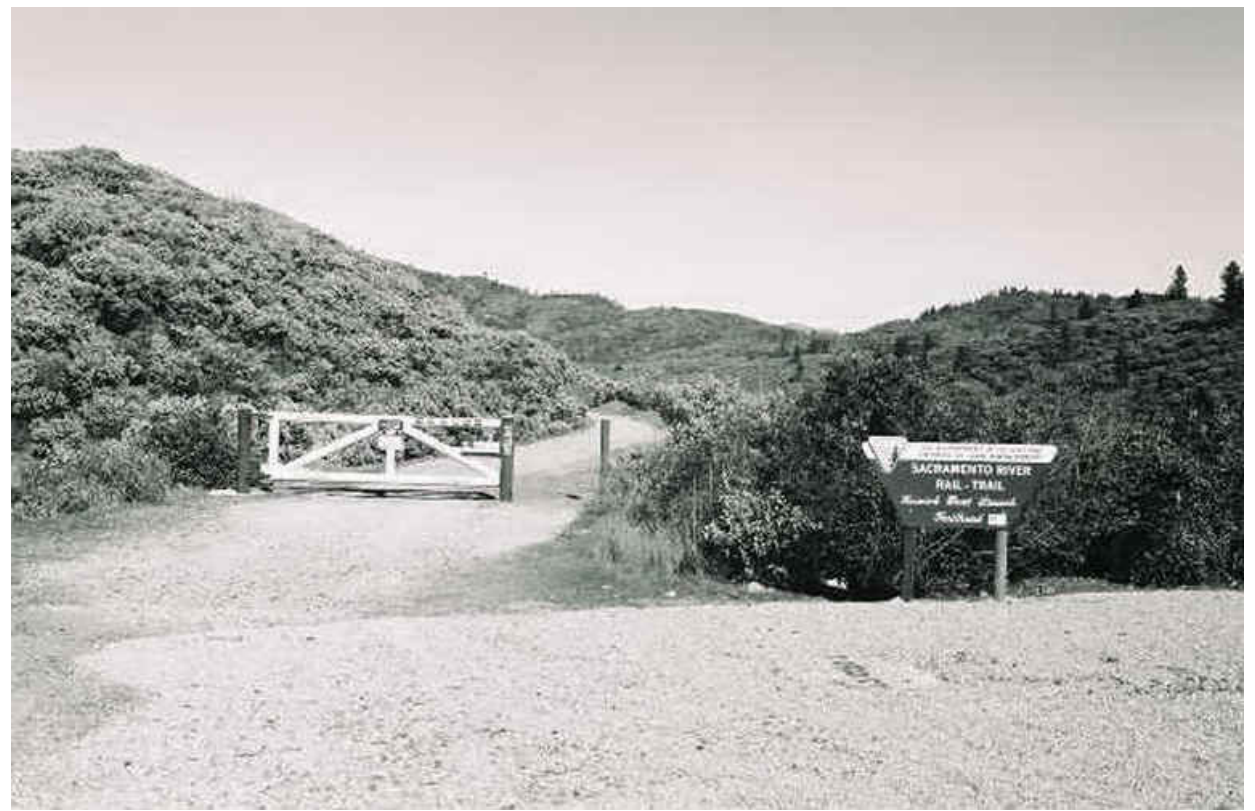

Figure 10: Sacramento River Rail Trail

\section{Clear Creek}

Clear Creek originates on the eastern side of the Trinity Alps, west of Redding California, and flows south to its eventual confluence with the Sacramento River. Clear Creek channel morphology varies from steep confined bedrock reaches to wide meandering alluvial reaches. Clear Creek is blocked by two dams. On the lower end of the creek is the Saeltzer Dam, which is a small irrigation diversion dam just upstream from the confluence with the Sacramento River. Further upstream is the Wiskeytown 
Dam, which is a large storage/diversion dam operated by the Bureau of Reclamation (BOR).

Land use, beginning with the discovery of gold at Reading Bar in 1848, and continuing today with aggregate mining in and along the channel as well as flow/sediment regulation at the Wiskeytown Dam, has dramatically changed the landscape of the lower Clear Creek watershed. As a result of the environmental degradation, including impacts on the listed chinook salmon stemming from these activities, restoration activities including adding spawning gravel, removing fish barriers, controlling erosion, reducing fuel loads and improving stream flows have been central to management plans for the creek.

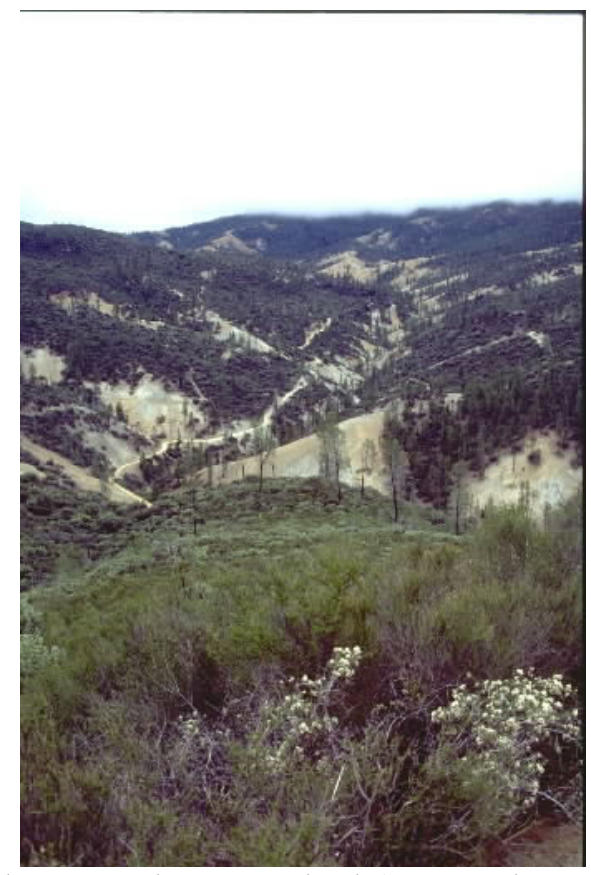

Figure 11: Clear Creek Watershed (BLM Photo Library, n.d.)

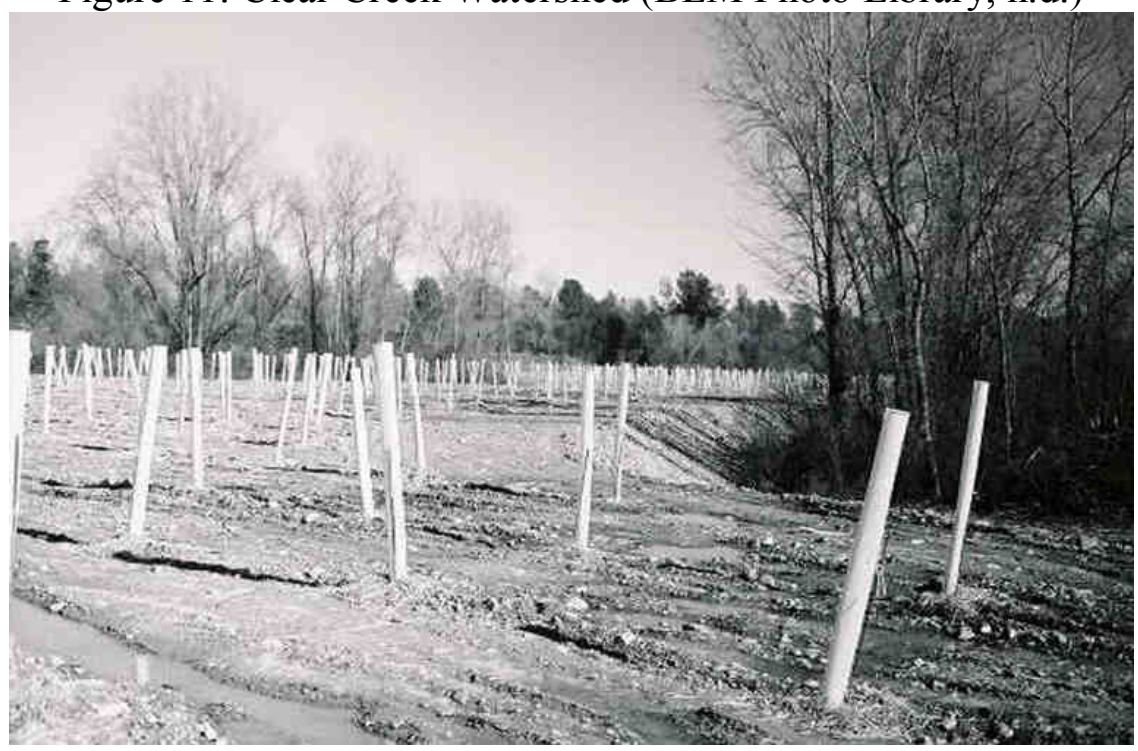

Figure 12: Clear Creek Streambed Restoration Project 
Located approximately ten miles northeast of Redding, the Shasta-Chappie OHV area is one of the few tracts of land dedicated to off-highway vehicle use. It includes miles of trails across a variety of terrain and covers elevation ranges from 600 to more than 4,600 feet. Ecosystem values range from Scramento River riparian areas, manzanita chaparral and knobcone pine at lover elevations. At higher elevations, include oak woodland areas, ponderosa pine and Douglas fir stands and on North slopes. While the Shasta-Chappie OHV area itself is managed by the BLM, it abuts lands managed by the US Forest Service, specifically Forest Service managed campgrounds which provide camping sites, day use parking, vehicle loading ramp, and a full-time site attendant.

The Shasta-Chappie OHV area has been received the RAC's attention for several reasons. First, it was one of the areas, in addition to the Cow Mountain area under the Ukiah Field Office, that the RAC used to shape the development of OHV standards and guidelines. More recently, the Shasta-Chappie OHV area has reappeared on the RAC agenda because of access issues following the September $11^{\text {th }}$ attacks. Because the main access to the staging area is accessed via the Shasta Dam, access has been restricted as a result of security concerns. ${ }^{4}$ At the time of this writing, the RAC and the BLM staff are working within the agency and with the Bureau of Reclemantion (which manages Shasta Dam), to develop a solution to the limited access currently available to the ShastaChappie OHV area (Redding, n.d.).

\section{Ukiah}

The Ukiah Field Office is located in Ukiah, California and has responsibility for approximately 300,000 acres of public lands that offer a variety of opportunities for outdoor recreation including hiking, camping, OHV use, mountain biking, horseback riding, rafting, and wildlife/bird viewing. Lands within the Ukiah Field Office's area of responsibility range from just north of the town of Ukiah and stretch south beyond the southern edge of the San Francisco Bay. Like the lands managed by the Arcata and Redding field offices, the lands managed by the Ukiah office are quite diverse, including oak savanna and freshwater aquatic ecosystems. These lands provide habitat to black bear, mountain lion, bald eagle, peregrine falcon, tule elk as well as a wide range of other species. Because of the inclusion of the entire San Francisco metropolitan area, the BLM lands face unique demands, especially for recreational opportunities. Two of the holdings that have garnered the greatest attention from the RAC are Cache Creek and Lake Barryessa (BLM Ukiah [Ukiah], n.d.).

\footnotetext{
${ }^{4}$ The Shasta Dam is the third largest concrete dam in the United States behind Grand Coolie and Hoover Dams.
} 


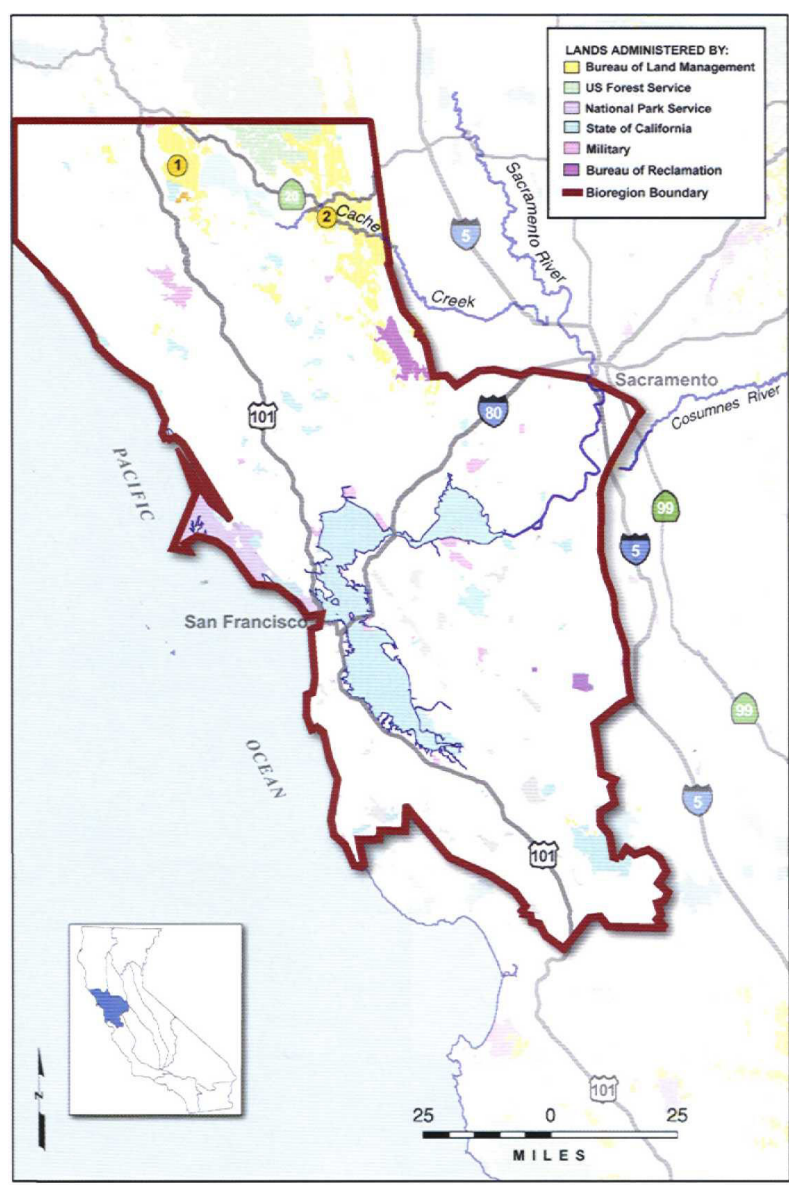

(1) Cow Mountain Recreation Area

2) Cache Creek Management Area

Bay Delta

Figure 13: Bay Delta/Ukaih Field Office Lands

(BLM Bay Delta, 2000, p. 4)

\section{Cache Creek}

Cache Creek is an 80,000 acre secluded, hilly expanse of oak woodlands, grasslands, and chaparral located west-southwest of the town of Ukaih. The area includes both roughly 35 miles of the main fork of Cache Creek and 2.5 miles of the north fork, as well as several tributary creeks that contain permanent water.

Habitat values along the creek include wetland grasses, rushes and sedges that grow under a canopy of cottonwoods, willows, oaks and alders providing excellent wildlife habitat. Approximately half of the Cache Creek holding is shrubland comprising mixed chaparral, serpentine chaparral and chemise chaparral vegetation. The remainder of the area is about equally divided between native oaks and grassland. The area also holds pockets of the rare adobe lily. Wildlife resources include numerous bird species including wild turkey and bald eagles and large animals species including tule elk, black bear and blacktail deer.

The Cache Creek Natural Area is designated as a Primitive Area, and as such, is closed to motorized vehicles and does not have developed campgrounds or facilities. The management plan for the area was structured in order to improve habitat for wildlife and rare plants, to protect cultural resource values, and to offer primitive recreation 
opportunities, such as wildlife viewing, river running, hiking, equestrian use, hunting and fishing. The area also contains archaeological resources dating back 12,000 years. More recent archaeological finds include areas that the Hill Patwin Indians used as a refuge after their first contacts with Euro-Americans (Ukiah, n.d.).

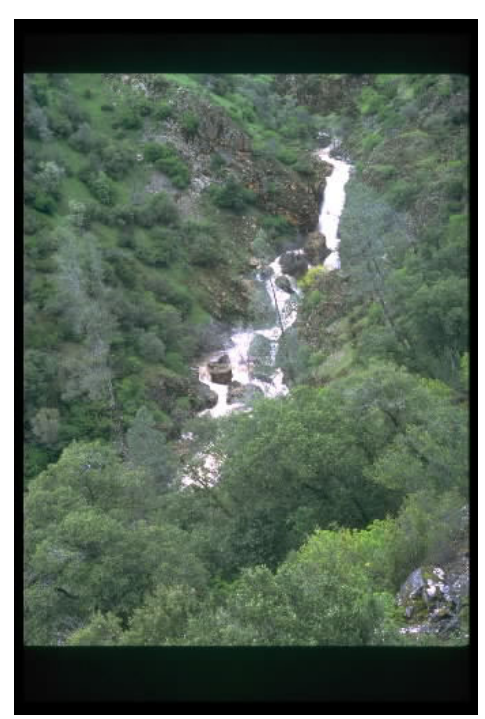

Figure 14: Cache Creek

(BLM Photo Library, n.d.)

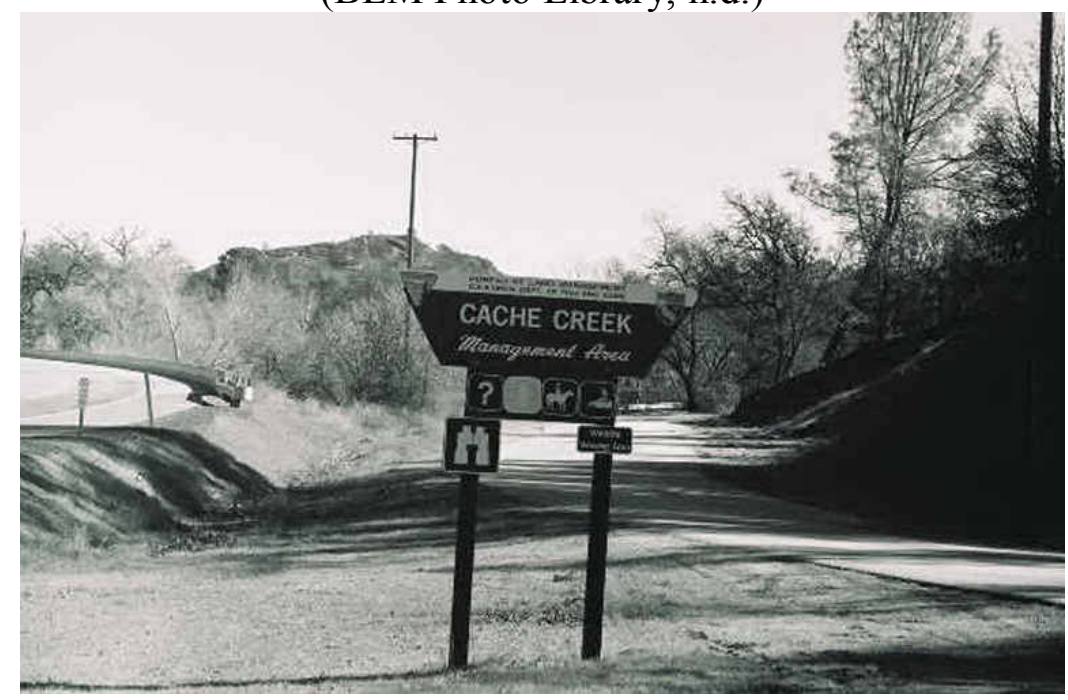

Figure 15: Cache Creek Recreation Area

\section{Lake Barryessa (BOR)}

Lake Berryessa is located in Napa County, Northeast of the town Napa and west of Davis California. Although the Lake is in fact managed by the BOR rather than the BLM, there are several proposals that would turn the lake and management responsibility for it over to the BLM and would fall under the Ukiah Field Office in that 
eventuality. As such, it has been the source of repeated discussions by the RAC as well as being the site for several field trips. Lake Barryessa is a reservoir formed when the Bureau of Reclamation built Monticello Dam on Putah Creek in 1957. The Monticello Hydroelectric Power Plant is owned and Operated by the Solano Irrigation District. Electrical energy is generated by three hydroelectric units utilizing water release to Putah Creek from Lake Berryessa through the existing northern penstock of Monticello Dam. Electricity is transmitted to Pacific Gas and Electric Company's power grid. The installed capacity is 11.5 megawatts. Construction of the Monticello Power Plant began in September 1981 and the first electrical energy was generated on March, 91983.

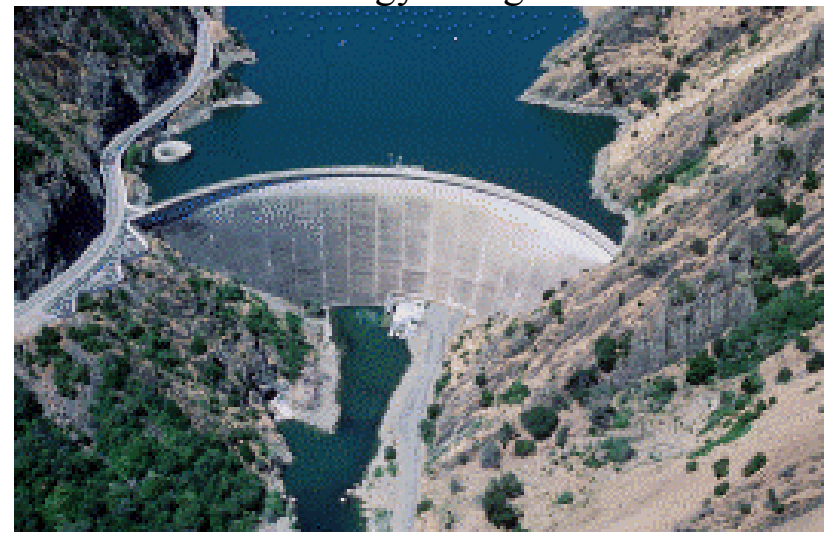

Figure 16: Monticello Dam

(BOR Lake Berryessa, n.d.)

The Lake Berryessa Recreation Area is federally owned public land administered by the Bureau of Reclamation, though, again, there are proposals to transfer ownership and/or management to the BLM.

To give some sense of the size and character of the lake, Lake Berryessa has 165 miles of shoreline, which are divided into five different areas:

15 miles of high-density recreation areas (resort areas)

12 miles of general outdoor recreation areas

17 Miles of dispersed recreation areas

106 Miles of semi-primitive areas, most of which are closed to the public 15 Miles of restricted and easement areas, all of which are closed to the public 


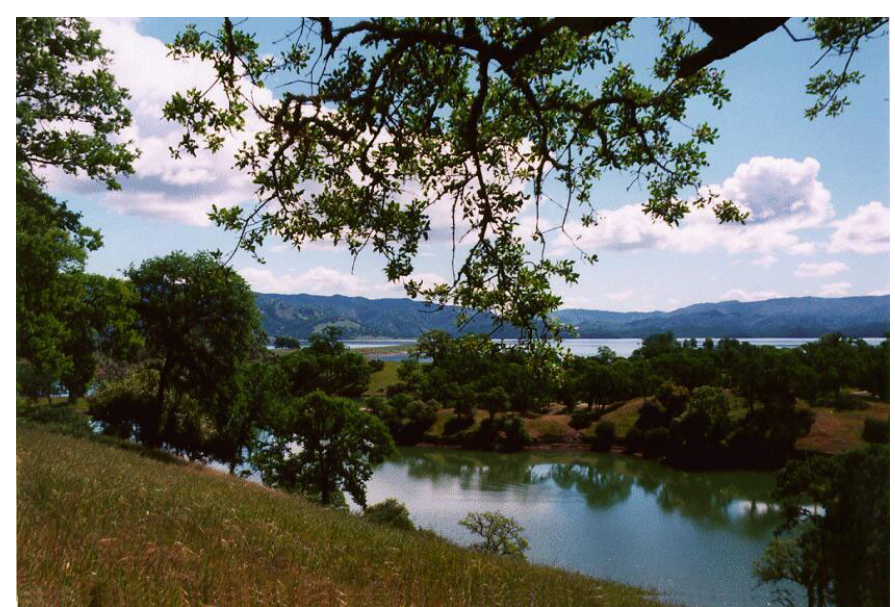

Figure 17: Lake Berryessa Shoreline

(BOR Lake Berryessa, n.d.)

Seven concessionaires have contracts with the BOR to provide recreation support services. These contracts give concessionaires management and oversight responsibility for 688 short-term RV and campsites (398 of these are tent only sites), 1300 long-term sites, most of which are occupied by privately owned trailers, marinas and boat ramps, restaurants, snack bars and picnic areas, convenience stores and tackle shops, shower, toilet and laundry facilities as well as dump stations.

The concession contracts have been in place for over 40 years and will expire in 2008-09. Much of the current discussion of future management options for Lake Berryessa revolve around alteration of these contracts in order to remediate a variety of overuse and pollution issues. Over the past years, violations of State and County wastewater regulations had been noted at Pleasure Cove, Spanish Flat, Lake Berryessa Marina, Rancho Monticello, Putah Creek and the Markely Cove Resort and the California Regional Water Quality Control Board issued Notices of Violation for instances uncovered. While remedies were developed to correct the contamination, these issues percipitated discussions regarding the appropriateness of the BOR maintaining management of the Lake and concessionaires given the BOR's limited involvement with recreation management issues (BOR Lake Berryessa, n.d.). 


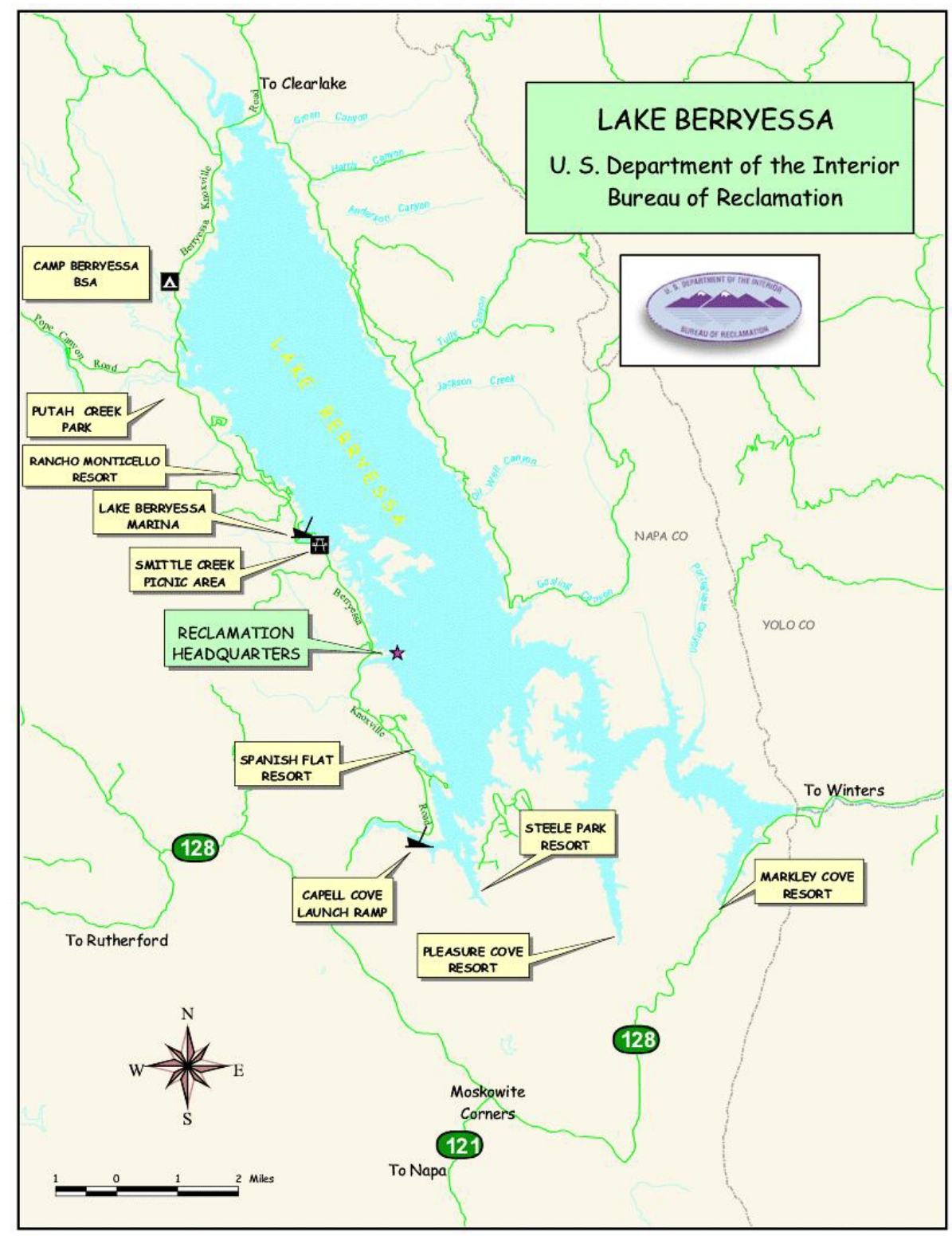

Figure 18: Lake Berryessa

(BOR Lake Berryessa, n.d.)

\section{Conclusion}

The intent of this chapter has been to provide the reader a grounding in the historical, institutional and physical context of the Northwest California RAC. Historically and institutionally, it is apparent that the Bureau has a long tradition of turning to users as a means supporting the management processes of the agency. Public lands agencies like the BLM have often been pointed to as examples of captured agencies, and at first glance this seems to be true. However, as Foss revealed in his 
research, Farrington Carpenters' decision to rely on cattlemen to carry the fledgling agency was both a pragmatic one and one that would lay unique foundations for future opportunities. The makeup of the BLM's user groups has evolved substantially over time, but it is clear that the agency has a long history of citizen involvement to which to refer as the current RAC model develops. Beyond the rich historical and institutional traditions of the agency, the diversity of lands and range of uses for them also stands out. Ranging from the costal ecosystems of the King Range to the recreation and resource values of the Sacramento river valley, the Northwest California BLM lands offer an enormous range of potential uses and opportunities for individuals and groups such as the RAC to develop connections. The results of the field research to determine what connections, if any, the BLM has built between RAC members and place is the subject of the next chapter. 


\section{Chapter 6: Findings}

\section{Introduction and Background}

The preceding chapter established a contextual picture of the agency in which this collaborative initiative takes place and described the lands for which the BLM and one particular RAC have responsibility. This chapter turns its focus to the research findings gathered from the guided conversations with current and former RAC members and BLM staff, as well as observations of RAC activities and an examination of BLM documentation related to the activities of the Northwest California RAC.

Before describing the findings of this field research, it is useful to review the major points of the theories that comprise the framework for this study as well as the research strategy used to answer the question posed by this study. Taking these issues in reverse order, the question that this study endeavors to understand is what role, if any, a public agency can play in establishing the social bond that is necessary for the development of a collaborative governance that expresses civil society. For the purposes of this research, the social bond can be understood as a foundational relationship between individuals and within groups that is characterized by a mutually felt and shared attitude toward truth. Research and theory from the field of environmental psychology offers a potential framework that can be used to understand how one potential element, place, may provide the foundations from which the requisite social bond and civil society can emerge.

Looking to the environmental psychology literature, two theories offer special potential as a means of understanding the connection between place and the social processes that bolster collaborative governance and civil society. The theories of place identity and place attachment, conjoined with Jungian psychoanalytic theory as described by Singer and Loomis, provide a new and innovative means not only to understand a here-to-fore unexplored factor that may support the emergence of the social bond. This factor also reveals potential strategies for public agencies to use in efforts to make the discourse of collaborative governance more robust and effective.

\section{Place Identity}

The primary application of to highlight here is Twigger-Ross and Uzzell's use of Breakwell's identity process model as the basis of understanding the nature and processes of this aspect identity. Based on Breakwell's work, they identify four principles that govern the selection, assimilation and evaluation of information that shapes and grounds identity. These four principles are distinctiveness, continuity, self-esteem and selfefficacy.

To understand the first of these principles, distinctiveness, Twigger-Ross and Uzzell draw from work on settlement and community identity (Feldman, 1990; Hummon, 1990) who have found distinctiveness expressed in terms of identification as a 'city' versus 'country' person. Hummon's (1986) work not only indicates that individuals distinguish themselves from others based on place, but also that they may develop and elaborate narratives describing the benefits of living where they do and disadvantages of living elsewhere. Lalli (1992) and Eyles (1968) found that individuals distinguish 
themselves by connecting themselves to a narrower locale, such as a neighborhood. Lalli shows how "the bond to a particular part of town also contributes to one's differentiation from residents in other town areas." (Lalli, 1992, p. 25) Eyle's research found neighborhood identification being used as a means to not only distinguish themselves from others, but also to claim perceived characteristics ascribed to their own places. (Eyles, 1968).

Their own research in the London docklands found that individuals expressed their distinctiveness at different levels. The first they describe as settlement identification or city v. country. At a second level, place identification, study participants expressed their distinctiveness as a resident of a particular place, as opposed to an urban or rural setting. Still other participants described themselves in terms of local identification, relating themselves to particular people and places in that local area. Lastly, Twigger-Ross and Uzzell found that some described themselves in personal ways relative to the places in which they resided. In this instance, individuals tended to describe themselves in a specific place in relation to the changes that had taken place there. Their distinctiveness emerged from having been there through all the change, as compared with those who had arrived since the changes.

Turning to the second principle, continuity, Breakwell (1986) indicates that maintaining a continuous sense of self-concept is also a motivator of action. As applied by Twigger-Ross and Uzzell, place can be understood as one means by which a continuous sense of self can be maintained between past and present. From earlier literature on continuity, they break this principal down into two types, Place-referent continuity and place-congruent continuity.

The first, place-referent continuity, can be understood as a reference to past experiences and actions. Examples from existing research show a variety of expressions of this principle. Devine (1994) shows how historic places can function as a means of fostering and maintaining the national identity of individuals and of groups. Rowles (1983) and Lalli (1988) both show how long time residents use their communities or towns as a means to maintain a link with past experiences. Twigger-Ross and Uzzell's research found that place-referent continuity was expressed primarily as a desire not to move away from an area and was discussed with reference to past events in the respondents lives.

Place-congruent continuity can be understood as the fit between the environment and what residents' want to do or achieve and differs form place-referent continuity in that it refers to generic characteristics of place rather than specific places (Twigger-Ross and Uzzell, 1996, 208 \& 216). Feldman provides an example of a person selecting places to live based on their ability to preserve their settlement identification, i.e. in order to preserve their identification as a city or a country person (Feldman, 1990). Twigger-Ross and Uzzell found respondents expressed this principle by comparing their current environment to previous environments in regards to specific social and physical characteristics of that place. Others described their current environment in terms of general qualities that they valued (Twigger-Ross and Uzzell, 1996, p. 214).

Twigger-Ross and Uzzell describe the principle of self-esteem as a positive self valuation or evaluation of the group(s) of which one is a member. In short, it is concerned with a person's feelings of worth or social value. Korpela (1989) provides the link to place by arguing that favored environments can have a positive impact on self- 
esteem. Lalli (1992) and Uzzell (1995) each show how residence in an historic town can create a sense of pride by association. Twigger-Ross and Uzzell found that residents discussed the positive impact of place on self-esteem in a variety of ways, including pride in their neighborhood and changes in it, the status associated with residing in particular places and the experience of lifted spirits associated with physical attributes of places.

The final principle in Breakwell's model, self-efficacy, is defined as "an individual's belief in their capabilities to meet situational demands," and "is a measure of personal agency (Twigger-Ross and Uzzell, 1996, 208)." Self-efficacy is connected to place by the possibility that the environment facilitates, or in the least, does not act as an obstacle to the ability of an individual conduct his day-to-day activities. Winkle (1981) describes the manageability of environments in terms of residents' ability to organize information from the environment to determine whether or not that setting supports their objectives. Twigger-Ross and Uzzell contrast this to an unmanageable environment, which is then perceived as a threat to self-efficacy. Participants in their study expressed a sense of self-efficacy in terms of their ability to both carry out the mundane activities of shopping, getting to work and other community settings as well as a sense of personal safety in the community and environmental quality.

\section{Place Attachment}

The major concepts combined under the heading of place attachment are drawn from initial work under a variety of different headings including: community attachment, sense of community and sense of place. Shumaker and Taylor describe place-attachment as "a positive affective bond or association between individuals and their residential environment (Shumaker and Taylor, 1983, p. 233)." To this, Milligan adds the idea that emotional bonds to place decrease the perceived substitutability of other places for the one in question (Milligan, 1998, p. 6) Altman and Low (1992) develop comprehensive schema that describes the range of features and aspects captured under the heading of place-attachment. Although they describe several aspects of place-attachment, including range of scales, types of actors, types of relationships and temporal aspects, the feature of place-attachment described by Altman and Low that is most useful for this project is the nature and organization of attachments. They suggest that attachment can be understood in terms of three distinct qualities: affective, cognitive and behavioral.

Mesch and Manor's (1998) study of residents of a large urban area found that attachment to place was expressed by a majority of participants in their study. Their findings reinforce the use of each of the three qualities identified by Altman and Low; affective or emotional and cognitive. Although their study examined cognitive and affective aspects of place attachment, their findings suggest that there is also a behavioral component to place attachment. They argue that the emotional and cognitive links to an environment affect the extent of involvement in keeping up the neighborhood, willingness to organize in collective action and the efforts to minimize disorder and incivility as an expression of crime in the community. (Mesch and Manor, 1988, p. 526) Further, their findings suggest that not only do individuals become attached to place, but that such attachment influences both individual and group engagement in the community.

Milligan, in her study of place-attachment to a university coffee house, adds two additional processes to the concepts described in Altman and low: the interactional past 
of a site and the interactional potential of a place. Milligan defines the interactional past as "the past experiences associated with a site, or, in a word 'memories' (Milligan, 1998, p. 2)." That is the interactional past of any particular place and the strength of the relationship or attachment to place is related to the degree and meaningfulness of the experiences. By contrast, the interactional potential of a place refers to the specific features of a place that shape, constrain and influence the activities that are perceived as able to happen there. It is the collection of conscious and unconscious expectations for what can, should and/or will happen in and around a particular place. Beyond the addition of these theoretical concepts, Milligan's study also reinforces the behavioral and emotional aspects of place attachment. She argues that "when speaking nostalgically about a site, people reflect back fondly on its negative traits... because of the impact of the emotion they felt in the place... something that is linked to the site in their minds (Milligan, 1998, p. 11)." Milligan's findings demonstrate the behavioral consequences of substantial changes to an environment that is the source place attachment. The implication of her findings is that not only can individuals form emotional, cognitive and behavioral attachment to place, but that individuals or organizations can have a role, through an understanding of the interactional past and potential of a place, to both affect that attachment or to capitalize on that place attachment.

The research described in Brown and Werner's 1985 study has findings also consistent with all three of the qualities outlined by Altman and Low. Emotionally, they found that residents in the cul-de-sacs they studied demonstrated emotional, cognitive and behavioral attachment to place. Emotional attachment was expressed in terms of satisfaction with the physical environment. Cognitive attachment was expressed as a conception of what was possible within the environment. Finally, behavioral attachment was exhibited through the level of contact between and among members of the environment.

In their study of the interconnectedness between religion, identity and attachment to sacred places, Mazumdar and Mazumdar add further evidence of the behavioral expression of place attachment. In examining the attachment of Hindus to their residences, they found that through a series of personal actions, attachment was both created and then reinforced. Initially, through purification of the exterior of a home and the sacralization of the inside of the home, attachment to the home as a sacred place is created. That attachment is then maintained through on-going behaviors or rituals. What is clear in their findings is that not only are these rites and activities an expression of a behavioral attachment to place, but they are also an expression of religions (cognitive) and emotional connectedness to space (237).

\section{Singer-Loomis}

In addition to the two theories described above, which explicitly link individuals and groups to the environment, there is a third theory, drawn from Jungian psychoanalytic theory, which is valuable in conceiving how humans and the environment are connected but that also provides a basis for conceiving of how public agencies can craft strategies that can draw on and capitalize on human/environment connections. This theory suggests ways in which agency staff can employ place to enhance the social bond necessary for civil society to emerge and collaborative efforts to be successful. The work 
of Jungian analysts June Singer and Mary Loomis is especially helpful in developing an understanding of how individuals and place relate, in that their understanding of Jung provides a means of describing how individuals are oriented toward their environment as well as how they take in and process information about that environment. So, beyond helping build the understanding of human/environment connections, Jungian psychoanalytic theory offers a means of assessing the activities of the agency in an effort to determine how it may contribute to or inhibit the development of the social bond through the use of place.

A more extensive description of Singer and Loomis' conception of Jungian theory can be found in Chapter 4. For the purposes of this chapter, a review of the eight modes is useful in examining the activities of the Bureau. The eight modes are:

Introverted Sensation: This mode draws on kinesthetic and proprioceptive bodily sensations - i.e. the sense of physical states such as stress, relaxation, excitement, etc.

Extraverted Sensation: This mode relates to the physical connections to life through senses - auditory, tactile, visual, etc.

Introverted Intuition: This mode recognizes symbols of the unconscious, beggar, father/hero, etc. - it is the inward imagination that generates ideas and suppositions

Extraverted Intuition: This mode allows for seeing the possibilities in a situation. Tends to be aware of ambiance over specifics of décor, tenor of a conversation over the specific of the topic - the source of hunches

Introverted Thinking: The conceptual problem solving mode - focused on ideas, concepts or symbols - characteristic of philosophers and mathematicians

Extraverted Thinking: The logical problem solving mode that is focused on the outer or physical world.

Introverted Feeling: The mode that draws connections to inner values, be they personal, family, societal - even abstract, spiritual, mystical or potentially even conflicting with other held values.

Extraverted Feeling: The mode that draws connections to others through shared experiences and recognized intrinsic value - it is the mode that draws in the human factor of decisions.

To reiterate, the inclusion of this theory is not as a means of predicting behavior or analyzing RAC members, but rather to provide a theoretical framework for understanding how individuals and groups relate to the world around them and then to examine the means by which the Bureau works with the RAC and both utilizes or fails to take advantage of opportunities to strengthen the social bond that enables collaborative 
governance efforts to be successful. The more specific value of Singer and Loomis' interpretation for this project is their use of Jung in understanding the range of senses or understandings of place that can be held and influence behavior. They recognize that while there is a shared experience of a physical place (extraverted - sensation), there are other means of experiencing and reaction to place, such as a recognition of symbols at an unconscious level (introverted intuition) or in the values participants conceive of as being part of place (extraverted feeling). Again, Singer and Loomis' interpretation is of particular value because of their recognition of the dynamic nature of Jung's theory, which allows for the possibility of different modes operating for an individual at various times or in different situations.

\section{Findings}

\section{Expressions of Place Identity and Place Attachment}

As has been noted before, Altman and Low (1992) develop a schema that proposes three dimensions -- emotional, cognitive and behavioral -- that are of value in understanding attachment to place. Combining these dimensions of place attachment with operationalized understandings of other researchers (Milligan, Mazumdar and Mazumdar, Brown and Werner and Hidalgo and Hernandez) provides a framework for examining the comments and expressed sentiments of RAC participants and BLM staff.

\section{Emotional expressions of place attachment}

Nearly all of the researchers identified above describe place attachment as including some level of affective or emotional connection to place. Conversations with RAC participants revealed a variety of comments whose language and emphasis as an expression of concern for or appreciation of places confirm the existence of this type of attachment.

While discussing how she became involved with the RAC, one member related a story about a management decision the BLM had proposed for the Black Sands area of the King Range. She noted that she and others who opposed one of the proposed management options expressed a "great cry". In addition to her emotional concern for Black Sands related to the BLMs management of that area, this participant also described how she is a California native and spent time camping in portions of Northern California. In describing her own experiences of the area, she also noted that she was appalled by the loss of redwoods.

Another participant, upon reflecting back on his involvement with the RAC as well as a variety of other activities on and around the public lands noted that, "I still have a love for the land". This same individual provided a briefing to the RAC during the January 2002 business meeting on the activities of the organization he is affiliated with. In his concluding remarks he commented that "there are a lot of treasures out there," referring to his perception that are extensive and beautiful holding as a part of the public domain. 


\section{Cognitive Expressions of Place Attachment}

Cognitive attachment to place is operationalized in this analysis as intellectual or rational consideration of the land, the activities that occur on the land and participants relationship to the land. For example, one RAC member started off by commenting on his emotional attachment to the land by saying, "I live in a place that's too damn beautiful." He continued though by giving an indication of his cognitive attachment to or intellectual consideration of his relationship to the land, saying, "I have to do it (be involved) even if I'd rather be elsewhere. It's about saving the wilderness." That is, in addition to his emotional attachment to the land, this RAC member has given thought to what that attachment means to him and where it fits in his scheme of priorities and activities.

As he described the work that he does and how he became a member of the RAC, another individual provided evidence that he, too, had some level of cognitive attachment to place. He described his work and involvement in the BLM's wild horse and burro program as well as trail access issues by saying that he believes in the importance of "taking care of and preserving the environment and the lands."

Other participants demonstrated a cognitive attachment to place in their efforts to build their knowledge in a way that supports their attachment to place. One participant noted that after taking a job which, on a day-to-day basis with the public lands, he started taking an extension course on environmental policy and ended up taking all of the courses offered on the subject. Another RAC member related that after moving to the area, he studied natural resources planning and interpretation and then switched to management/policy and communications, because it seem to better suit his needs working for a local environmental advocacy organization. While one interpretation of these actions would suggest that taking these courses merely supported their professional activities, the fact that both individuals had given up alternate jobs or careers that were not connected to the public lands or place adds weight to the likelihood that taking place related courses is an expression of the cognitive dimension of place attachment.

A conversation with another RAC member indicates that he had given extensive thought to the place in which he resides, its significance in his personal history, and why it is important to him. He began by noting that while he was at university, he discovered the west and the landscapes there, particularly the Pacific Ocean, saying that "it's just fantastic". He then turned this expression of emotional attachment toward the cognitive dimension by saying that he felt that there is lots of public access and a spirit of access, that keeps western places open, more so than on the East coast. He continued this thread of conversation indicating his cognitive attachment, by noting that he is trained in the fine arts, especially sculpture ad so "I am aware of forms and structures." He was struck by the lack of sympathy for the positive things in the landscape. Later in the same conversation, he commented, "I love the complexity of the old growth." Again, he then moved from this expression of the emotional dimension to the cognitive dimension through an intellectual description of that complexity such as the interconnections between species and the impacts actions have on place. 
The final dimension of place attachment described by Altman and Low is behavioral. RAC members generally expressed two behavioral place attachment in two general ways: in their recreational activities and their professional activities. A number of the RAC members indicated that they were sportsman and had spent significant amounts of time on the land pursuing those activities. Two of the RAC members who lived in the Sacramento River Valley mentioned that they had done a great deal of fishing in the area. One of these RAC members also noted that he had also hunted on the public lands for a number of years after moving to Northern California. Another longtime resident of the area also noted that he had also hunted extensively on the public lands in Northern California and proudly showed off a buck that he had killed in the Trinity Alps.

Several other RAC members noted that they were avid trail users and identified that as a source of their attachment to place. One person stated that he had hiked "every significant land holding of the BLM" in Northern California. Another described how both he and his family had a long history of equestrian activities, including the Tevis $100^{5}$ on the public lands in Northern California and more recently had become involved in the ultra-running community in the area as well. This person also mentioned that following our meeting and conversation, he, his wife and his daughter were driving to Auburn CA, to run on the Western States trail (see foot note \#1 below). A further RAC member provided a link between those who had behavioral attachments through recreational activities and those who had behavioral attachment through professional activities. This person was a long time OHV enthusiast who had driven most of the accessible off highway trails in Northern California and also made a career change to the OHV industry starting in the early nineteen-eighties. "I opened a 4WD shop in 1981, which we ran until 1994. I joined the California 4WD association in 1986 and later became the field rep for the association. I'm in my eighth year in that position."

In addition to this RAC member who was able to shape his recreational interests into a professional position, other RAC members provided evidence that their professional lives are a behavioral expression of place attachment. One example of this was provided by a RAC member who had spent much of his life as a steam fitter at the geo-thermal fields in the area around the Ukiah Field Office. In addition to his work as a steamfitter, he held a grazing lease to roughly 1400 acres near Lakeport and noted that he and his family spent 12 years living off the ranch only. Another RAC member shared a similar experience that also indicates a professional behavioral attachment to place. After moving to the coast, he spent time working on fire teams in the eastern part of the state and became concerned about the health of the forest. This lead him to get involved with campus organizing at the College of the Redwoods and then at Humbolt State University and finally taking a position with a regional environmental organization. In this case, professional behavior and decisions were driven by attachment initially to the Northern part of California and over time, to a narrower region in Northwest California.

Another RAC member, one who had early described his behavioral attachment to place through his recreational activities, also noted professional activities that express a behavioral attachment to place. As a member of a County Board of Supervisors, this person became a member of the Sacramento River Conservation Area, a stakeholder group which includes 10 counties looking at a belt along the river from Redding to

\footnotetext{
${ }^{5}$ The Tevis 100 is one of the most well respected endurance horse events in the country. It spun off the Western States 100 trail run, which is one of the oldest and most prestigious ultra-marathons in the world.
} 
Sacramento. Through his work with this group, he described a strong connection to and awareness of the issues on the lands around the Sacramento River. A second elected official and RAC member also described a behavioral attachment to place related to his profession. After being elected to the board of supervisors in 1997, this individual it took a year of work and many endorsements to become a member of the RAC. He explained that this effort made sense because the land in the county is $90 \%$ federally owned. While the decision of both of these individuals to become involved with the RAC can be viewed as a political decision driven by the relationship between their localities or constituencies and the Bureau, the fact that RAC membership requires time and commitment well beyond the basic responsibilities of their elected offices indicates that it is also a behavioral expression of place attachment.

\section{Expressions of Place Identity}

The second theory that provides a means of understanding the connections between individuals, groups and the environment is place identity. The existing research that most shapes the operationalization of place identity used here is Twigger-Ross and Uzzell's use of Breakwell's four elements of identity: distinctiveness, continuity, self-esteem and self-efficacy.

\section{Distinctiveness}

Existing research on this dimension finds perceived distinctiveness in terms of identification with a particular settlement or as being a "country", "town" or "city" person (Lalli, 1992; Hummon, 1990; Feldman, 1990) and that people use these types of place identification to distinguish themselves from others. There were few strong references to how RAC members perceived themselves to be distinct from those who live either in other parts of the state or from those in other regions in Northwest California, as in most cases they were more focused on the areas of similarity among themselves rather than highlighting characteristics that distinguished them for each other or others.

However, there were some indications that there is at least a subtle culture of distinctness associated with being from this area of Northern California. For example, local media often refer to the "Nor' State" area and the "North Country" when describing where they are and who lives there. It seems clear that this is more than merely identifying a geographic location, but is largely an effort at establishing and reinforcing the uniqueness of the people who live in that part of the state as well as the information and products they consume. Also, each of the BLM Field Managers and Public Affairs Office made comments about the benefits of having RAC members who lived in and around the BLM lands in the District. The BLM staff felt that this gave them a better understanding of the issues related to land management in that area, i.e. RAC members are distinct from those who live outside the region. Going even further, one BLM Field Manager noted that not only is there some awareness that the RAC members see themselves as distinct from those living in other areas, but that those distinct characteristics are a benefit to the function of the RAC. That is, if they were all from another region, they may be interested in the issues, but they would not have the same background and knowledge as those from the area. The comments of one RAC member further support this likelihood by noting 
that people consider themselves to be totally different from other parts of the state... Northern CA v. Southern CA and Coast v. Valley.

\section{Continuity}

In addition to distinctiveness, Breakwell's 1996 work indicates that the desire to maintain a sense of continuity in one's self concept is also a motive for action.

Continuity can be understood as continuity over time between past and present selfconcepts. The concept of continuity is further divided into two types of individualenvironment relationships: place-referent continuity and place-congruent continuity. Place-referent continuity suggests that the identification of place and objects in a place as well as experiences and actions associated with place that are associated with one's memories can create coherence and continuity in self-conception (Korpela, 1989, 251). By contrast, place-congruent continuity maintains a stable self-conception through characteristics of places that are generic and can be found more than one specific place.

The comments of a number of RAC members indicate the kind of longevity and strong, intentional association with specific places that is associated with place-referent continuity. One long-time resident of the area noted that he originally moved to French Gulch when he was 9 years old, moved away for a time as a young adult and then chose to move back in 1971. Moreover, this individual said that his step-father worked in the timber industry in and around this area, which suggests that previous experiences in this geographic area are important to his personal history and self-concept. Two other members of the RAC shared similar experiences of opportunities to leave the area for educational or professional reasons, who later returned, at least in part because of personal connections to the area.

Another individual, who recently retired from participation on the RAC, related that not only was he a longtime resident of the area, but that he also had 40 years of experience as a voluntary member of the BLM's State Advisory Board, District Advisory Committee and then most recently the RAC. In addition to this individual, three other RAC members indicated that they were not only longtime residents of the area, but that each also had close ties to place through either ranching or equestrian activities.

Although there was less evidence of place-congruent continuity, at least two RAC members did make comments that suggest that they identified with characteristics in this or previous environments that helped them maintain continuity in self concept. The first revealed that his father had worked in the timber industry in another area along the west coast. As a result, he had spent his early life, prior to moving to northern California in a similar environment to the one in which he chose to spend his adult life. Further, for a portion of time that this individual had chosen not to live in northern California, he lived in Eugene, Oregon, and at that time, gave up pursuit of a career in medicine and started instead to work as a logger. Although it was initially a means of earning money for school, he eventually made the decision to stay in the industry and noted several times that he would not change his choices if given the opportunity. One other RAC member noted that he had spent the formative years of his childhood in Montana. He later married a mid-western girl who did not like the cold, but would live in Northern California. His comments suggest that the choice was a compromise that allowed him to maintain some consistency in his experience of place. That is, the characteristics of the 
area in Northern California where they settled were consistent enough with his earlier experiences to maintain a sense of continuity.

\section{Self-esteem}

Twigger-Ross and Uzzell define self-esteem as "a positive evaluation of oneself or the group with which one identifies; it is concerned with a person's feeling of worth or social value (Twigger-Ross and Uzzell, 1996, p. 208)". Korpela found that the experience of favorite environments can support self esteem. Lalli and Uzzell separately found that individuals can develop a sense of pride by association when living in historic towns. Twigger-Ross and Uzzell point out that the support of self-esteem related to the environment is more than a mere positive evaluation of the environment. That is, evidence that this dimension is in operation would consist of more than comments that an individual likes a particular place. It requires that the place positively contribute to the individual's self-concept.

One instance of place related self-esteem was encountered following a conversation with a RAC member who had acquired several small tracts of BLM land in a land exchange. Despite having had knee surgery several fairly recently, the individual offered a guided tour of some the new and old property near his home. During the course of a short hike, the individual showed a series of old and new timber plantings and explained the experimental nature of the new planting in terms of how some seedlings were on shaded slopes and others were in the shade of existing stands, in hopes of determining which grew faster and was more productive. In the processes of the tour he also showed off a giant Douglas fir tree, which he explained was his favorite tree on the property. One several occasions, the individual noted how excited he was to have acquired this land. Taken in total, the tour this individual lead, the things that were pointed out and the language used all indicate that he both had great pride in the place, but also derived a positive emotional boost from living and working there, all of which are consistent with Twigger-Ross and Uzzells notion of place related self-esteem.

A further indication that the RAC's work supports the development of a place based sense of self-esteem was revealed in a review of Busniess Meeting Minutes immediately after the RAC finalized and voted on the Standards and Guidelines for Rangeland management. Members of the RAC asked that the BLM publish notification of the Standards and Guidelines' completion in agency publications as well as local media in order to celebrate their completion (March 1-2, 2000 RAC Minutes). This stated desire to celebrate the successful completion of the explicitly place specific standards and guidelines indicates some sense of self-esteem as related to the RAC's work, as well as some sense of self-efficacy. That is, the connection between the development of the Standards and Guides and the specific topography of northwest California, combined with the desire of the RAC to publicly announce and celebrate their completion, indicates that there was a sense of pride attached to the place and the work in which the RAC was engaged. 


\section{Self-efficacy}

Self-efficacy can be understood as the belief of an individual, that he or she has the capacity to meet demands of a situation. As it relates to place, one's sense of selfefficacy is maintained when the environment supports or at least does not interfere with a person's everyday lifestyle (Twigger-Ross and Uzzell, 1996, p. 208). Winkel (1981) suggests that a manageable environment is one in which those who reside there are able to collect and organize place related information in such a way as to predict whether or not that environment supports or hinders their ability to achieve goals or purposes. Winkel also indicates that self-efficacy is connected to both the physical and social environment. Manageability becomes not only what the individual can do to affect the environment but also how the physical and social environments affect his ability to function.

Two primary examples of how place affects a sense of self-efficacy were revealed by RAC members. The first was revealed in the comments of a timberman who not only had lived and worked in the area for most of his adult life, but whose stepfather also worked as a timberman in the area. This individual noted that his stepfather had always told him not to become a timberman, because he believed that timber would someday run out. In this example, the place has supported this individuals sense of self-efficacy in that, not only has there continued to be timber sufficient for the industry to survive, but also because he was able to make a career for himself and support his family as a timberman.

The second example also relates to the timber industry in the area. In this instance, a RAC member noted that his father had worked in the timber industry until the local mill closed, putting his father out of work. This individual stated that rather than placing responsibility on environmentalists for the mill closure, his father had blamed the industry for over-harvesting. As an adult, this individual was influenced by this experience to make his career with a regional environmental organization that works to establish and protect wilderness areas. In this example, despite the experience of a family member's job loss, this individual's ability to establish a livelihood was supported by a connection to place.

A number of other RAC members shared comments that suggest that rather than having a sense of self-efficacy because the environment does not interfere with their lifestyle, develop a sense of self-efficacy because they are able to manage or affect the environment. For example, one participant shared a story of how he first came into contact with the local BLM Field Office and their use of advisory groups. He related that he became involved with the Shasta-Chappie OHV park when the BLM management plan called for trails that would have come into a watershed above the town where he lived and owned property. He got involved opposing the development of these trails, was asked to join an implementation team, and realized success in his efforts in that there are not any OHV trails in the watershed now.

Another RAC member described his involvement as an advisor to the Northeast California RAC (NERAC) and one of the Nevada RACs, both of which are dealing with $\mathrm{OHV}$ issues in the Black Rock Desert. A subgroup of the NERAC and the Nevada RAC, 
which includes other federal agencies as well as state, tribal and multiple use advocates, is helping develop various alternatives, including the preferred alternative, for the EA/EIS. This experience contributes to this member's sense of self-efficacy in that he has had the opportunity to shape the proposed management of a place that he has a direct connection to.

One other RAC member described his move from the East Coast, at which point he joined a forest fire team and spent about a year in the Sierras. During that time he developed concerns about the forest health, among other things, and moved to the coast where he became active with student environmental organizations and later joined the board and became a senior staff member of a regional environmental organization. In the capacity first as a fire fighter and later working with environmental organizations, this individual has engaged in a range of place related activities that would support his sense of self-efficacy.

Upon examining the comments and experiences of the RAC members, it seems clear that there is strong evidence that most if not all express some place connection, be it place identity or place attachment. The question remains, however, as to what extent, can or does the Bureau utilize or enhance this connection to place as a means of building the social capital necessary for collaborative governance initiatives to be successful. The next section of this chapter describes what observations of RAC processes, conversations with RAC members and a review of RAC documents reveal about how the Bureau functions related to these issues.

\section{Reference to Place and other contributions to social capital}

This section examines data gathered from conversations with RAC members, observations or RAC processes and a review of BLM documentation of RAC proceedings. The findings of this review are organized around the modes described by Singer and Loomis. As noted before, the use of Singer and Loomis' understanding of Jung is not intended as a means of psychoanalyzing participants nor to predict behavior, but rather is used as a means of framing the various ways that individuals perceive the world around them, particularly in this case, place. Stated differently, the modes provide a means of assessing the activities of the BLM and the RAC in order to determine how those activities and their implicit and explicit references to place would be perceived. Earlier descriptions of Singer and Loomis' conceptions of Jung in this chapter and in Chapter Four presented the modes in the order described by the two analysts. It is also worth highlighting again that Singer and Loomis' conception of Jung's theory is both dynamic and interactive, such that the modes are not mutually exclusive and there may well be interplay and overlap between them.

In this section, the findings are presented in a two-tiered schema. The first tier is organized around specific activities or processes used by the BLM and the RAC which appeared in RAC members comments, observations, BLM documents or some combination there of. The second tier of the organization focuses on which of the eight modes the RAC activities call on, generally focusing first and more heavily on the extraverted modes followed then by the introverted modes. This order has be chosen because, not surprisingly, instances of RAC processes that call on extraverted modes, or 
those that tend to be focused on the external world, tended to be expressed more often and with greater emphasis than instances that call on introverted modes.

\section{Field Trips}

The first of the RAC activities and processes that stands out as a means by which the Bureau has contributed to the development of the social bond by drawing on and building RAC members connection to place is through the use of field trips. The Bureau has a long history of conducting field trips as a means of getting participants of its various advisory groups out onto the land in order to better understand the management issues of specific areas. One RAC member who had been a member of various advisory groups for 40 years shared a story of one field trip in particular, when the Bureau transported the entire advisory group by helicopter to the management area in question, taking along tents and food for several meals, in order that the advisory group could gain an understanding of the issues faced by the Bureau in its management of the area.

Current RAC field trips, while not as extensive or elaborate, stand out in the comments of both the RAC participants and Bureau staff. RAC field trips tend most often to be day trips, organized around the BLM's Field Office that is hosting the business meeting the following day. In most cases, field trip sites can be reached within a reasonable drive from the Field Office. In those cases that it is important to conduct a field trip to a site that is too remote from any of the Field Offices to conduct a day trip, the Bureau will typically make arrangements to host the business meeting in the nearest town with adequate facilities for the meeting.

Without exception, when discussing the field trips, RAC members and BLM staff noted the value of the experiences in one way or another. On closer review, many of the comments made during extended conversations support the notion that the field trips call on Singer and Loomis's modes, starting with Extroverted Sensation. Briefly, extraverted sensation can be understood as the physical connection to the world, through the senses. A third of the participants and two of the Field managers made comments consistent with this mode. Among these comments, one RAC member noted that the field trips were their means of getting out and seeing the areas and becoming aware of what is going on on the ground. Another went so far as to say that the field trips offer the first change to "see, smell, and taste" the areas they are talking about.

The Field Managers also noted the importance of the experience in terms of extraverted sensation. One acknowledged the importance of the field trips saying RAC members "have to see how the thing looks" in order to understand the issues and contribute to a recommendation. Stated another way, this same Field Manager suggested that the field trips were a means of gaining what he described as "ground truth," or the detailed level of understanding necessary to engage in a discourse about which of many management alternatives is appropriate. Another Field Manager described gaining a local flavor or "sense of place," which is needed for the same reason.

The second mode that a variety of RAC member and BLM staff comments connect with is extraverted thinking. Loomis describes the extraverted thinking function as that which connects one to the physical world and provides the means of breaking down problems into constituent parts such that it can be dealt with in a logical, reason and efficient manner. 
All three of the Field Managers made comments to suggest that the field trips provided an experience of place such that members called on or applied this mode. One example of how the field trips acted within this mode arose in the comments of a Field Manager who led a field trip to a regional lake. As noted in the last chapter, management of Lake Berryessa currently falls to another federal agency (BOR), but it has been proposed that the BLM would be better suited for the task. The Field Manager indicated that the RAC had the opportunity to see the lake first hand and discuss the management issues at the site and in the vehicles following the field trip. According to the Field Manager, "they were able to articulate what they saw as the bottom line - the problems we (the Bureau) would face if we were to manage the lake." Another Field Manager, who was noted above as describing the field trips as a means of gaining what he called "ground truth," used the term again, in this case to describe RAC members assessment of problems and options available to the Bureau. In this situation, he noted that the field trips were a means for the RAC members to "ground truth the options" or to test the options, positions offered as a potential course of action. That is, the field trips enabled the RAC to apply some logic or rationale to the assessment of the situations and places they experience.

Here again, a third of the current RAC members made statements that corroborate the connection between the field trips and Singer and Loomis' Extraverted Thinking mode of perception. One RAC member noted that the field trips had the effect of getting them away from abstract arguments and enabled them to be more practical and efficient. Another RAC member, who was involved in the group's initial work developing the Standards and Guidelines, commented on how the field trips moved them away from emotional positions of whether or not there should be cattle on BLM lands to a reasoned, fact based discourse about what the best management practices were in terms of prescribed burns, herbicide use, fencing and so forth. Still another RAC member reflected on his experiences seeing a particular site from multiple perspectives. He stated that while he thought he had an understanding of the area from his prior experience, the field trip allowed him to see a new perspective and better understand and evaluate the management implications. Here again, the field trip and experience of place connected with the extraverted thinking mode and allowed individual RAC members as well as the entire RAC to draw on that mode.

Turning now to the next mode, Extraverted Feeling can be understood as the mode that connects us to other human beings through shared experiences and recongnition of the intrinsic value of the "human factor". The development of strong human relationships is closely linked to this mode. During a conversation with one of the BLM staff, this individual noted that the field trips are one of the places where one sees RAC members interacting most directly. He noted that one often sees the diversity of the members spread across each vehicle. Observations from the January, 2002 field trip supported the assertion that members were well distributed around the BLM vehicles, often with commodity users, environmentalists and local government officials not only sitting in the same vehicle, but often sitting next to one another engaged in conversation both about the issues seen on the field trip as well as any of wide range of other topics both personal and professional.

RAC members noted similar experiences during field trips, in one case saying that "it's real and it breaks down barriers, both who we are as different and who we are as 
similar." Another member reflected back on a camping trip to one of the areas that the BLM is responsible for managing, also saying that the experience, "brought us all together" both literally and figuratively. He meant literally in that the group was physically together and were provided with an opportunity to develop their relationships, and figuratively in that they members were able to get a common sense of place and the issues of place together.

Another shared experience that was raised by a RAC member as having a similar effect included BBQs hosted by a local youth organization at one of the field trip sites. Despite the political and ideological differences the individual members of the group brought with them, this experience appears to have contributed to the group's shared connection to place. Here, again, five of the fifteen members of the RAC mentioned experiences associated with the field trips, experiences when the group was together in place that helped build or reinforce the personal and group relationships that the extraverted feeling mode benefits.

Although there was far less evidence that the field trips called on extraverted intuition, comments from a few respondent's comments did suggest that it was present to some extent. Extraverted intuition is as the mode that allows us to "see the possibilities in a situation (Loomis, 1991, p. 83)". It is the mode that allows one to be aware of the ambiance of a room as opposed to the details of the décor or the tenor of a conversation over the specific words and phrases. One example of how the field trips call on this mode was expressed in the comments of one of the newest members of the RAC. After her first field trip, she commented that she and the rest of the members who were riding in her vehicle spent a lot of time talking about the landscape. She reflected that rather than talking about current management issues they talked about the history of the area and various historic issues. She felt that this set the context for her later participation in management related discourse.

In another instance, the RAC took a helicopter trip, overflying an area under consideration for possible OHV use. Initial assessment of the site on paper suggested that it would be ideal for OHV usage. Based on the collective sense of the place that developed among the members while visiting the place, the decision was made not to recommend OHV use. In part this was an expression of the extraverted sensation mode, in that they group saw the land, but moreover, one RAC member's comments indicated that it was their general sense of the place, the ambiance of the place, that lead the group to decide against recommending this.

Others RAC members also noted that the experiences on the field trips opened their perspectives and also tended to help keep the rhetoric down. While the operation of this mode is subtle, it seems possible that what is occurring here is that the experiences and shared context of the field trips help members be more attuned to the subtle expressions of what some RAC members described as rhetoric and others described as party line. That is, findings from the interviews directly and indirectly indicate that as members become attuned to the context and tenor, they were less likely to tolerate either explicit or more subtle, politically charged language and similarly, were less likely to use it themselves. This is a crucial indication that a social bond has developed among RAC members.

Although the introverted modes are focused inward, towards emotions, unconscious symbols and other aspects that are not part of the external or shared world, there do seem 
to be some aspects of the field trips that call on introverted modes, namely introverted thinking and introverted feeling. Introverted thinking is described by Loomis as problem solving, which involves concepts, ideas or symbols and is primarily concerned with gaining knowledge or meaning. It is the mode used by philosophers and mathematicians (Loomis, 1991, p.84). Several RAC members and BLM staff noted that the filed trips give the opportunity to look at issues from various perspectives. For example, one RAC member referred to a float trip on the Sacramento River above Red Bluff and his recognition that it was "a totally different area and type of country." On seeing the same river in a different place, he found it easier to understand why people feel differently about the use designation of the river. In effect, seeing the variations in the geography and characteristics of the water that were different than those in his community further down stream, he not only viewed and gained an understanding in a new context, but place had the effect of putting him into a stance where he exercised his introverted thinking mode in order to work through the issue from a different perspective.

In contrast to introverted thinking, introverted feeling provides the connection to one's inner values, in a manner unlike the application of intellectual logic alone. Many of the RAC member comments regarding their emotional attachment to place are indicative of introverted feeling associated with place. One RAC member, when concluding comments at the RAC business meeting regarding a wilderness proposal his organization is working on, noted that "there are still a lot of treasures out there," referring to BLM lands, some of which that had been sites for earlier field trips. Two other members, when describing their connections to the BLM prior to becoming RAC members, described their attachment to a BLM land acquisition that includes one of the few remaining stands of old growth redwood. Both individuals commented that that acquisition and the management questions associated with it had been among the primary reasons for their early contact with the BLM and interest in the RAC. Management of that acquisition remains a recurrent agenda item on RAC meetings and has been the site of two field trips. So although introverted feeling is associated with inner values, it seems clear that it can be expressed through an association with place and that the field trips provide a strong enough connection to place to support its expression.

There seems to be reasonably strong indications that the use of field trips by the BLM can drawn on many of the eight modes described by Singer and Loomis. That is, the field trips, visits to specific places, can draw on the various modes of perception and understanding, suggesting further that there is a link between the activities that the Bureau has the RAC members participate in and their connection to place. While all of the eight modes are always in operation in each individual, it is also true that individuals have modes that are dominant or stronger. By utilizing processes and procedures that access a wider range of the eight modes, the agency is more likely to see the connection to place emerge and therefore the group will achieve better results than if the agency focused only on one or few (probably extraverted) functions.

Further, the frequent comments by RAC members that they can better see other perspectives, gain a common understanding, and find common points of agreement suggests that this connection to place is contributing to the social bond between members and enables them to work together more effectively. 


\section{Business Meetings}

As noted in the example above referring to the acquisition of the Headwaters Reserve, it was noted that not only was the site a destination for two separate field trips, but that it was also a recurrent agenda item for the business. This connection between filed trips and business is the second area of BLM activities that highlights the connection between RAC members, place, and the development of the social bond. There appear to be at least two ways that the activities of the RAC business meetings help strengthen the members' connection to place and therefore the development of the social bond. The first is the inclusion of agenda items focused on the places that have been sites for field trips. The second is the inclusion of agenda items that, while not the sites for field trips, are focused on specific places or types of places with which the RAC or individual members have intimate, first hand experience.

A review of the meeting minutes from the last nine RAC meetings ${ }^{6}$ reveals that of the nine unique places that were addressed as specific agenda items, four of them were also sites for at least one field trip. Two cases, Headwaters and the Sacramento river, were the sites for more than one field trip each. Three other places were similar in use or issue. The Klamath River, like the Sacramento, is under consideration for Wild and Scenic designation. The Cow Mountain and Knoxville OHV sites share many general land and specific trail and management characteristics with the Chappie Shasta OHV area. One final area, the Weaverville Community Forest and viewshed, has been proposed as the future field trip. It seems likely that individuals who have strongly developed Extraverted Thinking, Introverted Thinking or Extraverted Sensation are likely to respond to this sort of connection between Business Meeting agendas and Field Trips. Simultaneously, these connections between RAC activities is likely to build and support the sense of cognitive attachment to place described by Altman and Low.

Lastly, in terms of the RAC activities building a shared sense of place identity, there is evidence of RAC membership contributing to a sense of self-efficacy. One member noted that, "My town (Junction City) is surrounded by BLM land. Their management has a bearing on what we can do in our back yards." He continued by explaining that he felt that it was important to have an influence on what happens on the other side his and the remainder of his town's fences. In this instance, it appears that RAC membership and activities supports the self-efficacy element of Place Identity by enabling members individually and collectively to affect their own and their communities' lives through place oriented action. In part this operationalizes the extraverted thinking and extraverted sensation modes of Singer and Loomis' framework. The extraverted thinking mode operates as the official can exercise his own individual logic as well as the logic of the entire RAC to make management recommendations in response to specific conditions around his town. The extraverted sensation function operates in that it is the mode by which he sees the effects of the RACs work on land management adjacent to his town.

\footnotetext{
${ }^{6}$ BLM policy requires that minutes be retained by the Field Offices for no less than three years. As a result, minutes for meetings prior to December of 1999 were not available for review. However, conversations with RAC members and BLM staff suggest that earlier meetings were essentially the same in the parallels between agenda items and field trips.
} 


\section{Other Non-Place Contributions to the Social Bond}

Beyond the place connected RAC activities that contribute to the development of the social bond, there appear to be at least two non-place connected activities that also help develop the social bond. The first of those is the conscious addition of social times to the RAC agendas. The social times take two related forms. The first is the informal times around meals during both the field trip and the business meeting. This meal times are unstructured and allow members of the RAC as well as the BLM staff to mingle and interact with one another in unstructured ways.

In addition to the informal meal times during the field trip and business meeting, the Field Office which hosts each meeting also organizes a slightly more formal dinner for the evening between the field trip and the business meeting. This meal has taken forms ranging from camping trips to various BLM recreation areas, meals at local restaurants to the recognition dinners hosted to recognize the retirement of longtime RAC and DAC members. In most cases, there is no formal agenda associated with these meals. All of the BLM staff contacted indicated that these social times had a substantial impact on the relationships between and among the members of the RAC as well as the BLM staff. In a comment that was typical of the impressions other BLM staff shared, one staffer indicated that these social times not only developed "personal level connections" but that they also "feed the process in the formal meetings" as well. RAC members noted on several occasions that their conversations during these social times were fairly diverse. For example, one RAC member noted that it was not unusual to see a member of Group 2 (members of local and regional environmental organizations) sitting, eating and talking with members of Group 1 (resource user groups such as ranching and mineral extraction). Further, it was just as likely that these individuals would be talking about RAC issues as they would be to talk about non RAC issues (six and observations of lunches and formal dinner). The interaction at lunch during the field trip that took place during the January, 2002 RAC meeting further supported the sense of diverse interaction during social times. The largest group that congregated at lunch was composed of two timbermen, one recreation representative, two BLM staff, one rancher, and one environmentalist. The conversation during this lunch covered a variety of topics, including discussion of RAC business items and several topics not directly connected to RAC activities. One member even indicated that he made a conscious effort to make sure he interacted with and included everyone in social times, especially if he felt they had a different perspective than did he. He noted that he felt it was important not only to interact with everyone in order to get to know each person, he also wanted to be sure that no single person would become isolated or excluded from the group and the group's interactions. Taken in total, RAC members and BLM staff members' comments and observations of the RAC suggest that the social times, both the informal and more structured times, do contribute to the social relationships between the members.

One other issue emerged from conversations with members, which seems to contribute to the nature and dynamics of the social bond between and among the RAC members as well as with the BLM staff: member selection. Several RAC members noted how important they felt it was that the other members of the group had taken a stance that 
allowed or enhanced the group's ability to successfully work together. Some individuals indirectly described the character of the RAC's membership by noting their attitude about the group as being shaped by their opinions of the members. For example, one individual commented that he was having a pleasant and fun experience on the RAC, "Primarily because of the other members." When asked about the character of the RAC members and how new members were identified and selected, several of the BLM staff indicated that they consider not only the perspective that a potential member brings to the RAC, but also whether they have a willingness to work through a collaborative process. The attitude regarding the character of the RAC's membership is perhaps best summed up by the comment, "The BLM chose members well".

\section{Barriers To the Emergence Of the Social Bond}

Although there are many indicators that RAC members do have a strong connection to place, that RAC activities support and enhance individual and collective connection to place and most importantly, and that these connections contribute to the emergence of the social bond, there are nonetheless barriers that hinder the development of the social bond. These barriers, in large part, are related to BLM processes and procedures, in some cases shaped by agency or administrative culture, and in others directly tied to formal legislation and regulation, which are inconsistent with a relational process model such as that implied by the RAC.

An initial barrier that can be identified from comments of both BLM staff and RAC members is a sense of uncertainty about the current and future focus of the RAC. When the RACs were chartered in 1992, the initial mandate from the Washington Office of the BLM was the development of Standards and Guidelines for rangeland management. Following the completion of the Standards and Guidelines, each individual RAC has had greater autonomy in identifying what issues or concerns should receive its attention. In the case of the Northwest California RAC, there has been some perceived difficulty identifying one or a set of issues to take on. As a result, members and BLM staff are having difficulty focusing their attention and energy and the group is struggling to find direction. One member noted that although they get reports on issues and areas, they "get lost in the shuffle." The BLM also feels this lack of focus, as is indicated by their own efforts to determine what role the RAC should take in the operations of the agency. One BLM staffer's rhetorical question "Where do we see value of the RACs within the context of the state, federal and field office priorities?" shows their own efforts to identify issues and purpose for the RAC. Another Field Manager noted that following the completion of the Standards and Guidelines, the RAC's identity was less clear.

Another barrier that many of the RAC members noted and that the BLM staff seemed aware of as well, revolves around the orientation that new RAC members receive when joining the group. Currently, new members receive little if any formal orientation to the group. This was, however, not always the case. The few RAC members who have been on the Committee since its initial charter in 1992 or who were members of the prior District Advisory Committee indicated that they had taken part in an extensive and formal orientation program. This orientation lasted at least two days and was aimed at members gaining an understanding of the BLM's history and organizational structure, the RAC's authorization, its charter and requirements, expectations for the group, decision 
making processes entailed in the RAC, and the specifics of 'consensus' as it is defined by the charter. The orientation also was structured to provide new members the basic knowledge that would be required as they worked to make decisions and recommendations. For example, the initial RAC orientation included training for all new members on the basic concepts of rangeland management and health so that they would be prepared to engage in discussions of riparian area health, carrying capacity, etc.

The current orientation is much less formal and less extensive and is primarily made up of a briefing by the BLM's PAO and in some cases the local Field Manager. Members' comments also indicate that there is some uneveness in the content of what little orientation there is. One current member indicated that there had been little more than a welcome and introductions to other members. Another member indicated that some reading materials had been provided as a way to learn about the organization and the RAC. One of the BLM staff members went so far as to say that new members learn "mostly through osmosis,' suggesting that they pick up the basics of what the group does and how it functions from experience and from the other current members.

Members themselves and BLM staff both seem aware of the lack of formal orientation. One long standing member of the RAC, when asked to describe the orientation he received, commented that he did not know how newer members could function without a more formal orientation. Another newer member suggested that there was a need for a 'new members manual' that would help new members get up to speed both on the processes and issues of the RAC. The BLM staff indicated that there has been some discussion of development of such a manual or other more structured orientation process, but no action has yet been taken.

The difficulty raised by the current lack of a formal or structured orientation process is that there is considerable variation in members' understanding of the group's processes, expectations, history and general culture. That is, the lack of an orientation limits the development of a shared understanding among group members, while the existence of consistent orientation would support the development of relationships between and among members, through creating a common procedural and organizational context. This has been problematic in instances when the group has taken on contentious issues. That is, because there is variation in individual member's expectations and understandings of how the group will function and what outcomes are possible, the group has had to struggle not only with the issues themselves, but have had to simultaneously develop a common sense of its culture. While all groups must work through the various stages of group process, having an established orientation would likely minimize the time and energy spent working through the early (forming and storming) stages of group process.

A more specific barrier, one that stems in part from a lack of orientation, is confusion about the RAC's charter and requirements, particularly its voting and consensus requirements. More explicitly, the requirements imposed on the RAC by the charter, are inconsistent with a relational model of group process and tend to impede the development of the social bond. As was noted earlier, the RAC is organized around three constituent groups, four resource users, four regional or national environmentalists and four local government officials and/or academics. The RAC charter defines consensus as a majority vote from each of these three groups, i.e., three members of each group must vote for a recommendation in order for it to be forwarded on to the Bureau for action. 
This requirements has given rise to two issues of difficulty for the RAC. First, several RAC members indicated that they feel that consensus should be defined as what all members of the group can live with, rather than based on an interest representation scheme. Second, RAC members also feel that this consensus scheme, and its associated quorum requirement, are too stringent and limit the RACs ability to make recommendations to the Bureau. Both concerns, quorum and consensus as defined in the RACs charter, hamper the group's ability to work from a relational model.

One final issue that emerged from the conversations with RAC members, but that is not yet clearly defined, is one of representation. In several conversations the issue of representation arose, most often as a sort of criticism of Group 2 members of the RAC, from members in other groups. The general criticism, explicitly or implicitly, is that environmentalists "represent" some constituency and in representing some other interest group, are not legitimate users in and of themselves. Interestingly, Group 2 members of the RAC made no comments to indicate that they shared this sense of the role or position. Although the vast majority of comments from Group 2 as well as Group $1 \& 3$ members do not suggest that this issue of representation has functioned as a barrier to civic discourse, the fact that nearly $25 \%$ of those who participated in the guided conversations mentioned the issue suggests that it deserves further consideration. Possible next steps to give additional attention to this topic are discussed in the next chapter.

\section{Summary}

A review of the findings presented in this chapter reveals several issues that should be highlighted here. First, it is clear that individual RAC members bring a strong connection to place with them to the group. In and of itself, this finding is not important to the questions posed by this research, but it does suggest that such connections are available to the agency in any effort it may make to build the social bond. More significantly, it is apparent that the agency does use processes with the RAC that are likely to capitalize on the individual connections to place in ways that build the social bond. The field trips in particular appear to support the development of place oriented social relationships in a way that enable the group to work effectively together. The clear connection between the field trips and business meeting agendas ensures that not only is the social bond developed around place, but more importantly, that the agency is creating experiences that develop a collective connection to place that enables civic discourse to occur. Moreover, it is doing so in a way that individuals with a wide range of perceptual strengths will recognize and respond to. That is, from the perspective of Singer and Loomis' understanding of Jungian psychoanalytical theory, the BLM's organization of RAC activities and experiences are structured in such a way that a wide range of perceptual modes will be potentially engaged. There is evidence that a variety of modes are expressed in this setting, but moreover, this offers the agency a new means of developing strategies that will support the expression of an effective civic discourse. This is analogous to utilizing different learning styles in a classroom, thus enhancing the total learning produced.

Although there are strong indications that the BLM is working with the Northwest California RAC in a way that draws explicitly and implicitly on place to develop a strong social bond, there are barriers to the development of these relations. Among these 
barriers is the lack of a formal orientation process that would help new members become engaged members of the RAC. While a formal orientation process is something that can be of benefit to any group process, rational or relational, establishing a mechanism that would establish a sense of context and expectations consistent with a relational model is particularly important since it is a model than is likely to be less familiar that the more common rational processes. Another barrier that seems likely to be typical of many collaborative groups established under federal agencies is the tension between the FACA imposed structure and protocols embodied by the RAC's charter and the consensus processes that are likely to be at odds with voting, representation, and quorum protocols. This tension is particularly challenging to a relational model like the one that seems to be emerging from the RAC in that it has the potential to pull members out of relationship and place them back into role stances that may be anathema to genuine and therefore fragile relationships. The implications of these findings for public administration theorists, educators and practitioners are the subject of the next and final chapter. 


\section{Chapter 7: Conclusions}

This project began with the description of a small sample of the sorts of events that many social theorists point to as examples of a disintegrating social fabric. Whether in response to an incident of mass school violence, ecoterrorism or violent protest against international financial institutions, many of those who comment on these incidents and propose solutions to them call on the long intellectual history of civil society to make recommendations that they believe will reconstruct the social fabric and social institutions.

This chapter begins with a summary and review of the major elements of the study. The chapter also describes the major implications of the findings for practitioners, teachers as well as next steps for additional and continued research.

\section{The Literary Response}

Civil society has reemerged as one response to the social climate described earlier. The civil society literature falls into three general areas and can be understood as proposing a revitalized civil society as a response to a wide range of social concerns. The first segment of the literature (e.g. Bennett, 1998; Crane, 1997) suggests that our problems stem from excessive government, one that interferes in nearly every aspect of our lives, whether by determining the contents of gasoline, the shape of computer keyboards or creating a mushrooming welfare state. For authors within this segment of the literature, civil society offers the opportunity for self-governance through the free market without interference from the state. Others, falling into a second segment of literature (e.g. Glendon, 1992; Elshtain, 1997) argue that the problems lie in the hyperconsumerism and hyper-individualism which in turn flow from the present dominance of liberal, market based institutions. They suggest that civil society can serve as a means of rebuilding the values that can in turn prevent the market from running amok. Those working within the third segment of the literature (e.g. Putnam, 1995; Walzer, 1991) lament what they identify as increasingly degraded social institutions that leave a growing portion of society without voice or leverage as to the distribution of goods within society. In this case, civil society is seen as the means of building the social capacity necessary for much broader participation in the political process.

The contemporary civil society literature locates the institutions of civil society in the space between the public/government sector and the private/market sector. In their current condition, neither the political institutions of the public sector nor the market mechanisms of the private sector are capable of providing the basis for the social bond to develop. The divisiveness of American politics and the lack of trust expressed by citizens effectively limits the ability of current political institutions to provide the basis for the social bond. At the same time, the institutions of the market presume that the social bond exists as a check on its own more corrosive social aspects. Thus it remains oblivious of the need for its social institutions to function in a way that fosters the development of the social bond.

Research like that of Robert Putnam in "Bowling Alone" implies that in the past, the social bond existed in paradigmatically common cultural, religious or political perspectives. But as Putnam's and other research suggests, the commonality of 
those perspectives no longer remains strong enough to provide a basis for a social bond. In their current constitution, both political and market institutions fail to provide a basis for the social bond. It is into this void that public organizations must move to provide the structure and create the conditions from which the social bond can emerge. The study undertaken here has endeavored to answer the question of how the BLM, as a public agency, resolves tensions between its historically rational model of operating with a more relational model that is required to support processes which enable the development and emergence of the social bond.

\section{Theoretical Framework}

One possible mechanism open to public agencies in their efforts to support the development of the social bond can be found in the relatively new field of environmental psychology. Chapter 4 describes two theories drawn from environmental psychology and one from psychoanalytic theory to outline the nature and characteristics of this mechanism. The two theories from environmental psychology that offer particular promise in showing how connection to place contributes to the emergence of the social bond are Place Attachment and Place Identity. These theories and empirical research associated with them indicate that an alternative basis for the development of the social bond can be found in physical place. That is, place can act as the source of the social bond that is necessary of any discourse to occur in the first place. Initially developed by Harold Proshansky, place-identity is described as "those dimensions of self that define the individual's personal identity in relation to the physical environment by means of a complex pattern of conscious and unconscious ideas, beliefs, preferences, feelings, values, goals, behavioral tendencies and skills relevant to this environment." (Proshansky, 1978, p. 155) Developing the theory further, Twigger-Ross and Uzzell apply Breakwell's identity process model as the basis of understanding the nature and processes of place identity. Starting from Breakwell's work, they operationalize placeidentity in four principles that govern the selection, assimilation and evaluation of information that shapes and grounds identity. These four principles are distinctiveness, continuity, self-esteem and self-efficacy. Twigger-Ross and Uzzell's research findings provide one means to assess agency activities and the impact on the RAC. Place identity provides one way for connections between individual or group and place to be expressed, that has proven useful in observing the work of the RAC and the agency's activities that use and hinder the use of place to foster a robust social bond.

Place attachment is the second theory that contributes to this framework for understanding the role place has in structuring the social bond and fostering the emergence of civil society. The major concepts drawn together under the heading of place attachment are drawn from initial work under a variety of different headings including, community attachment, sense of community and sense of place. Shumaker and Taylor describe place-attachment as "a positive affective bond or association between individuals and their residential environment (Shumaker and Taylor, 1983, p. 233)." To this, Milligan adds the idea that emotional bonds to place decrease the perceived substitutability of other places for the one in question (Milligan, 1998, p. 6) Altman and Low (1992) develop comprehensive schema that describe the range of features and aspects captured under the heading of place-attachment. Although they 
describe several aspects of place-attachment, including range of scales, types of actors, types of relationships and temporal aspects, the feature of place-attachment described by Altman and Low that is most useful for this research is the nature and organization of attachments. They suggest that attachment can be understood in terms of three distinct qualities: affective, cognitive and behavioral. Based on the research of Altman and Low, Milligan and others, place attachment provides the second tool by which to examine the agency's activities with respect to development of a connection to place.

Turning then outside of the environmental psychology literature, chapter four also draws on the conceptualization of Jungian psychoanalytic theory developed by June Singer and Mary Loomis. The contribution Singer and Loomis' interpretation of Jung make to this project is several fold. First, their use of Jung is helpful in understanding the ways place can be perceived as well as the range of senses or understandings of place that can be held and influence behavior. Second, Singer and Loomis provide a framework for understand that there are other means of experiencing and reaction to place below the level of consciousness, such the recognition of symbols at an unconscious level (introverted intuition), such as symbols of "opportunity" or "space" or "rugged individualism" that have come to characterize the American West. Another mode of perception that operates below the level of consciousness is introverted sensation, by which one might experience particular emotional states related to the physical environment. Perhaps, as noted earlier, the most well known example of introverted sensation would be a sense of anxiousness about the arrangement of a room, which is inconsistent or in conflict with its intended use (extraverted intuition). Other important perceptions that Singer and Loomis' schema give structure to include how one may conceive of himself as being part of place or a recognition of the human factor in decisions related to place (extraverted feeling). The use of Singer and Loomis' interpretation is of particular value because of their recognition of the dynamic nature of Jung's theory, which allows for the possibility of different modes operating for an individual at various times or in different situations. It is critical to note that the use of Singer and Loomis is not as a means to predict behavior or to attempt to determine the personality types of study participants, but rather to provide a theoretical framework by which data from the field study can be organized. That is, Singer and Loomis's work provides a way of understanding the range of ways individuals perceive a given situation both at and below the level of consciousness. That understanding is then used to examine the processes used by the agency in order to determine which processes may contribute to the strength of the social bond and which may impede or in fact set back its development and to postulate strategies that will enable agencies to be effective in the future.

\section{Research Strategy}

In order to do this, a study developed based on Sorokin's logico-meaningful method, which observed one BLM RAC and the way it has evolved since it was chartered. Sorokin's (1962) description of the logico-meaningful has been employed here because of its usefulness in investigating complex patterns of social interaction. Sorokin as well as Sjoberg and Nett (1968) argue that the logico-meaningful methond is an ideal means of studying and developing an understanding of complex social processes that include what is communicated. That is, this method allows the researcher to build an 
understanding of the discourse that takes place within the setting being studied, via the complex processes of interaction among stated goals, prior knowledge and experience as well as what participants perceive as taking place. They proposes the logico-meaningful method as an approach that is best applied where processes are complex and subtle and involve more factors than can be managed by traditional predictive methodologies, which focus on a limited set of predetermined variables.

Both before and during the field research phase of the project, a review of the existing literature and research on the BLM was reviewed in order to develop a richer contextual understanding of the agency, its history and its culture. This review included an examination of the legislative history that gave rise to the current organizational form as well as its predecessor agencies. More importantly, this review gave attention to the agency's response to its founding in terms of the use of advisory, citizens and user groups and the organizational culture that emerged as a result.

Activities to collect data in the field proceeded by first identifying one RAC in which it was likely, based on an assessment of the character and informal operating processes adopted by the group, that a strong social bond had been built, thereby making civil society discourse possible. The characteristics examined to make this determination included number of RACs within the state and the acreage managed by Federal agencies and acreage managed by the BLM. It was assumed that the smaller the area of land the RAC works on, the more likely it is that the group has found and worked from a shared sense of place. Once the group was selected, a field study was conducted simultaneously with a review of the agency's history, culture and prior use of citizen/user groups and an examination of the agency's lands, paying special attention to those with whom the RAC had involvement.

This field research comprised in depth, structured conversations with group members and agency staff, observations of the activities of group, and a review of available RAC related documents. These data were used to identify indications in the RAC processes and members' experiences that place has been a factor in building the social bond.

In addition to the data collection noted so far, visits were made to many of the places to which the RAC has visited on field trips or that have been the topic of business meeting agenda items. Like the review of the history and culture of the agency that was described above, these visits were intended to provided additional richness to the understanding of the RAC and agency's activities.

\section{Summary of Significant Findings}

Among the various findings that have been revealed in the field research phase of this study, there are three that are most significant. First, every member of the RAC expressed some indication of a connection to place. The individual connections to place varied in terms of which of the theories were expressed, place attachment or place identity, and varied also within each theory. That is, some RAC members expressed connections consistent with place attachment and others with place identity. Further, there was variation also within the theories, such as expressions of emotional place attachment versus cognitive attachment or place identity in a sense of distinctness or through a sense of continuity. Given the findings noted in the environmental psychology 
research, this is not a surprise, but is important in that it provides a key foundation from which a collective connection to place may be built.

The second and most significant finding of this study is that there are in fact ways through using sense of place that the agency operates which fosters the social bond. This occurs primarily through the field trips in which RAC members participate during the first day of each set of RAC meetings. It is during these field trips that RAC members are able to develop a collective connection to the places on which the RAC focuses. Conversations with RAC members indicate that the field trips support both place attachment and place identity and also work across the dynamics described by Singer and Loomis. From the perspective of the place attachment framework, RAC members and BLM staff indicate that the field trips contribute to the affective and cognitive attachment to place. Place identity, in terms of Breakwell's framework, is also supported through the development of a collective sense of each of the elements, distinctiveness, continuity, self-efficacy and self-esteem. Further, the field trips operate in a way that trigger perception at and below the level of consciousness. That is, the field trips develop a collective sense of connection to place by operating at conscious, sensing levels as well as unconscious levels. This finding is important in that it suggests that agency activities can function simultaneously in both rational and non-rational ways.

In addition to the use of field trips as a means of developing a collective connection to place, the tie between the field trips and the business meeting agendas further supports an emerging connection to place. While not every field trip was directly tied to the corresponding business meeting agendas, there is convincing evidence to suggest that RAC members draw extensively on their experiences in place to shape their positions in the business meetings. The group's discussion regarding possible management options open to the Bureau for Lake Berryessa are perhaps the clearest example of this. Because the management issues around the lake are not entrenched in traditional interest group positions, the connection between the field trips to the lake and business meeting discussions and recommendations are striking.

The third significant finding of this study is that there are structural and cultural (both organizational and social) barriers to the agency's use of place to develop the sort of social bond necessary for effective collaborative governance. Further, these barriers are largely an artifact of the agency's use of a traditional, rational model of operations. For example, despite the RACs informal decision to work under a non-rational, consensus model in which every member can live with a recommendation before it is referred on to the Bureau, the RAC's charter requires the use of a structured voting protocol that is counter to the consensus model. Further, the structure of the RAC and its membership reinforces an interest group based model that does not support collaborative or consensus model of operations. That is, because of the allocation of membership slots to particular types of users, there is a pre-established, and in some cases, artificial and imposed tension between members.

In addition to the tension between overlaying a rational model, embodied in the RAC charter, over a non-rational, consensus oriented group process, BLM staff have not taken advantage of the opportunity to orient new members (and possibly re-orienting existing members) to a consensus oriented model of operations. While long standing members of the RAC indicated that there was a formal and rigorous orientation process in the past, 
limited resources and competing priorities have lead the BLM staff to under-utilize an orientation process.

\section{Other Findings}

Although there is persuasive evidence that place and RAC processes that build a collective connection to place do exist and positively effect a social bond between RAC members, it is also clear that there are other elements of RAC operations that contribute to a robust social bond. Two elements that stand out are non-place social experiences and member selection. There is extensive evidence that various social experiences that RAC members and BLM staff participate in contribute to the social bond between and among members. The findings indicate that RAC members and staff find these social experiences an important opportunity to get to know one another, to engage on a personal level, in essence, to develop connections to one another that effects subsequent discourse related to RAC business.

In addition to the social experiences, both BLM staff and RAC members indicate that member selection has also played an important role in the nature and strength of the social bonds between and among members of the group. RAC members almost universally indicate that they feel that RAC members bring with them to the group a disposition that supports the development of positive and effective relationships. Further, BLM staff suggest that they give significant attention to the character and attitudes of individuals who are nominated for and receive recommendations for membership in the RAC. Although this sense that the RAC is comprised of 'good folk' and that this characteristic supports the work that the RAC does, it seems possible that this phenomenon may be more complex. That is, the assumption of the RAC members and BLM staff is that good people lead to good processes and outcomes. The question that is unanswered is whether it maybe the case that good processes lead to good people. This question is considered further in the subsequent sections of this chapter.

\section{Implications for Public Administration}

It must be acknowledged that because of the research strategy used for this study, the conclusions that can be drawn and implications described are somewhat limited. Never the less, some limited exploration of implications is possible.

For public administration professionals, the findings of this study suggest that there is at least one alternate, non-rational model of agency processes that has the potential to support the development of positive and robust management and policy outcomes. However, this relational model poses significant challenges to public administrators who operate in agencies dominated by a traditional or rational model of operations. In part, the findings of this study suggest that practitioners can move toward a more relational mode by employing conscious reference to place in building a bond among them.

While it seems clear that place is most likely to play a role in the processes of agencies that have some explicit connection to place, like public lands and natural resources agencies. However, working from Edward Casey's argument that western epistemology has been preoccupied with abstract notions of space and time over concrete 
notions of place, it takes little effort to identify other policy areas that have a strong potential connection to place, be it economic development or social welfare programs. Although this in part this is the sort of awareness of context that others have already described (see How Context Matters), returning to Twigger-Ross and Uzzell's use of Breakwell and for instance his uniqueness principle, place may well have substantive influence on policy issues not intuitively connected to place.

To support the move to a relational model, these findings suggest that administrators employ strategic efforts to capitalize on areas of interconnection between rational processes and relational processes. That is, building relationships where the relational model functions well and minimizing implications of the rational model where it functions in opposition to relationships. Looking to the operations of the Northwest California RAC as an example, this would play itself out in BLM staff's supporting the informal decision of the RAC to work in purely consensus based ways despite the organizational and voting protocols required under the RAC charter.

The findings of this study have implications for public administration education as well. A primary implication is the importance of contributing to the development alternate skill sets. That is, students of public administration learn skill sets that support a relational model of operations. This would mean learning to give attention to the nature and functioning of relationships and developing the skills to support the establishment and operation of those relationships. In addition to enhancing PA education to support the development of alternate skill sets, it will also need to give additional attention to alternate ontological paradigms. Although there is a growing portion of the field situated outside the functionalist paradigm, the move to a relational model of agency operations will be supported by greater attention to other ontological perspectives, especially ones that recognize and theorize a greater role for the expression of the unconscious aspects of human thought and behavior.

\section{Prospects For Future Research}

Recognizing the limitations of this study, it is useful to give some discussion to some potential avenues for future research. One of several avenues available to extend this research is an expansion of this current study. The study undertaken here does not allow for generalizable conclusions, so expansion of future research to include a larger population and more systematic study of that population may add further clarity to the range of activities an agency can employ to develop a collective connection to place. Additionally, such research may add detail to the elements of a connection to place that most effectively contribute to the emergence of the robust social bond necessary for collaborative governance. It seems likely that this research track will be iterative in nature, continued elaboration of the theoretical model introduced here, shaped by additional empirical research, followed by further refinement of the theoretical model.

A second, but related opportunity for future research will be an effort to add to the sophistication of a non-rational or relational model of agency operations. This would take the form of further exploration of existing theory (from environmental psychology, for example, or possibly from other fields such as cultural geography) to better fit the broad range of current public processes. 
Another avenue for future research will be focused on the identification of additional factors beyond place that may also have an effect on the social bond. The civil society literature recognizes that traditionally, common culture, religion, and politics have been the basis of the sort of social bond necessary to facilitate civil society. This study suggests that place can have a similar role. It seems likely that there are other factors that play such a role. Identifying them and exploring the mechanisms by which they operate will have significant potential for the field of public administration.

A topic for further exploration noted in the previous chapter centers around the issues of representation in collaborative groups such as the RAC. As noted in the last chapter, there was no explicit indication that this issue of representation had hindered the appearance of civic discourse, the appearance of the issue in members' comments in the first place requires some additional scrutiny. Because the relational model proposed in this project is based on genuine and robust social relationships, the notion of representation seems likely to impede the expression of such relationships. Questions to be explored in future research would include how extensive is the sense of representation and subsequently, whether any existing perception of representation affects the nature of the social relationships, either positively or negatively.

One further opportunity for research was noted earlier in this chapter. That is, the exploration of the nature of the relationship between the processes employed by the agency and character of participation. One of the common themes in the conversations which took place during the field research phase of this project was that RAC members and BLM staff alike felt that the group was effective in part because of the quality of the RAC members. Specially, both groups felt that the successes of the RAC were due, at least in part, to the fact that the members genuinely engaged with one another and in the processes of the RAC and, moreover, that the willingness to engage was a characteristic that members embodied before joining the RAC. The question posed above is whether it may be the case that that characteristic may in fact be an outcome of the processes used by the agency, rather than something pre-existing in the members. The fact that some members of the RAC were active participants in litigation against other public lands agencies gives some weight to this possibility and suggests that more study is warranted.

\section{Concluding Comments}

This study began with a brief description of a set of social conditions that has and will continue to generate significant concern in society. The bulk of the civil society literature has given little if any systematic thought to either the role of public agencies can have in efforts to mend tears to the existing social fabric or to weave some new and different type of social fabric. That literature is also silent on the mechanisms by which the social bond is created and maintained in a way that enables civil society to emerge in the first place. While limited in its scope, this study of place and its role, has taken the first steps to fill that gap, and the findings suggest that place offers the opportunity to craft new and different strategies. 


\section{Bibliography}

Ahrentzen, Sherry. B. (1992). "Home as a workplace in the lives of women." In I. Altman \& S. M. Low, Eds. Place Attachment. New York: Plenum. 113-138.

Altman, Irwin and Setha Low Eds. (1992). Place Attachment. New York: Plenum Press.

Anechairico, Frank. (1998). "Administrative Culture and Civil Society: A comparative perspective." Administration and Society. 30:1. pp. 13-34.

Bachelard, Gaston. (1964). The Poetics of Space. New York: The Orion Press.

Beem, Christopher. (1996). "Civil Society in America: A Public Debate About Political Theory”. Working Paper \#52. Institute For American Values.

. (1999). "Private Action and the Public Good". Social Forces. 12/01/99. P. 803.

Bellah, Robert. et al. (1985). Habits of the Heart: Individualism and the Commitment in American Life. Berkeley: University of California Press.

Bennett, W. Lance. (1998). "The Uncivic Culture: Communication Identity, and the Rise of Lifestyle Politics”. PS: Political Science and Politics. 31:4.

Berger, Peter L. and Richard J. Neuhaus. (1977). To Empower People: the role of mediating structures. Washington: American Enterprise Institute for Public Policy.

Berman, Sheri. (1997). "Civil Society and Political Institutionalism". American Behavioral Scientist. 40:5. pp. 562-576.

Bureau of Land Management. (2000). California's Natural Wildlands Legacy: Bay Delta [Brochure]. Sacramento, CA.

Bureau of Land Management. (2000). California's Natural Wildlands Legacy: North

Coast [Brochure]. Sacramento, CA.

Bureau of Land Management. (2000). California's Natural Wildlands Legacy:

Sacramento Valley [Brochure]. Sacramento, CA.

Bureau of Land Management Arcata Field Office. (n.d.). Retrieved 4/12/02 from http://www.ca.blm.gov/arcata/index.html.

Bureau of Land Management California State Office. Retrieved 4/12/02 from http://www.ca.blm.gov/index.html. 
Bureau of Land Management Photo Library. Retrieved 4/12/02 from http://www6.ca.blm.gov/blm/index.html.

Bureau of Land Management Redding Field Office. Retrieved 4/12/02 from http:/www.ca.blm.gov/redding/.

Bureau of Land Management Ukiah Field Office. Retrieved 4/12/02 from http://www.ca.blm.gov/ukiah/index.html.

Bureau of Reclamation (n.d.). Retrieved 5/21/02 from

http://www.mp.usbr.gov//berryessa/facts.html

Boyd, Richard. (1999). "The Unsteady and Precarious Contributions of Individuals:

Edmund Burke's Defense of Civil Society". Review of Politics. (7/1/1999). pp. 465-470.

Breakwell, G. M. (1986). Coping With Threatened Identity. London: Methuen.

Brown, Barbara B. and Carol M. Werner. (1985). "Social Cohesiveness Territoriality and Holiday Decorations: The Influence of Cul-de-sacs.” Environment and Behavior. 17:5. 239-265.

Burnham, Walter Dean. (1982). The Current Crisis in American Politics. New York: Oxford University Press.

Cappella, Joseph N. and Kathleen Hall Jaimeson. (1997). Spiral of Cynicism: The Press and the Public Good. New York: Oxford University Press.

Casey, Edward. (1997). The Fate of Place: A Philosophical History. Berkeley: University of California Press.

Casey, Edward. (1993). Getting Back Into Place: Toward a Renewed Understanding of the Place World. Bloomington: Indiana University Press.

Cawley, R. McGreggor. (1981). The Sagebrush Rebellion. Unpublished Doctoral Dissertation, Colorado State University. Fort Collins, CO. . (1993). Federal Lands, Western Anger: The Sagebrush Rebellion and Environmental Politics. Lawrence, KS: University of Kansas Press.

Chalulupka, William, (1999). Everybody Knows: Cynicism In America. Minneapolis, MN: University of Minnesota Press.

Charney, Evan. (1998). "Political Liberalism, Deliberative Democracy and the Public Sphere." American Political Science Review. 92:1. pp. 97-112. 
Chawla, L. (1992). "Childhood Attachments.” In I. Altman \& S. M. Low, Eds. Place Attachment. New York: Plenum. 63-86.

Coats, Daniel R., Gertrude Himmelfarb, Don Eberly and David Boaz (1996). "Can

Congress revive civil society?" Policy Review. January, 1996. pp. 24-34.

Cooper, Marcus C. (1992). "Environmental Memories.” In I. Altman \& S. M. Low, Eds. Place Attachment. New York: Plenum. 87-112.

Crane, Edward. (1997). "Civil Society vs. Political Society: China at a crossroads". Vital Speeches. 63:20. 615-618.

Denson, Bryan \& James Long. (1999). "Eco-Terrorism casts shadow over Western States - Radical Groups turn from spray paint to bombings and arson". The Star-Ledger. 11/25/1999. P. 62.

Devine, P. (1994). A time and a place for the Irish - an explanatory analysis of significance of Irish historical place for maintaining Irish National Identity. Unpublished Msc. Thesis. Department of Psychology, University of Surrey.

Eberly, Donald. (1998). “Civic Renewal v. Moral Renewal.” Policy Review. Sept./Oct. 1998. pp. 44-49.

Ehrenberg, John. (1999). Civil Society: The Critical History of an Idea. New York: New York University Press.

Elshtain, Jean Bethke. (1997). “Authority Figures”. The New Republic. 217:25. 11-12.

Encarnacion, Omar G. (2000). “Tocqueville's Missionaries: Civil Society Advocacy and the Promise of Democracy". World Policy Journal. (4/1/00) pp. 9-18.

Etzioni, Amatai, (1996). The New Golden Rule. New York: Basic.

Eyles, J. (1968). The Inhabitants' Images of Highgate Village. London: LSE Geography Discussion Papers, no. 15.

Feldman, R. M. (1990). "Settlement Identity: Psychological bonds with home places in a mobile society." Environment and Behavior. 22, 183-229.

Foss, Phillip O. (1960). Politics and Grass. Seattle: University of Washington Press.

Frost, S. E. (1962). The Basic Teachings of the Great Philosophers. New York:

Doubleday.

Frederickson, H. George. (1982). "The Recovery of Civism". Public Administration Review. 42, pp. 501-508. 
Gallagher, Winifred. (1993). The Power of Place. New York: Harper Collins.

Gecas, V. (1982). “The Self Concept.” Annual Review of Sociology. 8, pp. 1-33.

Gellner, Ernest. (1994). In Conditions of Liberty: Civil Society and Its Rivals. London: Penguin.

Gitlin, Todd. (1995). The Twilight of Common Dreams: Why America is Wracked by Culture Wars. New York: Henry Holt.

Glaser, Barney G. (1978). Theoretical Sensitivity. Mill Valley, CA: The Sociology Press.

Glendon, Mary Ann. (1992). "Rights Talk". Journal of State Government. 65:1. 20-26

Hidalgo, M. Carmen, and Bernardo Hernandez. (2001) "Place Attachment: Conceptual and Empirical Questions.” Journal of Environmental Psychology. 21:3. pp. 273-281.

Himmelfarb, Gertrude. (1998). "Democratic remedies for democratic disorders."

Public Interest. 131. pp. 3-24.

Hiss, Tony. (1990). The Experience of Place. New York: Alfred A. Knopf.

Hogg, M. A. and D. Abrams (1988). Social Identifications. London: Routledge.

Honadle, George. (1999). How Context Matters: Linking Environmental Policy to People and Place. Hartford, CT: Kumarian Press.

Hummon, D. (1990). Commonplaces: Community Idology and Identity in American Culture. New York: State University of New York Press.

Hunter, James. (1991). Culture Wars: The Struggle to Define America. New York: Basic Books.

Ignatieff, Michael. (1995) “On Civil Society: Why Eastern Europe's Revolutions Could Succeed”. Foreign Affairs. 74:2. pp. 128-132.

Inglehart, Ronald. (1997) The North American trajectory : cultural, economic, and political ties between the United States, Canada, and Mexico . New York : Aldine de Gruyter.

Jung, Carl. (1935). "The Tavistock Lectures.” In $\underline{\mathrm{CW}}$. Princeton, NJ: Princeton University Press. pp. 5-182.

Keister, Rick. (1996). "Multicultural grazing boards off to a good start". High Country News. 28:17. 
Kemmis, Danniel. (1990). Community and the Politics of Place. Norman, OK: University of Oklahoma Press.

Korpela, K. M. (1989). "Place Identity as a product of environmental self regulations." Journal of Environmental Psychology. 9. 241-256

Krza, Paul. (1996). "Cow coup: Wyoming usurps federal grazing group". High Country News. 28:24.

Lalli, M. (1988). "Urban Related Identity.” In D. Canter et al. , Eds. Environmental Social Psychology. London: Kluwer Academic Publishers. . (1992). "Urban related identity: theory, measurement and empirical findings." Journal of Environmental Psychology. 12. 285-303.

Lifton, R. J. (1961). Thought Reform and the Psychology of Totalism: A Study of 'Brainwashing' in China. New York: Norton.

Loomis, Mary. (1991). Dancing the Wheel of Psychological Types. Wilmette, IL: Chiron Publishers.

Marx, Leo. (1976). The Machine in the Garden: Technology and the Pastoral Ideal in America. New York: Oxford University Press.

Mazumdar, Shampa and Sanjoy Mazumdar. (1993). "Sacred Place and Place Attachment.” Journal of Environmental Psychology. 13:3. pp. 231-242.

Mesch, Gustavo S. and Orit Manor. (1998). Social Ties, Environmental Perception and Local Attachement." Environment and Behavior. 30:4. 504-520.

Miller, S.M. (1995). "Building a Progressive Civil Society”. Social Policy. 27:1. 22-26.

Milligan, Melinda J. (1998). "Interactional Past and Potential: The Social Construction of Place Attachment.” Symbolic Interaction. 21:1. 1-33.

O'Connell, Brian. (1999). Civil Society: The Underpinnings of American Democracy. University Press of New England: Hanover, New Hampshire.

Palmer, Tom G. (1995). "Book Reviews - In Conditions of Liberty: Civil Society and Its Rivals". Cato Journal. 15:1. pp. 146-147.

Bureau of Land Management. (1998). Partners Across the West: Resource Advisory Councils. RAC Video Conference, Post broadcast publication. 
Proshansky, Harold M. (1976). "Environmental Psychology and the Real World." American Psychologist. 31: 303-310

169. . (1978). "The City and Self-Identity". Environment and Behavior. 10:2. 147-

Proshansky, Harold M., Abbe K. Fabian and Robert Kaminoff. (1983). "Place-Identity: Physical World Socialization of the Self." Journal of Environmental Psychology. 3. 57-83

Putnam, Robert D. (1995). "Bowling Alone: America's Declining Social Capital." Journal of Democracy. 6:1. pp. 65-78.

. (1995). "Turning In, Tuning Out: The strange disappearance of social capital in America". PS: Political Science and Politics. 28:4. 664-677. . (2001). Bowling Alone: The collapse and revival of American community. New York: Simon and Schuster.

Rahn, Wendy. (1997). "Media Message, Political Culture and National Identity". Presented at the Anneberg Policy Center Workshop on Mediated Politics:

Communication in the future of Democracy, Washington, DC.

Rahn, Wendy and John Transue. (1997) "The Decline of Social Trust Among American Youth: The American Economy, Value Change and Social Capital." Center for the Study of Political Psychology, University of Minnesota. Manuscript.

Rawls, John. (1971). A Theory of Justice. Cambridge, MA: Harvard University Press.

Rawls, John. (1993). Political Liberalism. New York: Columbia University Press.

Relph, E. (1976). Place and Placelessness. London: Pion.

Rosenbaum, Walter. (1991). Environmental Politics and Policy. Washington DC: Congressional Quarterly.

Rowles, G. D. (1983). "Place and personal identity in old age: observations from Appalachia." Journal of Environmental Psychology. 3. 299-313.

Rubin, Herbert J. and Irene S. Rubin. (1995). Qualitative Interviewing: The Art of Hearing Data. Thousand Oaks, CA: Sage Publications.

Sandel, Michael J. (1996). Democracy's Discontent: America In Serach of a Public Philosophy. Cambridge MA: Harvard University Press.

Seligman, Adam. (1992). The Idea of Civil Society. New York: The Free Press. 
Schmidt, James (1998). "Civility, Enlightenment and Society: Conceptual Confusions and Kantian Remedies." American Political Science Review. 92:2.

Schumaker, S. A. and R. B. Taylor. (1983). "Toward a Classification of People, Place Relationships: A model of attachment to place." In N.R. Feimer and E.S. Geller (Eds.). Environmental Psychology: Directions and Perspectives. New York: Praeger. pp. 219251.

Sjoberg, Gideon and Roger Nett. (1968). A methodology for social research. New York: Harper \& Row.

Sorokin, Pitirim A. (1962). Social and Cultural Dynamics. Vols. One-Four. New York. Bedminster Press.

Stivers, Camilla. (1988). Active Citizenship in the Administrative State. Unpublished Doctoral Dissertation. VPI\&SU. Blacksburg, VA.

. (1990). "The Public Agency as Polis: Active Citizenship in the Administrative State." Administration and Society. 22:1. pp. 86-106. . (1994). "The Listening Bureaucrat: Responsiveness in Public

Administration.” Public Administration Review. 54:4. pp. 364-369.

Strauss, Ansem and Juliet Corbin. (1990). Basics of Qualitative Research: Grounded Theory Procedures and Techniques. Newberry Park, CA: Sage.

Tajfel, H. Ed. (1978). Differentiation between Social Groups. London: Academic Press.

Tocqueville, Alexis. (1945). Democracy in America. (2 vols.). New York: Vintage.

Tushnet, Mark. (1997). "A Public Philosophy for the Professional-Managerial Class". Yale Law Journal. 106:5. 5-19.

Twigger-Ross, Clare L. and David L. Uzzell. (1996) "Place and Identity Processes." Journal of Environmental Psychology. 16. 205-220.

Uzzell, David L. (1995). "Conferring a Sense of Place Identity: the role of Museums." International Journal of Heritage Studies. 1:4.

Walter, Eugene V. (1988). Placeways: A Theory of the Human Environment. Chapel Hill, NC: The University of North Carolina Press.

Walzer, Michael. (1991). "The Idea of Civil Society: A Path To Social Reconstruction". Dissent. 39:2. 293-304.

Walzer, Michael. (1999). “Rescuing Civil Society.” Dissent. 47:1. pp. 62-68. 
Wattenberg, Martin. (1994). The Decline of American Political Parties, 1952-1992.

Cambridge MA: Harvard University Press.

Winkel, G. (1981). "The perception of neighbourhood change." In Cognition and Social Behaviour and the Environment. New York: Erlbaum.

Wolfe, Alan. (1997). “Is Civil Society Dead?” The Brookings Review. 15:4. 9-12. 


\section{APPENDIX A \\ Request for Expedited Approval of Research Involving Human Subjects}

Investigator(s): Eric K. Austin

[please print or type responses below]

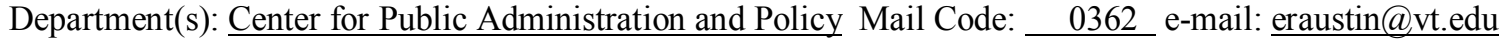

Project Title: A Theory of Place: The role of place in structuring group processes in BLM Resource Advisory Councils

Source of Funding Support: _ X__ Departmental Research Sponsored Research (OSP No.: )

[X] All investigators of this project are qualified through completion of the formal training program or videotape program provided by the Virginia Tech Office of Research Compliance.

Note: $\quad$ To qualify for Expedited Approval, the research activities must: (a) present not more than minimal risk to the subjects, (b) not involve any of the special classes of subjects, except children as noted, and (c) involve only procedures listed in one or more of the following categories. The full description may be found in the Expedited Review section of the instructions: "Application for Approval of Research Involving Human Subjects" or 45 CFR 46.110 (http://grants.nih.gov/grants/oprr/humansubjects/45cfr46.htm\#46.110)

Please mark/check the appropriate category below which qualifies the project for expedited review:

[ ] 1. Clinical studies of drugs and medical devices when proscribed conditions are met [see item (1), page

[ ] 2. Collection of blood samples by finger, heel or ear stick, or venipuncture subject to proscribed limitations [see item (2), page

[ ] 3. Prospective collection of biological specimens for research purposes by noninvasive means. Examples: hair and nail clippings, deciduous teeth, permanent teeth, excreta and external secretions, uncannulated saliva, placenta, amniotic fluid, dental plaque, muscosal and skin cells and sputum [see item (3), page

[] 4. Collection of data through noninvasive procedures routinely employed in clinical practice, excluding procedures involving $\mathrm{x}$-rays or microwaves [see item (4), page

[X] 5. Research involving materials (data, documents, records or specimens) that have been collected or will be collected solely for non-research purposes (such as medical treatment or diagnosis [see item (5), page

[ ] 6. Collection of data from voice, video, digital, or image recordings made for research purposes [see item (6), page

[X] 7. Research on individual or group characteristics or behavior (including, but not limited to, research on perception, cognition, motivation, identity, language communication, cultural beliefs or practices, social behavior), or research employing survey, interview, oral history, focus group, program evaluation, human factors evaluation, or quality assurance methodologies [see item (7), page ].

\begin{tabular}{lc}
\hline Investigator(s) & Date \\
\hline Departmental Reviewer & Date \\
\hline Chair, Institutional Review Board & Date
\end{tabular}

This project is approved for months from the approval date of the IRB Chair. 


\section{APPENDIX B Outline for Protocol to Accompany IRB Request}

\section{Justification of Project}

This research project fulfills the dissertation requirements for the completion of a Ph.D. from the Center for Public Administration and Policy. Further, this research will contribute to the civil society body of literature as it relates to public administration and more specifically, public lands management and policy. This body of literature examines the processes by which public organizations and citizens interact in attempt to address the variety of issues that arise in American communities. Specifically, this research will test the hypothesis that public agencies do play a role in fostering the emergence of civil society. This study will also test a corollary hypothesis that grounding civic discourse in a specific place supports the emergence of civil society. Research in this area can help public agencies develop the capacity to overcome the procedural and ideological barriers to successful public lands and natural resources policy.

In order to test these hypotheses, this research will study the evolution of groups called Resource Advisory Councils (RACs). These groups are convened and managed by the US Bureau of Land Management in order to develop Standards and Guidelines for rangeland management. While official documentation is of some value to this research, it is necessary to conduct this research by interviewing BLM staff facilitating these groups because they are the best sources of information regarding the stages of development as well as characteristics and elements that structure their groups' processes. The development of an understanding of the agency's role will simultaneously advance the theory describing natural resources policy development and at the same time may inform those studying processes in other areas of policy development.

\section{Procedures, Subject of Study and Procedures:}

The first step will be to identify a group of three to five RACs which have focused narrowly and passively on the development of standards and a similar number of RACs which have extended the scope of activities beyond the development of Standards and Guidelines and have engaged rigorously to do so. Once these groups have been selected, the researcher will identify and conduct interviews with BLM staff who have been involved with each respective group since their charter and are familiar with the events and process of the group they work with. These interviews will help identify the sequence of events as well as any crucial experiences that may have been important to the trajectory that the RACs followed. Questions will be asked of BLM staff from each $\mathrm{RAC}$ will be designed to develop and understanding of:

How the members were identified and the dynamics of members' selection, The story of how each group evolved,

\section{Critical events and elements in the groups' evolution, and}

The RAC members' connection to the resource areas they focus on. 
After the first set of interviews are complete, the researcher will review the data from these interviews and develop a loose schema describing the importance of place in agency efforts and how agency efforts have effected the emergence of civil society. The researcher will then identify any areas where additional data is needed to answer remaining questions and conduct secondary interviews with additional participants (either RAC members or BLM staff) who can add detail and richness to the understanding of how each RAC evolved and functions. The subjects of these interviews will be determined by the first interviews. That is, both the subjects to be interviewed and the topics to be raised in the interviews will be determined by what is revealed in the first set of interviews.

\section{Interview Process:}

Little if any systematic study of RACs, the role of public agencies in the emergence of civil society or importance of place as a context for this emergence. As a result, this study will using in-depth interviewing as described by Rubin and Rubin. They develop a model of qualitative interviewing that modifies ordinary conversations to draw out what others know and think about the subject of study, while minimizing the extent to which the interviewer imposes his or her own views. Working from the idea of a conversation, the authors highlight the active role of the interviewee in shaping the direction of the conversation. The interviewer and interviewee work together to in an effort to develop a shared understanding(Rubin and Rubin, 1995).

The researcher, because of the lack of guidance to structure specific interview questions and in order to bound the scope of the research, starts the interview with a broad, open-ended question that is broad enough to prompt interviewees to share their opinions and experiences. This "main question" as Rubin and Rubin describe it, is at the same time, narrow enough to delineate the subject of study. It is within these bounds that the interviewer and interviewee actively shape the content and direction of the interview.

Based upon the response to this main question, the researcher then formulates additional questions intended to draw out the details, depth and richness of the interviewees original response. The interviewer explores in an effort to clarify response, fill in additional or missing information, draw out longer or more detailed or give specific examples and experiences (Rubin and Rubin, 1995). Drawing also on grounded theory, the notion of theoretical sensitivity is useful again at this point because the researcher must not only be sensitive to the responses of the interviewee, but must also maintain an awareness of what he or she has learned from the relevant literature and experience as well as any previous interviews.(Glaser, 1978). As a result of the researcher's sensitivity to the array of experience, literature and data, the process of data collection must be open to adaptation. The processes described by Rubin and Rubin flexible as well as iterative and continuous as a way to collect rich data that enables the researcher to build theories that can describe the complexity of a setting or phenomenon (Rubin and Rubin, 1995).

\section{Analysis and Results:}

Data analysis begins to some extent during the process of collecting the data. That is, the data is reviewed and placed into propositional categories prior to each interview so that the researcher is able to modify the interview to reflect new learnings.

Final analysis or analysis of all the data begins as the researcher reviews and categorizes the data into themes. The researcher then compares the data both within and across themes. This allows the researcher to identify any new themes that were here-to- 
fore unrecognized and not captured. Categorization in this way may reveal new themes not previously identified. The processes of organizing and analyzing the data as described by Rubin and Rubin is iterative and allows for substantial flexibility in arranging the data so that similar ideas are grouped together in order to determine how the ideas relate to each other. Throughout this process, care is taken to ensure that the data does contain explicit information that would reveal the identity of the respondent. The end result will be a 'map' that describes key points and characteristics of the evolution of these groups. These discrete points or stages and characteristics as well as the role that the agency had in the process will provide a preliminary understanding of what role public agencies have in supporting or hindering the emergence of civil society.

\section{Risks and Benefits}

There are no physical, or economic risks to subjects taking part in this project. Social and psychological risks are minimal and limited. Because this project examines processes that revolve around potentially volatile public issues and because subjects are asked to share the opinions and attitudes about these processes, there is some risk of subjects revealing information counter to the opinions of or unpopular with other members of the group. However, ensuring the confidentiality and anonymity of subjects and their responses minimizes this risk.

There are no preconceived benefits to participants in this project.

\section{Confidentiality/Anonymity}

Interviews with subjects of this study will be transcribed by hand at the time of the interview. Interview transcripts will be numbered and a separate code sheet will be used so that the researcher will be able to determine which number interview transcript corresponds to which subject. The subject's name will not appear on the interview transcripts.

Following the interview, all interview transcripts will be transcribed into NUD*ST qualitative data analysis software. Subjects names will not be attached to data, though the numbered code associated with the original interview will be, so as to allow the researcher to connect specific data with subjects if need be. Again, through the processes of analysis and reporting, subjects' names will not be connected to any specific comments or quotes. Once the project is completed and has been approved by the dissertation committee, all raw data and the codes that would allow specific quotes to be identified will be destroyed.

\section{Informed Consent}

Please find attached the consent forms to be used for this project. Subjects will be provided with two copies of the Consent form prior to the start of the interview and will be given as much time as they need to read and complete the form. The researcher will retain one signed copy of the form and the subject will retain the second copy. Interviews will be scheduled at the convenience of subjects so as to minimize in disruption in their schedules. 


\title{
APPENDIX C VIRGINIA POLYTECHNIC INSTITUTE AND STATE UNIVERSITY
}

\author{
Informer Consent for Participants and Investigative Projects
}

Title of the Project: Dissertation Title: Building A Context For Civil Society: The Role Of The Bureau Of Land Management In Facilitating The Emergence Of Civil Society

Investigator: Eric K. Austin, doctoral candidate

\section{The Purpose of this Research/Project}

This research project fulfills the dissertation requirements for the completion of a $\mathrm{Ph} . \mathrm{D}$. from the Center for Public Administration and Policy. Further, this research will contribute to the civil society body of literature as it relates to public administration and more specifically, public lands management and policy. This body of literature examines the processes by which public organizations and citizens interact in attempt to address the variety of issues that arise in American communities. Specifically, this research will test the hypothesis that public agencies do play a role in fostering the emergence of civil society. This study will also test a corollary hypothesis that grounding civic discourse in a specific place supports the emergence of civil society. Research in this area can help public agencies develop the capacity to overcome the procedural and ideological barriers to successful public lands and natural resources policy.

In order to test these hypotheses, this research will study the evolution of groups called Resource Advisory Councils (RACs). These groups are convened and managed by the US Bureau of Land Management in order to develop Standards and Guidelines for rangeland management. While official documentation is of some value to this research, it is necessary to conduct this research by interviewing BLM staff facilitating these groups because they are the best sources of information regarding the stages of development as well as characteristics and elements that structure their groups' processes. The development of an understanding of the agency's role will simultaneously advance the theory describing natural resources policy development and at the same time may inform those studying processes in other areas of policy development.

\section{Procedures}

I am seeking participants from several Bureau of Land Management(BLM) Resource Advisory Councils(RAC) who voluntarily agree to be interviewed about their experiences and observations of RAC activities. If you voluntarily agree to participate in the study, I will initially interview you individually and privately for approximately one hour using open-ended questions so that I may hear your point of view. Rather than asking structured questions, I will be conducting what is termed an unstructured interview. Essentially, I will frame the topic of my research as attempting to find out what role the BLM has had in structuring the discourse and relationships of the RAC. I will ask an initial open-ended question to begin the interview and follow your lead after that so that you can tell me what you thing is important for me to know. I am interested 
in hearing your stories, examples and perspectives that will help me understand and then describe how the BLM works with the RAC. Following the initial interview, I will look for patterns and themes presented in the interviews. to obtain more details and depth so that I may capture your perspective and meaning, I anticipate that I will need to interview you one or two more times within a 8 week period. I will interview you at your convenience and in a location you specify. With your permission, I will observe a limited number of activities in which you and the RAC are engaged. As a voluntary participant, you have the right to decline to answer that I may pose.

\section{Risks and Benefits}

There are no physical, or economic risks to subjects taking part in this project. Social and psychological risks are minimal and limited. Because this project examines processes that revolve around potentially volatile public issues and because you are asked to share the opinions and attitudes about these processes, there is some risk of revealing information counter to the opinions of or unpopular with other members of the group. However, ensuring the confidentiality and anonymity of subjects and their responses minimizes this risk.

There are no preconceived benefits to participants in this project. However, I do hope that the interview process will afford you an opportunity to reflect about your activities with the RAC. Perhaps, an opportunity to consciously reexamine strengths and areas for potential improvement within the scope of RAC activities.

\section{Confidentiality and Anonymity}

I will assure your confidentiality and anonymity to the greatest possible extent. Interviews with subjects of this study will be transcribed by hand at the time of the interview. Interview transcripts will be numbered and a separate code sheet will be used so that the researcher will be able to determine which number interview transcript corresponds to which subject. The subject's name will not appear on the interview transcripts.

Following the interview, all interview transcripts will be transcribed into a qualitative data analysis software package. Subjects names will not be attached to data, though the numbered code associated with the original interview will be, so as to allow the researcher to connect specific data with subjects if need be. Again, through the processes of analysis and reporting, subjects' names will not be connected to any specific comments or quotes. Once the project is completed and has been approved by the dissertation committee, all raw data and the codes that would allow specific quotes to be identified will be destroyed.

\section{Compensation}

No Monetary or intangible contribution is associated with your participation in the study.

\section{Freedom to Withdraw}

You have the right to withdraw your participation from this research at anytime 
without penalty. You are free not to answer any question posed during an interview. You have the right to retract any statement you make, as well as the right to edit your interview responses.

\section{Approval of Research}

This Research has been approved by the Institutional Review Board for Research involving Human Subjects at Virginia Polytechnic Institute and State University (VPISU) and by the Center for Public Administration and Policy at VPISU.

\section{Subjects Responsibilities}

I voluntarily agree to participate I this research. I have the following responsibilities:

1. to be available for up to two separate interviews, each approximately one hour in length.

2. To specify convenient times and locations for the interview and to reschedule any interviews that unexpectedly interfere with responsibilities in as timely manner as possible.

\section{Subject's Permission}

I have read and understand the Informed Consent and conditions of this research project. H have had all my questions answered. I hereby acknowledge the above and give my voluntary consent for participation in this project.

If I participate, I may withdraw at any time without penalty. I agree to abide by the rules of this research project.

Signature

Date

Should you have any questions about this project, you may contact:

Eric Austin

9250 Kristy Dr.

Manassas Park, VA 20111

703-331-0645

eraustin@vt.edu 


\title{
Curriculum Vitae
}

\author{
Eric Keller Austin \\ 7890 N. $32^{\text {nd }}$ St. \\ Richland, MI 49083 \\ (H) 269-629-0319 $\quad$ (W) 269-387-8946
eric.Austin@wmich.edu
}

\section{Education:}

Ph.D. Public Administration

December 2002

Center for Public Administration and Policy

Virginia Polytechnic Institute and State University

Falls Church, Virginia

Master of Public Administration

1993

Center for Public Administration and Policy

Virginia Polytechnic Institute and State University

Blacksburg, Virginia

B.A. Political Science

1992

University of Wyoming

Laramie, Wyoming

Minor: Philosophy

Honors And Awards:

Pi Alpha Alpha - Public Administration Honor Society

Graduate Research Assistant - Center for Public Administration and Policy 1997-1999

\section{Teaching Experience:}

Western Michigan University, School of Public Affairs and Administration

Organization Theory and Behavior

Fall 2002

- Familiarize participants with the basic concepts, models, and theories of organization

- Develop students' understanding of individual, group, and organization behavior

- Provide a conceptual foundation upon which theoretical knowledge can be applied to organizational and managerial problems.

- Subjects covered include theories of organization; individual behavior; group dynamics; organization change; organizational performance 


\section{Virginia Polytechnic Institute and State University, Center For Public}

Administration and Policy

Concepts \& Approaches to Public Administration

Spring 2000/2001

- MPA Capstone Course, designed as an experiential, collaborative opportunity to integrate prior course work into the development of a organizational resource book reviewed by professionals in similar organizations

- Presented seminars on topics including organization culture, the climate facing public executives, organizational structure and patterns of social change facing public organizations

- Developed and maintained course website using CourseInfo software

Public Budgeting Processes and Their Policy Implications

Spring 1994

- Teaching assistant - facilitated and monitored students' work on a budgeting practicum project

Graduate Research Assistant

$1997-1999$

- Aided faculty in the development and use of distance learning technologies in support of existing and new courses

- Supported faculty in the development of course content and materials

- Organized resource development efforts in support of on-going departmental CAVE projects

\section{National 4-H Council}

Trainer - Building Common Ground Program

1994-1997

- Conducted training in facilitation and collaborative/creative problem solving for individuals and organizations involved in natural resources management

University of Wyoming, Political Science Department

Student Teaching Assistant - American Government

- Administered and graded tests

- Developed, assigned and graded term papers and oral presentations

- Facilitated and monitored students' progress

\section{Policy, Research and Analytical Experience:}

Virginia Polytechnic Institute and State University - Federal Reimbursement Unit, Institute for Public Policy Research

- Develop policy recommendations based on new and existing federal and state revenue maximization regulations

- Recommend internal policies and work processes for the expansion of revenue maximization efforts

- Coordinate data collection, analysis and reporting related to child welfare funding sources including Title IV-E reimbursement, Medicaid claims, Social Security benefits and child support enforcement with local agency staff 
- Supervise all on-going unit activities including regular and special projects, personnel actions, and budget compliance

Research Associate/Project Coordinator

1999-2000

Virginia Polytechnic Institute and State University - Federal Reimbursement

Unit, Institute for Public Policy Research

- Analyzed and presented data related to maximization of revenue for children in foster care

- Supported the completion of child support evaluation reports

- Collected, assembled and analyzed data related to both the target goals of the unit and to the evaluation project

- Oversaw and maintained access to electronic data collection systems and their use by program staff

Project Director

1994-1997

National 4-H Council - Environmental Stewardship Program

- Facilitated environmental problem solving workshops for public, non-profit and private organizations including the US Forest Service, US Fish and Wildlife Service, Ducks Unlimited and the Audubon Society and others

- Researched environmental legislation and policy to support curriculum development

- Designed and implemented pilot tests and program evaluation efforts for multiple environmental education curricula

- Managed the design and implementation of environmental curricula and programs including competitive bids and contracts

\section{Supplemental Experience:}

Organization Development Consultant

1995-1999

- Created and proposed design for organization assessment and re-engineering

- Facilitated organizational re-engineering processes

- Participated in the design and implementation of a new performance management and compensation systems

Intern

$1993-1994$

Towns of Narrows and Pearisburg, Virginia

- Compiled report on waste reduction technologies and feasibility

- Assembled and managed test sites for EPA mandated water testing

- Provided estimates of financial impact for proposed annexations

- Assisted in creation of economic development proposal

Tutor

$1991-1992$

University of Wyoming - Academic Enrichment Center

- Provided course support for undergraduate political science, philosophy and history students 


\section{Snowy Range Ski Area Centennial, Wyoming}

- Taught all levels of snowboarding and skiing using current educational techniques

- Participated in local and regional clinics to enhance teaching skills

\section{Published Journal Articles:}

The Social Bond and Place: A Study of How the Bureau of Land Management

Contributes to Civil Society - Published in Administrative Theory and Praxis, June 2002 (Vol. 24/No. 2) - A description of research studying how a public agency can utilize place to support the construction of a social bond, which is necessary for the emergence of civil Society.

\section{Manuscripts in Preparation or Under Review:}

Post-Modernity and the Public Lands: Towards A New Process of Policy Development Synthesis of three emergent concepts, decentralization, anti-administration and discourse as possible response to the normative clashes land managers face when developing public lands policy. Submitted to the journal Society and Natural Resources

Lacan's Symbolic Order, the Discourse of the Analyst and Public Lands Management an exploration of several concepts drawn from Lacan as an attempt to understand and resolve the impasse that characterizes contemporary public lands management and policy.

\section{Conference and Seminar Presentations:}

Public Administration Theory Network

Place, the Lacanian Symbolic and Public Lands Management - a description of several concepts drawn from Lacanian psychoanalytic theory and an exploration of their use in efforts to understand and craft new strategies to cope with the complexities of public lands and natural resource policy.

\section{Dissertation Research:}

An examination of the role public agencies have in fostering the emergence of civil society and the importance of place in such efforts.

\section{Professional Affiliations:}

- Member, American Society for Public Administration

- Member, Public Administration Theory Network

- Member, American Political Science Association

\section{Technology Skills:}

Advanced Computer Skills: Vtel and VCON video conferencing, CourseInfo web based course support, Windows, Word, WordPerfect, Access, Excel, and others. 